Full length articles

\title{
On the optimal design of place-based policies: A structural evaluation of EU regional transfers
}

\author{
Yashar Blouri *, Maximilian V. Ehrlich \\ University of Bern, Switzerland
}

\section{A R T I C L E I N F O}

\section{Article history:}

Received 23 August 2018

Received in revised form 24 February 2020

Accepted 2 March 2020

Available online 13 March 2020

\section{JEL classification:}

R10

R50

F10

F20

$\mathrm{H} 20$

\section{Keywords:}

Economic geography

Place-based policies

Structural estimation

Subsidies

Public investments

European structural funds

\begin{abstract}
A B S T R A C T
We quantify general equilibrium effects of place-based policies in a multi-region framework with population mobility, trade and agglomeration economies. Using detailed data on EU transfers, we estimate the local effects of different transfer types on productivity, income and transportation costs. Integrating these estimates into the model, we derive the spatial distribution of economic activity and corresponding welfare that would have materialized without transfers. We show that EU transfers have improved welfare. Substantial further welfare gains could be reached by reallocating funds across regions without increasing the budget. We identify the welfareoptimal spatial distribution for each transfer type and show that wage subsidies should rather be directed to few poor and peripheral regions while investments in transport infrastructure are most efficient in highly productive and/or central regions.

(c) 2020 The Authors. Published by Elsevier B.V. This is an open access article under the CC BY-NC-ND license (http:// creativecommons.org/licenses/by-nc-nd/4.0/).
\end{abstract}

\section{Introduction}

Public policy of most developed countries intervenes in the spatial distribution of economic activity. First of all, this concerns large-scale programs that are designed specifically for the purpose of directing resources towards well defined geographic areas such as inter-regional transfers, place-based subsidies and local tax exemptions. These interventions are usually motivated by the widespread concern that economic development generates unequal living conditions across regions. While there have been ample empirical studies about the effects of transfers in recipient regions, the general equilibrium effects of these policies are not well understood (see Neumark and Simpson, 2015). We make progress in this direction by evaluating the general equilibrium effects of European regional transfers based on recent advances in the quantitative analysis of economic geography (see e.g. Allen and Arkolakis, 2014; Redding and Rossi-Hansberg, 2017).

\footnotetext{
* Corresponding author.

E-mail addresses: yashar.blouri@vwi.unibe.ch (Y. Blouri), maximilian.vonehrlich@vwi.unibe.ch (M.V. Ehrlich).
}

Place-based policies cover a range of measures: The most important ones include wage subsidies, investments in local transportation infrastructure, and transfers aimed at strengthening local productivity. ${ }^{1}$ In our application of EU regional policy these categories represent about $80 \%$ percent of total expenditure. The relevance and nature of spillovers to non-treated regions - and thus the general equilibrium effects - vary significantly across these three general types of place-based policy instruments. For instance, wage subsidies exert spillovers via market-size effects, local transportation investments have immediate consequences for the entire transportation network, and local productivity gains dissipate to non-recipient regions via the price indices of imported goods.

Our analysis shows that EU regional transfers have improved welfare significantly for the period 2007-13. At the same time, we demonstrate that substantial further welfare gains could have been reached by reallocating transfers across regions without increasing the budget. By
${ }^{1}$ We consider transfers focusing on local technological development as investments in production amenities, e.g. investments in local energy supply, schools or broadband technologies. For projects examples of EU regional policy see http://ec.europa.eu/regional_ policy/en/projects. 
identifying the welfare-optimal spatial distribution for each transfer type, we show that wage subsidies should rather be directed to a few poor and peripheral regions while investments in transport infrastructure are most efficient in highly productive and/or core regions. Investments in transport infrastructure and production amenities are complementary and have contributed more to welfare than wage subsidies.

We incorporate the main types of regional transfers into a quantitative model capturing costly inter-regional trade, population mobility and endogenous agglomeration economies. We fit the multi-region model to detailed data about European NUTS2 regions spanning a period of 20 years and thereby recover location fundamentals reflecting regional consumption and production amenities. ${ }^{2}$ The application focuses on one of the largest regional policy schemes: The European Structural \& Cohesion Funds. Already since 1975, these policies are central to the process of European integration and since then the budget has grown continuously. During the budgeting period 2007-13, the Structural \& Cohesion Funds accounted for approximately one third of the EU's total budget (European Commission, 2008). Using novel data that specifies not only the regional distribution of transfers but also the type of expenditure, we obtain causal estimates of the direct (partial equilibrium) effects of transfers on local outcomes.

By estimating the core model parameters for the specific context of EU NUTS2 regions, we ensure that our model performs well in matching empirically observed patterns across European regions. Combining the model structure and the estimated parameters, we are in a position to study the general equilibrium effects of transfers. In particular, we analyze the effects of place-based policies on aggregate efficiency and regional inequality, as measured by the coefficients of variation of income and population density. We compare the observed equilibrium to counterfactual scenarios where transfers are discontinued or distributed based on a naive rule that pays a uniform transfer to every region. Ultimately, we are interested in the degree of welfare gain one could reach by optimally designing the place-based policy without expanding the size of the program. To this end, we solve a global optimization problem and derive the welfare optimal distribution of transfers across regions for each transfer type given the current level of taxes.

The counterfactual simulations suggest that the EU place-based policy led to a positive welfare effect of $2.08 \%$ compared to a scenario without transfers. This effect is mainly driven by improvements in the average level of public infrastructure because the existing policy does not realize the potential of distributing the investments in a welfare optimizing way across regions. In particular, this becomes evident when comparing the current scheme to the uniform distribution of transfers. Considering all transfer types jointly, this naive rule dominates and would yield additional efficiency gains of $0.52 \%$ age points compared to the existing scheme. We find that switching to the optimal distributions for all transfer types while keeping taxes as well as the aggregate mix of types constant would raise aggregate welfare in the European Union by approximately 1.06 percentage points compared to the existing scheme. For individual transfer types, the most sizable benefits from moving to the optimal spatial distribution can be realized for wage subsidies: There, the existing benefit can be quadrupled.

Below, we discuss our approach with reference to the literature. We introduce the model in Section 3 and describe the estimation of model parameters in Section 4. Counterfactual policy scenarios are analyzed in Section 5. The last section summarizes and draws conclusions about potential reforms of transfers in Europe.

\footnotetext{
2 Eurostat, the statistical agency of the European Union, operates a regional classification scheme (Nomenclature des Unités Territoriales Statistiques) where NUTS2 corresponds to regional entities of $0.8 \mathrm{~m}$ to $3 \mathrm{~m}$ inhabitants. Currently, the EU consists of 273 NUTS2 regions.
}

\section{Literature}

Our paper relates to a sizable strand of literature evaluating the effects of place-based policies (e.g. Glaeser and Gottlieb, 2008; Kline and Moretti, 2014; Neumark and Simpson, 2015). Boldrin and Canova (2001) initiated a number of studies focusing on place-based policies in the EU. Becker et al. (2010) address the endogeneity of transfer recipience by exploiting a discontinuity in the mechanism that determined transfer eligibility and show that the policy induced local growth and income effects beyond a simple consumption stimulus. ${ }^{3}$ In order to estimate the parameters underlying the link between local characteristics and transfers, we follow their quasi-experimental identification strategy but apply it to outcomes that have not yet been studied, i.e. we estimate the impact of regional transfers on local production amenities and transportation costs.

Most evaluations of place-based policies use reduced-form analyses and identify the local effects in recipient regions. Hence, they mostly ignore spillovers on other regions and thus quantify partial equilibrium effects. However, the aggregate efficiency of spatially targeted transfers depends critically on migration responses, adjustments in land rents and local prices in general. Migration responses to place-based transfers can be substantial as documented by Einiö and Overman (2016) and Ehrlich and Seidel (2018) for regional transfers in the UK and Germany. Consistent with our findings, Egger et al. (2014) document that EU transfers have reduced net migration across member countries. Complex spatial interactions occur not only via relocation of households and firms but also via interregional trade and investments. ${ }^{4}$ Accordingly, for a comprehensive evaluation of the effectiveness of place-based policies, migration and trade channels are relevant. Reduced-form analyses are usually not capable of identifying these interdependencies. In particular, as these spillovers are not limited to neighboring regions, a structural framework is required to derive the net effect of place-based policies. ${ }^{5}$ The EU recognizes the importance of spillovers and expects that "all Member States benefit from positive spillovers generated by investments in cohesion countries" (see European Commission, 2017). We show that partial equilibrium effects focusing on the local effects in recipient regions significantly overestimate the impact of wage subsidies and investments in production amenities. However, positive spillovers dominate for investments in transportation infrastructure.

In order to identify the general equilibrium effects of place-based policies, we build upon recent work in quantitative economic geography (e.g. Allen and Arkolakis, 2014; Caliendo et al., 2018; Redding, 2016; Desmet et al., 2018) and link it to data about regional characteristics. The combination of a structural model, regional panel data, and quasi-experimental variation in transfer recipience allows us to estimate almost all parameters of the model, compute spatial equilibria that materialize under different policy schemes, and to conduct welfare analyses. Assuming that the identified parameters of the model remain constant, we can compute the effects of large-scale policy changes. The non-linearities prevalent in economic geography (both in theory and data) make it particularly relevant to go beyond marginal changes as typically obtained in empirical evaluations.

Our paper closely relates to recent contributions in the quantitative analysis of the spatial effects of public policies: Fajgelbaum et al. (2019) and Eeckhout and Guner (2017) evaluate the degree of spatial misallocation due to taxes; Ossa (2017) analyzes welfare costs of

\footnotetext{
${ }^{3}$ Further reduced-form evaluations of European regional policy include MidelfartKnarvik and Overman (2002), Mohl and Hagen (2010), Pellegrini et al. (2013).

${ }^{4}$ E.g., an increase in local income will raise demand not only for locally produced goods but also for goods produced in regions that have close trade links with the transfer recipient. Similarly, changes in productivity and transportation costs will induce a reshuffling of bilateral trade.

5 Some reduced form analyses reduce the issue of spillovers (i.e. the violation of the stable unit treatment value assumption in the identification of the treatment effect) by excluding observations in the spatial proximity of treated regions from the control group (e.g. Kolko and Neumark, 2010).
} 
subsidy competition in the US, and Gaubert (2017) studies the effects of place-based policies on the location choice of heterogeneous firms. We deviate from these papers in a number of ways: First, we compare different channels of place-based policies i.e. wage subsidies, investments in production amenities and in transportation infrastructure. Second, we derive the welfare optimal spatial distribution of different types of place-based transfers for a given tax setting. Third, we determine the factors that define the optimal place of investment for each type and show complementarities between different transfer types. ${ }^{6}$ Simultaneous, independent work by Fajgelbaum and Gaubert (2019) show that the efficient, spatial allocation is characterized by a linear relationship between regional expenditure and wages, which can be implemented by a combination of proportional taxes and lump sum subsidies. This is consistent with our findings for wage subsidies if we allow the federal government to set the level of taxes far beyond the observed level and abstract from non-local ownership of fixed factors. ${ }^{7}$ However, we focus on the optimal distribution of wage subsidies for the observed level of taxes. In that case, wage subsidies are no longer lump sum but will be shifted to the poor regions since the proportional tax rate can only be used to a very limited degree to redistribute from high wage to low wage regions. Furthermore, we relate to the literature analyzing investments in transportation infrastructure. Recent papers by Alder (2016), Fajgelbaum and Schaal (2019) identify the optimal transportation infrastructure network in trade models. Baum-Snow et al. (2018) analyze transportation infrastructure investments in China. Allen and Arkolakis (2016) develop an analytical solution for how infrastructure investments between neighboring regions impact trade costs between all other region dyads. We employ this framework and highlight the interrelations between investments in local transportation infrastructure and other transfers such as wage subsidies and investments in local production amenities.

\section{Model}

Our analysis builds on te framework introduced by Allen and Arkolakis (2014) and Redding and Rossi-Hansberg (2017) featuring multiple regions, endogenous agglomeration economies, and a land market mitigating the concentration of economic activity. The economy is endowed with $\bar{L}=\sum_{n} L_{n}$ workers in total and each worker inelastically supplies one unit of labor earning a wage $w_{n}$. Every region $n \in N$ is endowed with an exogenous quality-adjusted supply of land $H_{n}$. Workers have heterogeneous preferences across locations and, in equilibrium, mobility of workers equalizes indirect utility. Accounting for idiosyncratic location-specific preferences reduces mobility between regions. ${ }^{8}$ Trade between regions $i$ and $n$ is inhibited by iceberg transport cost $d_{n i} \geq 1$, where the first subscript refers to the place of consumption. The model allows for unbalanced trade due to regional transfers and regional imbalances in asset holdings. A central government influences the distribution of economic activity by paying regions wage subsidies or by investing in local productivity amenities and local transportation infrastructure. In equilibrium, these three types of transfers are shown to exert quantitatively important spillovers on neighboring regions via trade, migration and imbalances in asset holdings. The directions of spillovers depend on the transfer type. In the following, we lay out the model details and discuss how regional transfers and federal taxes are integrated.

\footnotetext{
${ }^{6}$ Fiscal equalization of local tax base as studied by Albouy (2012) and Henkel et al (2018) leads to regional redistribution but neither affects productivity nor trade costs.

${ }^{7}$ In this regard our optimal design of the transfer scheme can be understood as a second-best scenario for a government being constraint to keeping the tax rates constant. In order to reach the first-best spatial allocation of a $6.0 \%$ welfare gain, a proportional tax rate of approximately $38.13 \%$ would be required, which amounts to about 156 times the observed level of the tax rate. For the implications of a flexible budget see Section 5.3 .

8 Due to the principle of freedom of movements for workers in the EU, we allow for mobility across countries. An alternative assumption as in Redding (2012) would restrict mobility to within-country migration.
}

\subsection{Preferences, demand, and production}

Utility of an individual $\omega$ residing in $n$ has Cobb-Douglas form

$U_{n}(\omega)=b_{n}(\omega)\left(\frac{C_{n}}{\alpha}\right)^{\alpha}\left(\frac{H_{n}}{1-\alpha}\right)^{1-\alpha}$,

where $\alpha \in[0,1], C_{n}$ represents a composite good, $H_{n}$ is residential land use and $b_{n}$ is a location-specific preference shifter, which is drawn for each worker independently. The idiosyncratic amenity term $b_{n}$ captures the idea that workers have heterogeneous preferences for living in each location. We assume that location preferences are drawn i.i.d. across locations and workers from a Fréchet distribution with cumulative distribution function

$G_{n}(b)=e^{-B_{n} b^{-\varepsilon}}$,

where the scale parameter $B_{n}$ determines average amenities for location $n$ and the shape parameter $\varepsilon>1$ governs the dispersion of the value of amenities across workers for each location.

We consider an Armington (1969) setup where the composite consumption good consists of a set of varieties differentiated by the place of origin. Individuals have constant elasticity of substitution preferences such that the varieties are aggregated according to

$C_{n}=\left(\sum_{i \in N} \frac{\sigma-1}{c_{n i}}\right)^{\frac{\sigma}{\sigma-1}}$,

where $\sigma$ refers to the elasticity of substitution. Maximizing (3) subject to the budget constraint delivers total demand for a variety of the differentiated good $c_{n i}=\frac{p_{n i}^{-\sigma}}{P_{n}^{1-\sigma}} \alpha y_{n} L_{n}$ where $y_{n}$ denotes region $n$ 's per capita income, $L_{n}$ is location $n$ 's labor force, $P_{n}=\left(\sum_{i \in N} p_{n i}^{1-\sigma}\right)^{\frac{1}{1-\sigma}}$ refers to the price index and $p_{n i}=p_{i} d_{n i}$ is the consumer price for a variety produced in $i$ and consumed in region $n$.

The production side is characterized by external economies of scale where location $n$ 's productivity depends on local production amenities $\tilde{a}_{n}$ and the distribution of labor

$a_{n}=\tilde{a}_{n} L_{n}^{\mu}$.

Agglomeration elasticity $\mu \geq 0$ governs the strength of external agglomeration economies arising due to the concentration of population. Spillovers in this specification are assumed to be external to firms and entirely local. Every location produces one unique differentiated variety under perfect competition, which can be traded across regions. Alternatively, agglomeration economies may be imbedded in the spirit of the new economic geography, which yields qualitatively similar results.

Competitive markets lead to profit maximizing prices $p_{n i}=\frac{d_{n i} w_{i}}{a_{i}}$. Accordingly, the value of trade flows from region $i$ to $n$ can be stated as

$X_{n i}=\alpha y_{n} L_{n} \frac{p_{n i}^{1-\sigma}}{P_{n}^{1-\sigma}}$.

Substituting profit-maximizing prices in the demand functions, we obtain the the fraction of region $n$ s expenditure on goods produced in region $i$ 
$\pi_{n i}=\frac{\left(\frac{d_{n i} w_{i}}{a_{i}}\right)^{1-\sigma}}{\sum_{k \in N}\left(\frac{d_{n k} w_{k}}{a_{k}}\right)^{1-\sigma}}$,

as well as the price index in region $n$

$P_{n}=\left(\frac{1}{\pi_{n n}}\right)^{1 /(1-\sigma)} \frac{d_{n n} w_{n}}{a_{n}}$.

\subsection{Trade costs}

Infrastructure investments represent one of the main instruments of European regional policy. Evidently, these investments reduce transportation costs between two regions that are connected by a newly established or improved transportation link, say between regions $r$ and $i$. Moreover, these investments are expected to impact trade costs for any other region pair for which the new link is located on the least-cost path. While these groups of beneficiaries can in principle be identified, the least-cost path itself is likely to be endogenous, which complicates the analysis. Therefore, we employ a framework recently developed by Allen and Arkolakis (2016), which assigns a certain probability for a good shipped between two regions that it passes any other region. The idea is that shipments are carried out by a continuum of traders with idiosyncratic costs for different routes. Accordingly, there is a non-zero probability that shipments between two regions pass any transportation link.

We refer to a transportation link as the direct connection between two adjacent regions $r, i$, which incurs direct iceberg trade costs $\tilde{d}_{r i}$. For elements representing non-adjacent region pairs $n$ and $i$ it is assumed that $\tilde{d}_{n i}=\infty$. In particular, we specify direct trade costs as a function of road travel time TravelTime $_{i}$ between adjacent regions:

$\tilde{d}_{r i}=e^{\beta \cdot \text { TravelTime }_{r i}}$.

Direct trade costs enter the weighted adjacency matrix $\tilde{\mathbf{D}}=\left[\tilde{d}_{r i}^{-\theta}\right]$. The aggregate trade costs for shipping a good across non-adjacent locations $n, i$ are given by the product of direct trade costs along the chosen path. We assume that path-specific trade-costs shocks occur and that traders choose the path by minimizing trade costs. In this setting, Allen and Arkolakis (2016) derive the expected trade costs from $n$ to $i$ as:

$d_{n i}=\Gamma\left(\frac{\theta-1}{\theta}\right)\left(f_{n i}\right)^{-\frac{1}{\theta}}$

where $\theta>0$ denotes the shape parameter of the Fréchet distributed trade-cost shocks and $\Gamma$ the gamma distribution. Variable $f_{n i}$ refers to the $(n, i)$ element of the route cost matrix $\mathbf{F}$, which, as long as the spectral radius of $\tilde{\mathbf{D}}$ is less than one, can be expressed as: $\mathbf{F} \equiv \sum_{K=0}^{\infty} \tilde{\mathbf{D}}_{n i}^{K}$ $=(\mathbf{I}-\tilde{\mathbf{D}})^{-1}{ }^{9}$ Due to path-specific shocks, which can also be interpreted as idiosyncratic tastes, trade between two regions can follow any route, including the most indirect ones with a certain probability. However, the probability of passing a certain link decreases with the costs of the detour that arises from the deviation from the least-cost route that would be applicable without shocks. A transport investment at link $r i$ is more relevant for trade between region pairs having their least-cost route in the proximity of $r i$ and accordingly pass the link more

\footnotetext{
9 The spectral radius is less than one, if either trade costs between connected locations are sufficiently large, the adjacency matrix is sufficiently sparse, or the heterogeneity across traders is sufficiently small. In our application, this is fulfilled. See Allen and Arkolakis (2016) and Appendix A.1 for more details.
}

frequently than for those region pairs with their least-cost route being distant from link $r i$. In the following, we estimate the effect of transport investments on travel time between adjacent regions, which impacts direct trade costs $\tilde{d}_{r i}$ according to (8) and affects expected trade costs between all other regions according to (9). ${ }^{10}$

In summary, we can reproduce the effect of a local transport-time reduction at any link ri for the aggregate European transport network. Such a modification of the transport network triggered by a local investment may result in a new spatial equilibrium with substantial relocation of economic activity far beyond the one explained by the direct effect on link ri.

\subsection{Regional and federal government}

The national governments levy labor income taxes $\left(\tau_{n}\right)$, which are transferred to the federal budget and used to finance aggregate transfers $T_{n}=T_{n}^{w}+T_{n}^{a}+T_{n}^{d}$. Reflecting the most important components of European regional policy, we consider local wage subsidies $T_{n}^{w}$, investments in local production amenities $T_{n}^{a}$ and investments in local transportation infrastructure $T_{n}^{d}$ - which reduce travel time across direct links. Thus, the government budget constraint is given by:

$\sum_{n \in N} w_{n} L_{n} \tau_{n}=\sum_{n \in N} T_{n}$

Public investments in roads between regions $n$ and $i$ reduce TravelTime $_{r i}\left(T_{i}^{d}, T_{r}^{d}\right)$ entering (8). In particular, we specify the following relationship:

TravelTime $_{r i}=\gamma_{r i}-\kappa^{d} \cdot \ln \left(T_{r}^{d}+T_{i}^{d}+1\right)$,

where TravelTime $e_{r i}$ is constrained to positive values and $T_{n}^{d}$ is adjusted by the number of $n^{\prime}$ s neighbors. ${ }^{11}$ These public investments reduce the travel time between all direct links, which again feeds back to expected trade costs across adjacent and non-adjacent regions according to Section 3.2. We assume that investments in public transportation are non-rival given that the average road is not congested. ${ }^{12}$

A further channel of regional transfers concerns R\&D activities, universities, broadband internet access, energy supply, etc., which we assume to impact local productivity. Hence, we introduce public investments in local production amenities rendering regional technology endogenous:

$$
\ln \left(\tilde{a}_{n}\right)=\ln \left(\bar{a}_{n}\right)+\kappa^{a} \cdot \ln \left(T_{n}^{a} / L_{n}+1\right) .
$$

Again a region specific level of productivity for a counterfactual situation without transfers $\bar{a}_{n}$ is empirically obtained using detailed data about regional transfers. ${ }^{13}$

We model the effects of transfers on transportation infrastructure $\left(T_{n}^{d}\right)$ and on production amenities $\left(T_{n}^{a}\right)$ in a simple way and assume that it is produced using a specific factor of elastic supply (e.g. concrete), which cannot be used for other purposes and is owned by all individuals equally. Government coordination is necessary to translate this factor into transportation infrastructure and production amenities. Therefore,

\footnotetext{
${ }^{10}$ Using a standard gravity model yields very similar levels of trade costs as shown in A.1. Thus, our analysis of $T^{w}$ and $T^{a}$ is robust to this alternative specification of trade costs. A comprehensive evaluation of $T^{d}$ requires the specification with endogenous least-cost path.

11 This constraint implies: $\left.\gamma_{r i}>K^{d} \cdot \ln \left(\sum_{n} T_{r}^{d}+1\right)\right) \quad \forall\{r, i\} \in N$ which is always fulfilled in the data. We also estimated the model using a log-log specification, which, however was an inferior fit with the data. The adjustment for the number of neighbors assumes that the sum of transfers $T_{n}^{d}$ is invested equally into the travel links to all $n$ neighbors.

${ }^{12}$ A varying degree of rivalry is incorporated in an earlier version, which is, however, not supported by the data. A further alternative includes complementarities of investments a the two nodes of a link. While these are empirically significant, our main results remain unaffected.

13 Empirical model-selection analysis yields the best fit for a log-log specification.
} 
individuals are willing to sell the factor for any positive price and government demand determines the quantity sold. The input factor can be freely shipped across regions. Without loss of generality, we assume that the price of this factor equals unity such that the government buys $T^{d}$ and $T^{a}$ units when it invests in infrastructure and production amenities. ${ }^{14}$ Equal ownership of the factor allows us to clearly differentiate between wage subsidies $T_{n}^{w}$, which directly increase income only in region $n$ on the one hand, and $T_{n}^{d}, T_{n}^{a}$ on the other hand where the direct income from investments is distributed equally but the effects through transportation costs and productivity are localized. The simplifying assumption of a uniform price of the input factor can be justified by construction firms operating at a multi-regional level. In Appendix D.3, we discuss an extension with infrastructure being built using exclusively local factors, which leads to region-specific prices in the transfer function.

Taxes in our model are locally distortive in the sense that higher labor taxes make a location less attractive for labor supply, but the tax has no effect on global labor supply. Note that inefficiencies of the public sector on the expenditure side are captured by the empirical estimates of $\kappa^{a}$ and $\kappa^{d}$. Thus, we refrain from incorporating an excess burden of taxation. This would only affect the optimal size of the public sector and would not have immediate consequences for the spatial distribution of public spending, which is the focus of this paper.

\subsection{Regional income}

Regional per capita income $y_{n}$ stems from after-tax wages $w_{n}(1-$ $\tau_{n}$ ), per capita subsidies $T_{n}^{w} / L_{n}$, rent income $\left(1-\iota_{n}\right) H_{n} r_{n} / L_{n}$ and per capita payments from a global portfolio $\chi$. We denote the tax rate by $\tau_{n}$ and the rent per unit of land by $r_{n} \cdot{ }^{15}$ As in Caliendo et al. (2018) and Monte et al. (2018), we assume that land is owned by locals and non-locals. Hence, individuals contribute a share $\iota_{n} \in[0,1]$ of land rents to a global portfolio, which redistributes rents as well as income from the factor producing transportation infrastructure and production amenities back to them in the form of a per-capita payment $\chi$. Thereby, we allow for trade deficits across regions, which is empirically relevant and particularly important in the context of place-based policy. For instance, regional transfers are likely to capitalize in local asset values, which benefit not only local residents but any asset holders in the recipient regions. Note that even with balanced asset holdings, trade imbalances apply in our model due to regional transfers. However, without taking into account imbalances in asset holdings, we may overestimate the effect of transfers on trade imbalances. Aggregate regional income amounts to

$y_{n} L_{n}=w_{n} L_{n}\left(1-\tau_{n}\right)+T_{n}^{w}+\left(1-\iota_{n}\right) H_{n} r_{n}+\chi L_{n}$,

where $T_{n}^{w}$ denotes the public wage transfers. Per capita payments accruing from the rent portfolio and from the production of infrastructure and production amenities can be expressed as $\chi=(1 / \bar{L}) \sum_{n \in N}\left(\iota_{n} H_{n} r_{n}\right.$ $\left.+T_{n}^{d}+T_{n}^{a}\right) \cdot{ }^{16}$ The difference between tax payments, rental contributions to the global portfolio and the revenue out of it generates imbalances in trade accounts. Regions displaying a higher value of $\iota_{n}$ than the average are characterized by a trade surplus. Trade balance may be stated as

$\Upsilon_{n} \equiv \iota_{n} H_{n} r_{n}+\tau_{n} w_{n} L_{n}-\chi L_{n}-T_{n}^{w}$

\footnotetext{
${ }^{14}$ In Section 4, we describe the estimation of the elasticities $\kappa^{a}, \kappa^{d}$ and the preinvestment levels $\tilde{a}_{n}$, TravelTime $e_{r i}$ and show that these are independent of the price assumed for the input factor.

15 Our results are robust to taxing aggregate income instead of wages.

16 Regional income is composed of the sum of wage payments, net rental payments, net wage transfers, and net payments for the ownership of the infrastructure-specific factor. The latter two balance out in total/global GDP.
}

Due to Cobb-Douglas utility, we can express the rental rate for land as $r_{n}=\frac{(1-\alpha) y_{n} L_{n}}{H_{n}}$ and reformulate per-capita income as

$y_{n}=\frac{1}{\alpha+\iota_{n}-\alpha \iota_{n}}\left[w_{n}\left(1-\tau_{n}\right)+T_{n}^{w} / L_{n}+\chi\right]$.

\subsection{Residential choice}

Using the above expressions for rental rate and price index (7) we obtain real income

$\frac{y_{n}}{P_{n}^{\alpha} r_{n}^{1-\alpha}}=\eta\left(\frac{a_{n} y_{n}}{d_{n n} w_{n}}\right)^{\alpha}\left(\pi_{n n}\right)^{\alpha /(1-\sigma)}\left(\frac{H_{n}}{L_{n}}\right)^{1-\alpha}$,

where $\eta=\frac{1}{1-\alpha}^{(1-\alpha)}$. Indirect utility of an individual in region $n$ depends on real income and a stochastic amenity term at the place of residence $V_{n}(\omega)=b_{n}(\omega) \frac{y_{n}}{P_{n}^{\alpha} r_{n}^{1-\alpha}}$. Since consumption amenities follow a Fréchet distribution and indirect utility is a transformation of the random amenity draw, the cumulative distribution function of indirect util-

ity is given by $G_{n}(V)=e^{-B_{n}\left(\frac{y_{n}}{P_{n}^{\alpha} r_{n}^{1-\alpha}}\right)^{\varepsilon} V^{-\varepsilon}}$. The probability that an individual prefers locations $n$ over all other locations corresponds to the share of region $n$ 's population. Using the above distributions, the share of population in location $n$ corresponds to

$$
\lambda_{n}=\operatorname{Pr}\left(V_{n} \geq \max \left\{V_{k}\right\}, \forall k \in N\right)=\frac{B_{n}\left(\frac{y_{n}}{P_{n}^{\alpha} r_{n}^{1-\alpha}}\right)^{\varepsilon}}{\sum_{k \in N} B_{k}\left(\frac{y_{k}}{P_{k}^{\alpha} r_{k}^{1-\alpha}}\right)^{\varepsilon}}
$$

where $\lambda_{n}=\frac{L_{n}}{\sum_{k \in N} L_{k}}$. A high value of $\varepsilon$ implies that the location-specific amenity draws are less dispersed. As a result, locations become better substitutes and an increase in the relative appeal of a location (i.e. increase in real wage) leads to a larger response in the fraction of workers who choose to locate there. In an extreme case of no location taste heterogeneity $(\varepsilon \rightarrow \infty)$, workers are not attached to specific locations such that the supply of labor becomes perfectly elastic.

From the cumulative distribution $G_{n}(V)$ follows that expected indirect utility of an individual living in $n$ is given by

$E\left[V_{n}\right]=\bar{V}=\delta\left[\sum_{k \in N} B_{k}\left(\frac{y_{k}}{P_{k}^{\alpha} r_{k}^{1-\alpha}}\right)^{\varepsilon}\right]^{\frac{1}{\varepsilon}}$,

where $\delta=\Gamma\left(\frac{\varepsilon-1}{\varepsilon}\right)$ is a constant term and $\Gamma$ ( ) refers to the Gamma function. Population mobility implies that the expected indirect utility of an individual has to be identical across all potential destinations such that, in equilibrium, locations are chosen optimally. Further substituting population share (17), we obtain:

$\bar{V}=\delta\left(B_{n}\right)^{\frac{1}{\varepsilon}}\left(\frac{y_{n}}{P_{n}^{\alpha} r_{n}^{1-\alpha}}\right)\left(\frac{1}{\lambda_{n}}\right)^{\frac{1}{\varepsilon}}$

If certain locations provide more utility than others, workers move to the place, which offers the highest possible utility. Hence, an increase in nominal wages is ceteris paribus accompanied by an increase in local population share. Moreover, due to agglomeration benefits, larger markets are more productive and pay higher wages. However, an inflow of population bids up land prices, which acts as a dispersion force and 
reduces real income. To ensure a unique equilibrium dispersion forces must dominate agglomeration forces in equilibrium. This leads to the following parameter restriction $(1-\alpha)+1 / \varepsilon>\alpha \mu$ and rules out that the whole population is located in one region. ${ }^{17}$

\subsection{General equilibrium}

Given the set of parameters $\left\{\sigma, \mu, \alpha, \varepsilon, \iota_{n}\right\}$, the general equilibrium can be expressed by the market clearing conditions on goods and labor markets, the government budget constraint, and the migration equilibrium condition. Market clearing on the goods market requires that location $i$ 's labor income is equal to the total expenditure for the goods produced in that location:

$w_{n} \lambda_{n}=\alpha \sum_{k \in N} \pi_{k n} \lambda_{k} y_{k}$

where per-capita income is given by (15). Labor market clearing follows from (6) and the location choice probabilities (17) jointly with real income in (16) close the model. With 264 NUTS2 regions, this yields a total of 70,488 equilibrium conditions. ${ }^{18}$ Based on these conditions and data for $\left\{\lambda_{n}, y_{n}, H_{n}, d_{n i}, T_{n}^{w}, T_{n}^{a}, T_{n}^{d}, \tau_{n}\right\}$, we can recover the endogenous outcomes $\left\{a_{n}, \pi_{n i}, B_{n}, w_{n}\right\}$. All other endogenous variables can be expressed in terms of these recovered variables and the exogenous variables. Note that for the counterfactual welfare analyses, we apply the exact hat algebra introduced by Dekle et al. (2007) such that the levels of location attractiveness $\left(B_{n}\right)$ are not needed.

\section{Estimation \& calibration}

As it is evident from the maps in Fig. 1, our data covers almost all NUTS2 regions in the EU27. ${ }^{19}$ The EU administers its place-based policies according to multi-annual budgeting periods. We fit the model to data for the three most recent budgeting periods, 1994-99, 2000-06 and 2007-13 in order to explore the validity of our model and to obtain time variation in local production amenities. For the analysis of counterfactuals, we focus on the most recent budgeting period, 2007-13. In total, we observe data for 264 European NUTS2 regions, which were eligible for EU transfers in the most recent period. Summary statistics of all our exogenous variables are reported in Table A.3, and Fig. 1 illustrates the spatial distribution of these variables.

Regional transfers: The EU Commission provides detailed information on regional transfers for all three budgeting periods. The data covers regional expenditures from all three sources of regional transfers, the European Regional Development Fund, the European Social Fund as well as for the Cohesion Fund. The transfers are classified according to 12 spending categories, which we assign to the respective transfer types. ${ }^{20}$ This assignment bases on the descriptions of representative projects financed via the respective categories. The allocation of transfer types is consistent with an empirical analysis exploring the significance of each transfer category for the respective outcome, i.e. travel time and local production amenities. In total, $37 \%$ of transfers were invested in production amenities, $34 \%$ in improvements of transportation infrastructure and $29 \%$ were channeled through wage subsidies.

\footnotetext{
17 For a detailed discussion see Redding and Rossi-Hansberg (2017) and Eq. (23) below. 18 Our system of equation has $264 \times 264$ bilateral trade shares according to (6) and 264 location choice probabilities (17), 264 equations for per-capita income (15) as well as 264 goods market clearing conditions (20), which sum up to 70,488 equations.

19 Due to missing data our analysis excludes the remote islands Madeira (PT30), Açores (PT20), Canary Islands (ES70) and the French overseas territories (FR91, FR92, FR93, FR94).

20 The categories are: 1) Energy, 2) Environment \& natural resources, 3) Human resources, 4) IT infrastructure \& services, 5) Research \& Technology, 6) Business support, 7) Social infrastructure, 8) Technical assistance, 9) Tourism \& Culture, 10) Urban \& rural regeneration, 11) Transport infrastructure, 12) Other. We assign categories $1-5$ to transfers in local production amenities $\left(T_{n}^{a}\right)$, category 11 to transfers in transport infrastructure $\left(T_{n}^{d}\right)$, and 6-10 to wage subsidies $\left(T_{n}^{w}\right)$.
}

The existing distribution of EU regional transfers is far from uniform, and place-based subsidies are strongly tied to regional economic development as well as political bargaining (e.g. Charron, 2016). The highest transfer intensities were observed in the Southern and Eastern periphery of the EU as shown in panel a) of Fig. 1. Notably, virtually all regions received a positive transfer from the central EU government. Yet, there is a substantial variation as total per capita transfers $\left(T_{n} / L_{n}\right)$ ranged between 34 Cents and 892 Euros. The relative distribution of transfer types ( $T_{n}^{w} T_{n}, T_{n}^{a} T_{n}, T_{n}^{d} T_{n}$ ) across regions varies quite significantly as is shown in Table 5 and Figs. A.3 in the Appendix.

Population shares and regional income: Cambridge Econometrics' European Regional Database provides information on population, employment, and per capita income for every NUTS2 region and the whole time period. Since the model assumes full employment, our simulations use employment data for $L_{n}$ as well as for the shares $\left(\lambda_{n}\right) \cdot{ }^{21}$ Per capita income $\left(y_{n}\right)$ is measured in 2005 constant Euros. Fig. 1 illustrates the spatial distribution of per capita income and population shares.

Residential land supply: Information about residential land-use stems from the dataset "Ecosystem types of Europe" published by the European Environment Agency. This data provides habitat information for $100 \times 100 m$ cells. For residential land-use $\left(H_{n}\right)$, we sum up all constructed, industrial and other artificial habitats for every NUTS2 region. Regional levels of $H_{n}$ are shown in panel d) of Fig. 1.

Price of land and contributions to global portfolio: We compute the price of the immobile factor - land - using the condition $r_{n}=(1-\alpha)$ $L_{n} y_{n} / H_{n}$ jointly with data on regional per capita income $\left(y_{n}\right)$, population $\left(L_{n}\right)$ and residential supply of land $\left(H_{n}\right)$ as described above. For the consumer's expenditure share in goods consumption we follow Eurostat (2016) and assume $\alpha=0.75$.

The trade balance is calculated by calibrating each region's share of the immobile sector paid into the international portfolio $\iota_{n}$. We solve for $\iota_{n}$ by minimizing the sum of squared errors between the observed trade balance $\Upsilon_{n}^{\text {Data }}$ and the model's trade balance as defined in (14):

$$
\min _{\iota_{n}} \sum_{n \in N}\left(\Upsilon_{n}^{\text {Data }}+T_{n}^{w}-\tau_{n} w_{n} L_{n}-\iota_{n} H_{n} r_{n}+\chi L_{n}\right)^{2} .
$$

Data for annual trade balance $\Upsilon_{n}^{\text {Data }}$ stems from Eurostat and is only available at the country level. To obtain region $n$ 's trade balance, we weigh the country's trade balance by regional GDP. Fig. A.2 in Appendix A illustrates the close fit between the data and the model's trade balance, where the correlation coefficient is 0.993 .

Wages: We obtain region $n$ 's wages $w_{n}$ by substituting income, wage transfers and payments from the international portfolio into Eq. (15). In our main analysis, we set tax rates $\left(\tau_{n}\right)$ constant across regions and thus tax revenue proportional to regional wages. This is legitimate as the two main sources of the EU budget are proportional to local income. By far the most important part of a country's contribution to the EU budget bases on a uniform rate applied to the gross national income (GNI) of each member state. In 2012, the EU-27 countries contributed $86.8 \%$ to the EU budget according to their GNI based valuation. The second most important component refers to contributions according to a harmonized VAT of $0.3 \%$. The value added tax contributed about $13.1 \%$ to the total budget and the remaining difference is accounted for by correction mechanisms. ${ }^{22}$ Tax rates $\tau_{n}=\tau$ are obtained from the government budget constraint (10) equating transfer expenditure and total tax revenue:

$$
\tau \sum_{n \in N} w_{n} L_{n}=\sum_{n \in N} T_{n}
$$

\footnotetext{
${ }^{21}$ Note that all results are robust to using population data instead.

22 Information about specific contributions to the regional policy budget is not available. Yet, the EU discloses countries' payments to the overall budget, which are a constant proportion of countries' GDP. In contrast, the ratio of regional transfers to local GDP (at NUTS2 level) ranged from $0.0004 \%$ (London) to $4.6 \%$ (Hungary, Northern Great Plain).
} 
(a) Total transfers per capita $\left(T_{n} / L_{n}\right)$

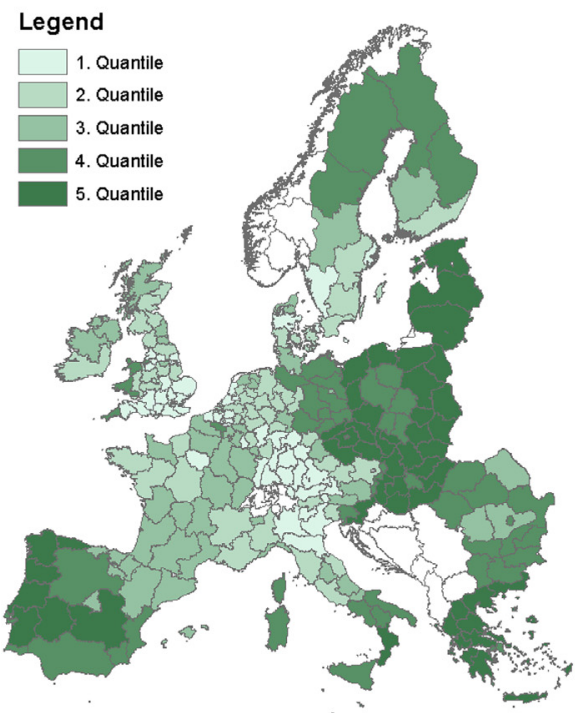

(c) Regional income $\left(y_{n}\right)$

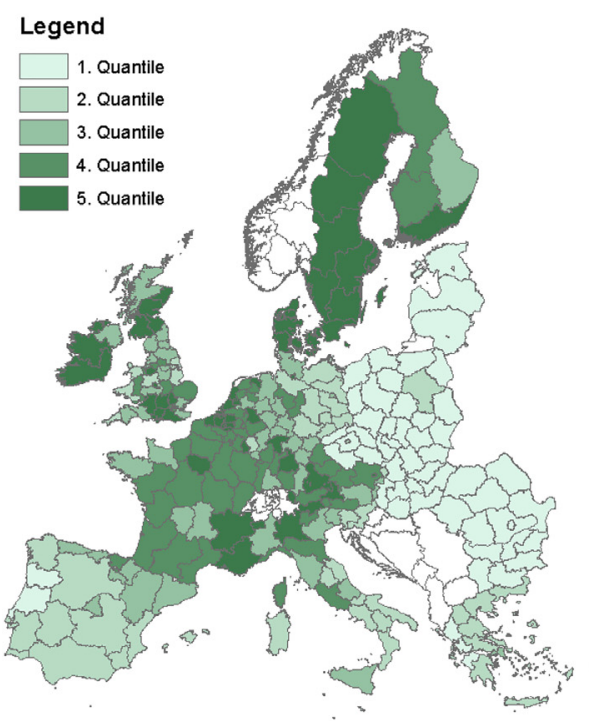

(b) Population share $\left(\lambda_{n}\right)$

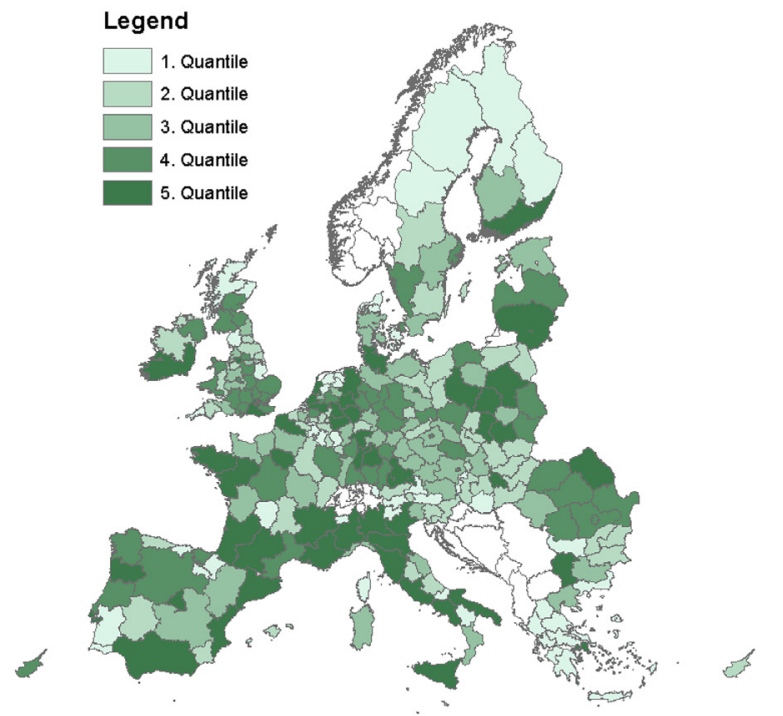

(d) Residential land supply $\left(H_{n}\right)$

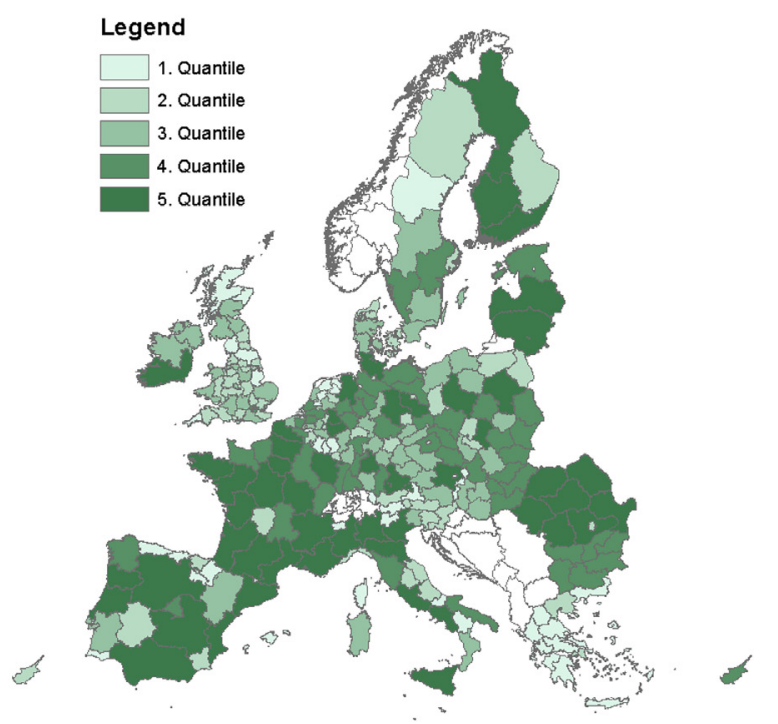

Fig. 1. Overview of observed variables. Notes: The figures depict quantiles of the reported variables. A darker shading in the map indicates a higher value.

As a robustness check, we use information about the financial contributions to the EU budget and set taxes equal to country-specific tax rates $\tau_{n}=\tau_{c}$, which are proxied by the national contribution divided by GNI. In this case, we introduce a scaling parameter $\nu$ to ensure that the government budget constraint is fulfilled i.e., $\nu \sum_{n \in N} w_{n} L_{n} \tau_{c}=$ $\sum_{n \in N} T_{n}$.

Transportation costs: We use Eq. (9) and information on TravelTime ${ }_{r i}$ together with parameter estimates for $\theta$ and $\beta$ to obtain expected transportation costs $\left(d_{n i}\right)$. Using GIS software, we identify adjacent NUTS2 regions and compute the elements of the adjacency matrix ( $\tilde{\mathbf{D}})$ based on road TravelTime ${ }_{r i}$ between the centroids of the respective regions, which is provided by the RRG Database. The latter contains detailed information on different speed limits, slope gradients, congestion etc. ${ }^{23}$

${ }^{23}$ Note that we assume regions maintaining a ferry connection to be adjacent in order to ensure a comprehensive transport network and trade between the EU continent and the islands. Information about ferry connections is obtained from openstreetmap.org.
TravelTime $_{r i}$ is measured in hours travelled on roads in the years 1999, 2006, and 2013 for the respective periods. By minimizing the sum of squared errors between observed freight and gravity Eq. (5), we estimate the factor converting travel time to trade cost $\beta$. For this, we need data on bilateral road freight among NUTS2 regions and set parameter values for the trade elasticity $\sigma=5$ and heterogeneity of traders $\theta=136.13$. The former stems from the European Transport Policy Information System for the year 2010 and we parameterize the elasticity of substitution $(\sigma)$ and trade heterogeneity $(\theta)$ according to estimations obtained by Simonovska and Waugh (2014) and Allen and Arkolakis (2016).

The non-linear least square estimates of our gravity equation yield a value of $\beta=0.068$. Fig. A. 1 in the Appendix depicts a strong correlation of -0.709 between demeaned freight data and trade costs with estimated $\beta$. Our estimate is slightly higher than the one obtained by Allen and Arkolakis (2016), which is likely due to differences in 
institutional settings and geography. ${ }^{24}$ We refer to Appendix A.1 for a more detailed discussion of the estimation of $\beta$.

Recovering location fundamentals and estimating elasticities $\{\varepsilon, \mu\}$ : We recover regional productivity by substituting (6) in goods market clearing (20). Given data for $\left\{\lambda_{n}, y_{n}\right\}$ and substituting parameters $\{\sigma, \alpha\}$, estimates of $d_{n i}$ as well as the already recovered information about $w_{n}$ we obtain $a_{n}, \tilde{a}_{n}$ and consequently equilibrium values for bilateral trade shares and real income (see Appendix A.5 for details). Recall that we invert the model for the last three programming periods such that we obtain a panel of the model's equilibrium values.

The shape parameter of the Fréchet distribution of location preferences can be estimated from a log-linearized version of (17). The denominator of this equation is constant across all regions. By including region-specific fixed effects in the empirical specification, we absorb time-invariant components of $\ln \left(B_{n}\right)$ such that we obtain $\varepsilon$ as the coefficient on region- and time-specific real income. However, estimating (17) is complicated by the simultaneous relationship between real income and local employment. As is common in the literature, we resort to a Bartik type instrument, which is constructed by pre-determined sector shares across regions and growth dynamics of the sectors at an aggregate level (e.g. Bartik, 1991; Diamond, 2016). In particular, we use the sectoral employment shares of NUTS2 regions in the year 1985 and interact them with the growth rates at the EU level. As an alternative instrument, we use the geographical centrality of a region, which affects real income via the price index but does not have a direct effect on population shares. Our estimates yield values between 2.9 and 3.5 and thus we set $\varepsilon=3$, which is in line with Bryan and Morten (2019), Monte et al. (2018), and Redding and Rossi-Hansberg (2017).

Having specified $\varepsilon$, we substitute real income from (16) in population shares (17) and solve for regional consumption amenities $B_{n}$ (see Appendix A.6 for details).

We obtain the agglomeration elasticity $\mu$ by estimating Eq. (4) for the panel of regional productivities jointly with data on regional employment for the corresponding years. Importantly, OLS estimates of (4) yield biased estimates because the model implies that higher local productivity reflects in higher wages and an inflow of population. Combes et al. (2010) propose to use information about the nature of soils in a region as an instrument for population density. The relevance of the instrument builds on the idea that some types of soils are more suitable to support a higher population density and more fertile soil has historically attracted a greater number of people. Since soil quality is no longer a relevant factor for productivity, it is a valid instrument to identify the effect of $L_{n}$ and productivity. We compute regional soil indices at the NUTS2 level based on raster data provided by the European Soil Data Centre. Specifically, we follow Combes et al. (2010) and compute indices for Depth to rock as well as for the Topsoil mineralogy. As is shown in Appendix A.3 both instruments turn out relevant in the first stage of the instrumental variable estimation and the instruments pass the Sargan test for overidentification. We estimate in our preferred specification an agglomeration elasticity of about $\mu=0.1$, which is well in line with Allen and Arkolakis (2014) and somewhat below the estimates obtained by Brülhart and Mathys (2008) based on a dynamic GMM estimation for European NUTS2 regions.

Transfer elasticity of production amenities and travel time: The transfer elasticities are estimated based on fixed effects regressions and regression discontinuity design (RDD) specifications of (11) and (12). In the latter case, we exploit the fact that a substantial share of regional transfers (so-called Objective 1 transfers) are paid according to an allocation rule that gives rise to a discontinuity: Regions are eligible for the highest transfer intensity if their per capita GDP falls below $75 \%$ of the EU average in some well defined years prior to the respective

\footnotetext{
24 First, trade and geographic barriers might be higher in Europe than in the US, which results in a higher factor converting travel time to trade costs. Second, transportation links are shorter for NUTS2 regions than for major cities located at the US Interstate Highway System as considered in Allen and Arkolakis (2016).
}

Table 1

Estimation and calibration of parameters.

\begin{tabular}{|c|c|c|c|}
\hline Description & Par. & Value & Reference \\
\hline Elasticity of prod. amenities & $\kappa^{a}$ & 0.006 & Estimation in Table A.1 \\
\hline $\begin{array}{l}\text { Elasticity of transport } \\
\text { infrastructure }\end{array}$ & $\kappa^{d}$ & 0.004 & Estimation in Table A.1 \\
\hline Share of consumption expenditure & $\alpha$ & 0.75 & Eurostat (2016) \\
\hline Elasticity of substitution & $\sigma$ & 5 & $\begin{array}{l}\text { Simonovska and Waugh } \\
\text { (2014) }\end{array}$ \\
\hline Agglomeration elasticity & $\mu$ & 0.1 & Estimation in Table A.1 \\
\hline Heterogeneity of preferences & $\varepsilon$ & 3 & Estimation in Table A.1 \\
\hline $\begin{array}{l}\text { Factor converting TravelTime }{ }_{r i} \text { to } \\
\tilde{d}_{r i}\end{array}$ & $\beta$ & 0.068 & Estimation in Section A.1 \\
\hline Heterogeneity of traders & $\theta$ & 136.13 & Allen and Arkolakis (2016) \\
\hline
\end{tabular}

Notes: The table reports estimated and calibrated parameters entering our model. The elasticity of substitution is within the range of common values in the literature and equivalent to Redding and Rossi-Hansberg (2017).

budgeting period (see Becker et al., 2010). We estimate these elasticities using data for all three budgeting periods. Accordingly, we employ the panel of recovered production amenities for 1994-99, 2000-06, 200713 and data for road travel times in these years for estimation of $\kappa^{a}$ and $\kappa^{d}$, respectively. This allows us to exploit changes in transfer intensities over time in addition to the cross-sectional variation and thus to improve the causal identification of transfer elasticities. Note that we include time-fixed effects in all specifications. The benchmark results for the estimates of both transfer elasticities are displayed in Table A.1 in Appendix A.2. It is evident that higher regional transfer intensities increase production amenities and decrease road travel time. Moreover, the effects are highly significant across specifications. For our quantitative analysis, we use the fixed-effect estimates $\left(\kappa^{a}=0.006\right.$ and $\kappa^{d}=$ 0.004 ) noting that the confidence bounds are overlapping with the RDD estimates at conventional levels of statistical significance. ${ }^{25}$ These point estimates imply that a $1 \%$ increase in per-capita transfers raises production amenities by about 0.006 percent by the end of the seven year period. A $1 \%$ increase in transfers to a transportation link yields a reduction of about 0.004 hours (equivalent to ca. 0.2 percent of the average travel time between links) at the end of the respective budgeting period. We use the estimated parameter $\kappa^{d}$ jointly with data about linkspecific travel time and transfers to compute $\gamma_{r i}$ according to Eq. (11). Analogously we obtain the fundamental location amenities $\bar{a}_{n}$ from Eq. (12) using the estimates for $\kappa^{a}$. The regression constants absorb the uniform price of the factor producing infrastructure and production amenities because of the logarithmic specification. Accordingly, our estimates allow us to quantify the percentage changes of TravelTime $r i$ and $\ln \left(\tilde{a}_{n}\right)$ for any percentage change in transfers independent of the input factor's price.

Table 1 provides information on all parameters entering our model. We performed sensitivity checks for the parameters set according to the literature and conclude that our qualitative results are robust to the choice of parameters within the usual range reported in the literature. An overview of our recovered variables is depicted in Fig. 2. A number of observations stand out: First, wages are lowest in the east and south of Europe, whereas production amenities are highest in the core as well as in Scandinavia and generally in cities. Eastern Europe shows low production amenities both net of transfers and once the EU investments are accounted for. Second, land rents are evidently highest in cities and tend to be relatively high in the UK, Northern Italy and Southern Germany compared to areas with low land prices in Central and Eastern Europe. Third, Germany and Eastern Europe display a high share of contributions to the global portfolio indicating a trade surplus while low shares of global investments in France, Greece and Portugal result in a trade deficit. Fourth, consumption amenities are highest in Eastern

\footnotetext{
${ }^{25}$ Note that the elasticities for production amenities and travel time are not directly comparable with prior estimates in the literature focusing on GDP or employment growth.
} 
(a) Share global portfolio $\left(\iota_{n}\right)$

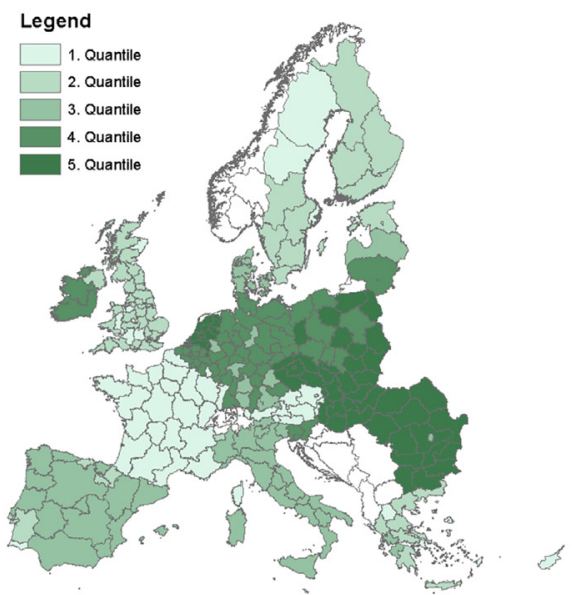

(d) Price of land $\left(r_{n}\right)$

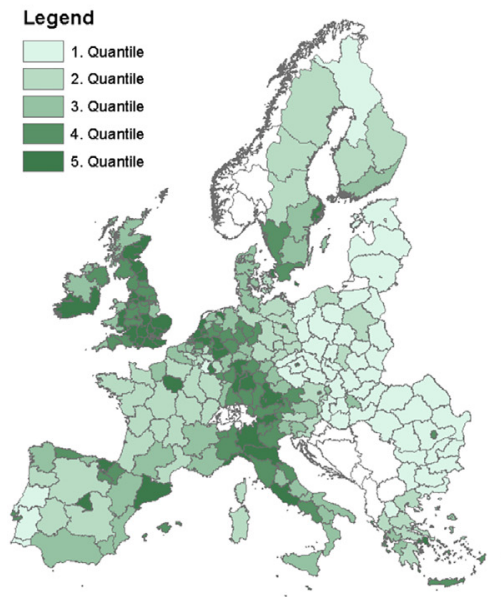

(g) Location amenities $\left(B_{n}\right)$

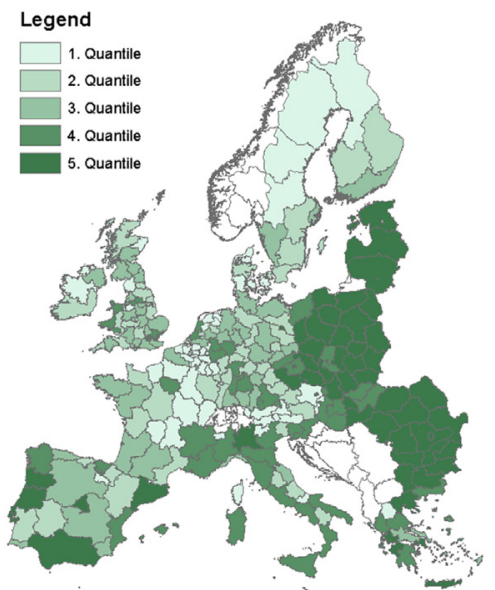

(b) Trade costs $\left(\sum_{i} d_{n i}\right)$

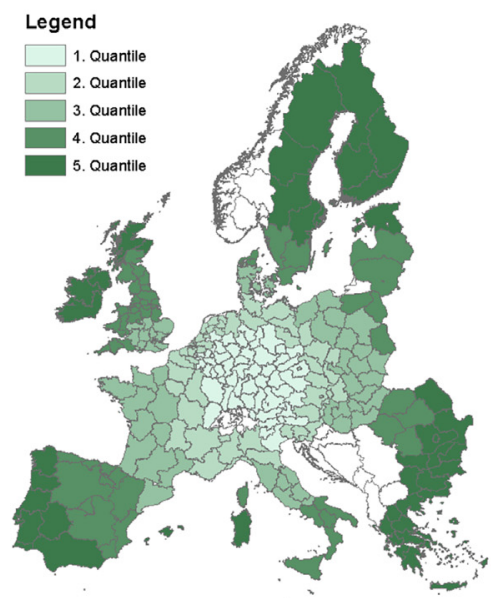

(e) Productivity $\left(a_{n}\right)$

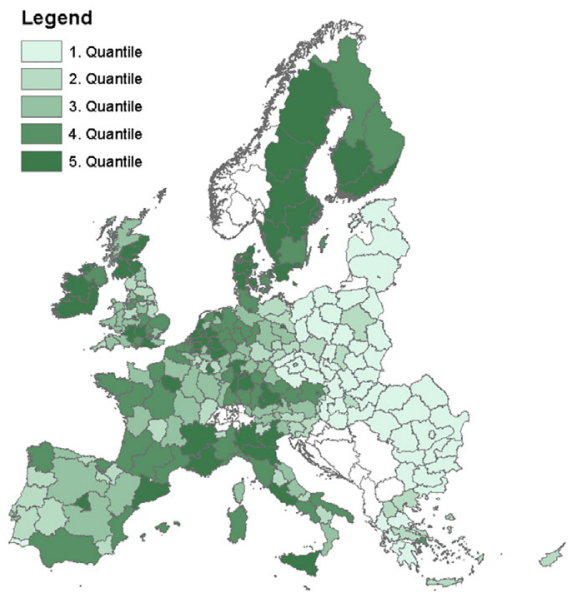

(h) Own trade share $\left(\pi_{n n}\right)$

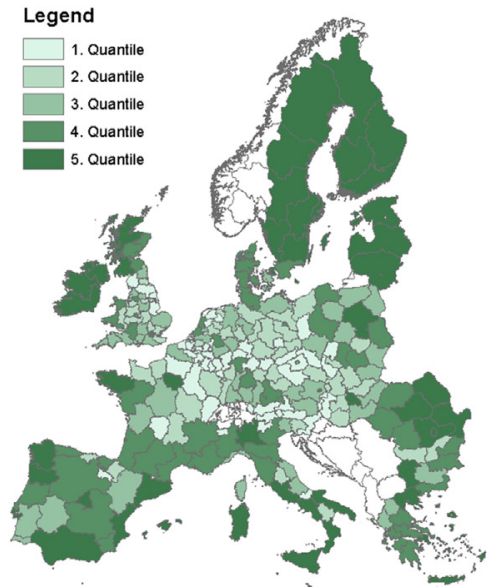

(c) Wages $\left(w_{n}\right)$

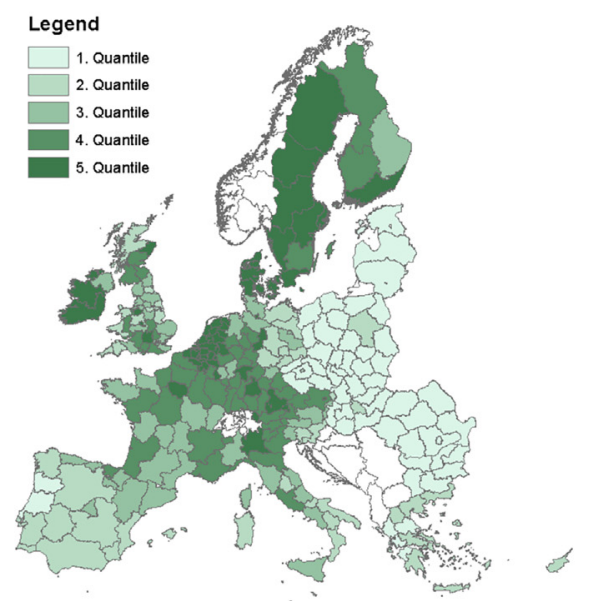

(f) Production amenities

- net of transfers $\left(\bar{a}_{n}\right)$

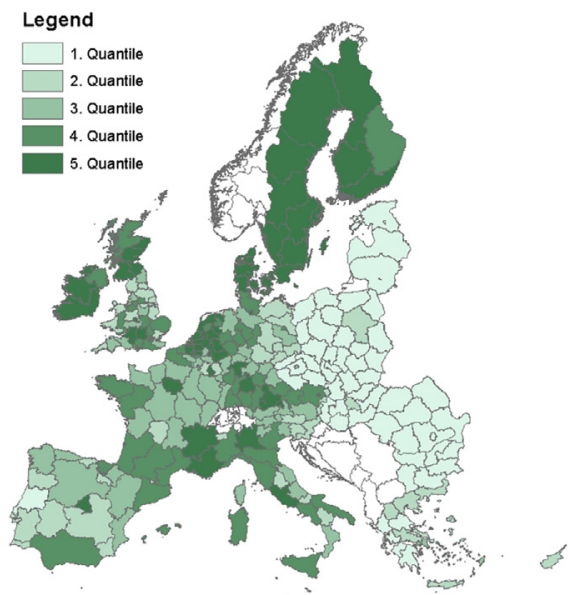

(i) Price index $\left(P_{n}\right)$

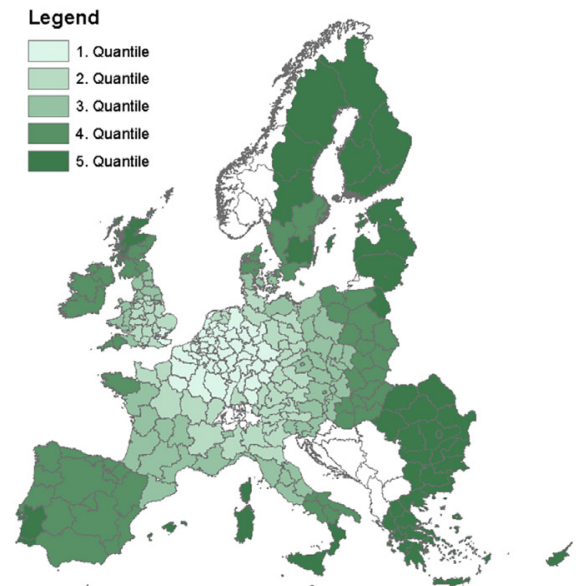

Fig. 2. Overview of estimated and recovered variables. Notes: The figures depict quantiles of the reported variables. A darker shading in the map indicates a higher value. 
Europe, the south of Spain, Greece, Portugal as well as in urban areas such as Paris, London, and Madrid. This captures on the one hand utility benefits conditional on real income and on the other hand regional migration costs. Fifth, the price index strongly correlates with the geographical market access as measured by the sum of trade costs. These patterns are well in line with stylized facts about economic geography in Europe and suggest that the model performs well in matching the distribution of economic activity.

\section{Counterfactual analysis}

We derive counterfactual changes in wages, trade shares and population shares which provide - jointly with direct effects of transfers on production amenities, trade costs, and income - sufficient statistics of the welfare effects of regional policy. A counterfactual change is denoted as $\hat{x}=\frac{x^{\prime}}{x}$, where $x$ is the observed variable and $x^{\prime}$ is the unobserved counterfactual value of $x$. In the counterfactual simulations, transfers enter in three ways: First, transfers influence the equilibrium via nominal wage subsidies raising income $\left(\hat{y}_{n}\right)$. Second, transfers impact transportation costs and thereby alter trade costs $\left(\hat{d}_{n i}\right)$ as well as regions' market access. Third, investments in production amenities proportionately raise production amenities $\left(\widehat{\tilde{\tilde{a}}}_{n}\right)$, which reduce prices of varieties produced in recipient regions. According to expected utility (19) the change in welfare across regions is given by:

$\widehat{\bar{V}}=\left(\frac{1}{\hat{\pi}_{n n}}\right)^{\frac{\alpha}{\sigma-1}}\left(\frac{\hat{y}_{n} \widehat{\tilde{a}}_{n}}{\hat{w}_{n} \hat{d}_{n n}}\right)^{\alpha}\left(\hat{\lambda}_{n}\right)^{\alpha \mu-(1-\alpha)-1 / \varepsilon}$.

From this equation, it is evident that a full cost-benefit analysis should not only consider direct effects of transfers $\left(\hat{y}_{n}, \widehat{\tilde{a}}_{n}, \hat{d}_{n n}\right)$ in the recipient region but also account for changes in trade share, population and local wages. These changes are derived from the full system of counterfactual equilibrium equations shown in Appendix B.

We isolate effects of different transfer mechanisms by studying three counterfactual situations: First, we analyze the effect of abandoning EU regional transfers altogether and set the corresponding tax rates to zero. The resulting outcome provides a welfare measure of EU regional policy. In a second counterfactual analysis, we show how the spatial equilibrium would change if transfers were distributed equally. In this case, the level of transfers is comparable to the observed one, in total and for each type. Hence, this counterfactual informs about how efficient the EU distributes transfers compared to a naive rule that gives every region the same. Third, we derive the optimal spatial allocation of transfers for each type of transfer separately as well as for the sum of transfer channels. This allows us to quantify potential efficiency gains from redistribution and to derive the factors that render a type of transfer efficient in some regions and inefficient in others. In these simulations, we keep tax rates and the aggregate mix of transfer types in Europe at the observed levels such that the optimality criterion focuses on the spatial distribution of transfers rather than the size of the program.

\subsection{No-transfer scenario}

What would be the (welfare) effects if the European Union abandoned its place-based policy scheme altogether? To analyze this question, we set both transfers and tax rates to zero.

Expectedly, we find that productivity and income losses would be most pronounced in Southern and Eastern Europe where the per capita transfers are the highest. The change in transportation costs due to suspending transfers would generally be most pronounced in peripheral regions in the south, east and north of Europe. These direct effects would translate into changes in wages, own trade shares and population shares. In particular, our simulation suggests that substantially more workers would relocate from Southern and Eastern European regions to the Center and North of Europe. The increase of inter-regional migration would amount to 0.68 percent of the European population. ${ }^{26} \mathrm{Fig}$. B.1 in the Appendix illustrates the changes predicted by the model for the no-transfer scenario.

Overall, the ten countries with the highest share of population emigrating would lose about $2.65 \%$ of their population when moving from the observed equilibrium to a situation without transfers. ${ }^{27}$ At the same time, average nominal per capita income in the regions of these ten countries would be about $1.51 \%$ lower than in the observed equilibrium. Accordingly, our findings suggest that EU regional transfers were quite effective in reducing migration from new member states in the east to the center. On average, abolishing transfers would also significantly increase average own trade shares by 3.05\%. Summing up over all welfare components, we find that the EU place-based transfers raised welfare by approximately $2.08 \%$ compared to the no-transfer scenario.

How did the individual types of transfers contribute to the welfare gain and to changes in regional inequality? In Table 2, we summarize the effects of individual transfer types on welfare and regional inequality as measured by the coefficient of variation. Panel a) isolates the wage subsidies as one mechanism of regional transfers, panels b) and c) isolate the effects via production amenity gains and changes in transportation costs while panel d) considers all three transfer channels simultaneously. ${ }^{28}$ In column (2), we report the change in welfare and inequality obtained with the observed spatial distribution of transfers relative to the counterfactual without transfers. Assuming that productivity and transportation costs remain unaffected by transfers, we find that the observed distribution of wage subsidies raised welfare by 0.05 percent. Reductions in regional inequality concern the second objective of regional policy. In this regard, it turns out that the observed distribution of wage subsidies has in fact significantly reduced inequality in terms of nominal income as well as real income. Analogously, assuming that the only direct effect of transfers is to raise local productivity, we find that the welfare gain due to the observed allocation of transfers amounts to 1.21 percent. A significant reduction in inequality is obtained as the production enhancing effects of transfers are concentrated in poor and peripheral regions. Finally, panel c) of Table 2 isolates the effects of transport infrastructure investments. Transport infrastructure represents not only a major part of expenditure but also contributed to the second-largest welfare gain, which amounts to about 0.82 percent. However, transportation infrastructure investments have only contributed to a relatively small reduction in regional inequality in terms of nominal and real income.

Considering the total effect of transfers via all three channels (Table 2d), we obtain a significant increase in welfare and a substantial reduction in regional inequality compared to the no-transfer scenario. These results are based on the assumption that local governments would not step in for the EU's investments. This is grounded in the EU Structural Funds' 'additionality principle', which stipulates that transfers must not replace public expenditures of the member states. ${ }^{29}$ Another caveat about the level effect of investments in infrastructure and production amenities is that the input factor is not drawn from other economic activities. From these observations follows that the level effect may contain an upward bias.

\footnotetext{
${ }^{26}$ According to European Commission (2014) the international migration within the EU amounted to about $1.2 \%$ of the working age population.

27 These countries are BG, CZ, EE, HU, LT, LV, MT, PL, RO, SK. The share of population of these 10 countries in the total European population is currently about $18.83 \%$.

${ }^{28}$ Note that the aggregate welfare effect is not equivalent to adding the individual components in panels a), b), and c) because the individual transfers enter non-linearly. For instance, investment in transportation infrastructure and production amenities are complementary.

29 The EU Commission verifies each member state's compliance with this principle at the mid-term of each programming period (European Commissions, 1996).
} 
Welfare and inequality effects of transfers.

\begin{tabular}{|c|c|c|c|c|c|c|}
\hline & \multicolumn{3}{|c|}{ (a) Wage subsidies $\left(T_{n}^{w}\right)$} & \multicolumn{3}{|c|}{ (b) Production amenities $\left(T_{n}^{a}\right)$} \\
\hline & Equal & Observed & Optimal & Equal & Observed & Optimal \\
\hline & (1) & (2) & (3) & (1) & $(2)$ & (3) \\
\hline Welfare $\left(\hat{V}_{n}\right)$ & $0.02 \%$ & $0.05 \%$ & $0.20 \%$ & $1.55 \%$ & $1.21 \%$ & $1.69 \%$ \\
\hline$\widehat{C V}\left(y_{n}\right)$ & $-0.18 \%$ & $-0.34 \%$ & $-0.51 \%$ & $-0.24 \%$ & $-0.82 \%$ & $-0.00 \%$ \\
\hline \multirow[t]{4}{*}{$\widehat{C V}\left(y_{n} P_{n}^{\alpha} r_{n}^{1-\alpha}\right)$} & $-0.12 \%$ & $-0.25 \%$ & $-0.35 \%$ & $-0.09 \%$ & $-0.66 \%$ & $0.01 \%$ \\
\hline & \multicolumn{3}{|c|}{ (c) Transportation infrastructure $\left(T_{n}^{d}\right)$} & \multicolumn{3}{|c|}{ (d) All transfers $\left(T_{n}\right)$} \\
\hline & Equal & Observed & Optimal & Equal & Observed & Optimal \\
\hline & $(1)$ & (2) & (3) & (1) & $(2)$ & (3) \\
\hline Welfare $\left(\hat{V}_{n}\right)$ & $1.19 \%$ & $0.82 \%$ & $1.22 \%$ & $2.60 \%$ & $2.08 \%$ & $3.14 \%$ \\
\hline$\widehat{C V}\left(y_{n}\right)$ & $0.04 \%$ & $-0.07 \%$ & $0.05 \%$ & $-0.18 \%$ & $-1.22 \%$ & $-0.44 \%$ \\
\hline$\widehat{C V}\left(y_{n} P_{n}^{\alpha} r_{n}^{1-\alpha}\right)$ & $0.11 \%$ & $-0.17 \%$ & $0.16 \%$ & $0.04 \%$ & $-1.06 \%$ & $-0.17 \%$ \\
\hline
\end{tabular}

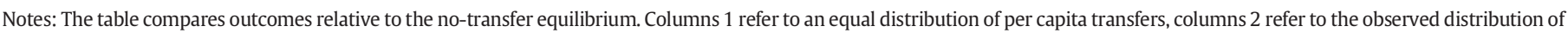

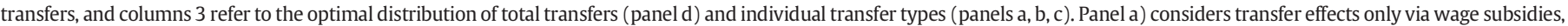

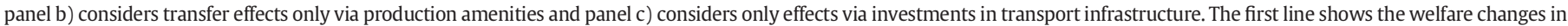

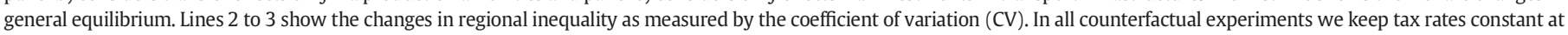
the observed level. When we restrict the analysis to one transfer type we keep taxes at the level required to finance the observed budget of the respective transfer type.

\subsection{Uniform distribution of transfers}

Another natural candidate for a policy experiment is to fix tax rates and distribute the government budget uniformly across regions. This naive distribution allows us to isolate the welfare implications of the regional distribution of transfers while keeping the level of taxes - required to finance the respective transfer type - and total expenditures for each type constant.

The consequences for welfare and regional inequality of this experiment are reported in column (1) of Table 2, where the effects are generally expressed relative to the no-transfer scenario. The counterfactual changes in local outcomes are depicted in Fig. B.2 in the Appendix. Moving from the observed to a uniform distribution of transfers, our model predicts significant immigration from Eastern and Southern Europe to the core and northern parts of Europe. Yet, the migration response would be less pronounced than in the case without transfers as the ten countries with the highest emigration would lose only about $2.17 \%$ of their population compared to the observed equilibrium. The reduction in nominal per capita income across regions in these countries would be about $1.38 \%$ compared to the observed equilibrium.

Looking at the different transfer types separately, we find that with regard to wage subsidies the existing distribution is more efficient than a uniform distribution as is evident from Table 2a. The welfare effect of the observed distribution of wage subsidies is more than twice the effect of a uniform distribution and inequality is notably lower. ${ }^{30} \mathrm{~A}$ uniform distribution would allocate more transfers to the center and thereby reach a welfare increase of 0.34 percentage points via the production amenity channel (Table $2 \mathrm{~b}$ ) and 0.37 percentage points via the transportation infrastructure channel (Table 2c) compared to the welfare gain of the observed distribution. Summing up over all transfer types, the uniform distribution dominates the observed one from an aggregate welfare perspective: We estimate an increase in welfare of about 0.52 percentage points when moving from the observed to the uniform distribution of transfers (Table 2d). Overall, the comparison of columns (1) and (2) in Table 2 illustrates that the existing distribution goes further in reducing regional income inequalities than a uniform distribution but at

\footnotetext{
${ }^{30}$ Note that the uniform distribution already implies a certain redistribution from high to low income regions due to proportional taxes.
}

the costs of lower efficiency obtained via investments in production amenities and transportation infrastructure. ${ }^{31}$

\subsection{Optimal distribution of transfers}

From a policy maker's point of view, a crucial question is whether there are efficiency gains that can be reached by changing the distribution of transfers across regions while keeping the aggregate shares spent on each transfer type as well as the tax rates (i.e. the program budget) constant. To maximize aggregate welfare, we use a "Mathematical Programming With Equilibrium Constraints" (MPEC) approach as introduced by Su and Judd (2012) and applied by Ossa (2014, 2017) for optimal tariffs and subsidies. This numerical optimization routine maximizes regions' welfare and uses the model's equilibrium equations as constraints. ${ }^{32}$

We derive the optimal distribution of transfers for each type separately and report the corresponding optimal welfare changes and impacts on regional inequality in columns (3) of Table 2. Fig. 3 shows the shares of the transfer budgets a region should receive according to the welfare optimizing algorithm. From Fig. 3a it is evident that the optimal distribution of wage subsidies deviates significantly from the observed one. In particular, the welfare optimal policy issues transfers to only a few regions in Eastern Europe while cutting subsidies in most other recipient regions. A redistribution of wage subsidies according to our optimal allocation yields a welfare gain of 0.20 percent compared to the no-transfer scenario, which is four times the gain achieved by the observed distribution (Table 2a). Importantly, the efficiency gain can be achieved at an even lower degree of regional income inequality. Focusing on transfers that operate via wage subsidies to a small set of regions allows for an unambiguous welfare increase without compromising regional equality. Note that an increase in the budget would clearly

\footnotetext{
31 Instead of a uniform distribution of investments, one may also consider a uniform, local, proportional tax rate, which is invested locally. This yields higher levels of investments in rich versus poor regions. While this setup conflicts with the EU's additionality principle and excludes wage subsidies, the aggregate welfare effects would be between the uniform and the optimal distribution.

32 The routine proceeds as follows: First, we draw random initial values for transfer shares. Second, we compute the general equilibrium allocation based on this draw. Third, we supply this information to a numerical solver, which maximizes a regions utility function. We randomize the initial values to show that the solver converges to the same solution suggesting that it is unique. For a detailed documentation of our numerical optimization approach, we refer to Appendix C.
} 
(a) Wage subsidies

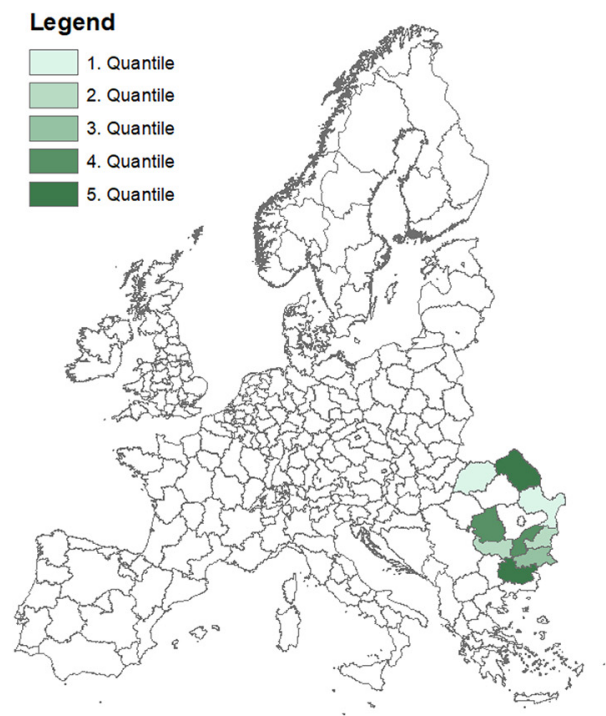

(c) Investment in production amenities

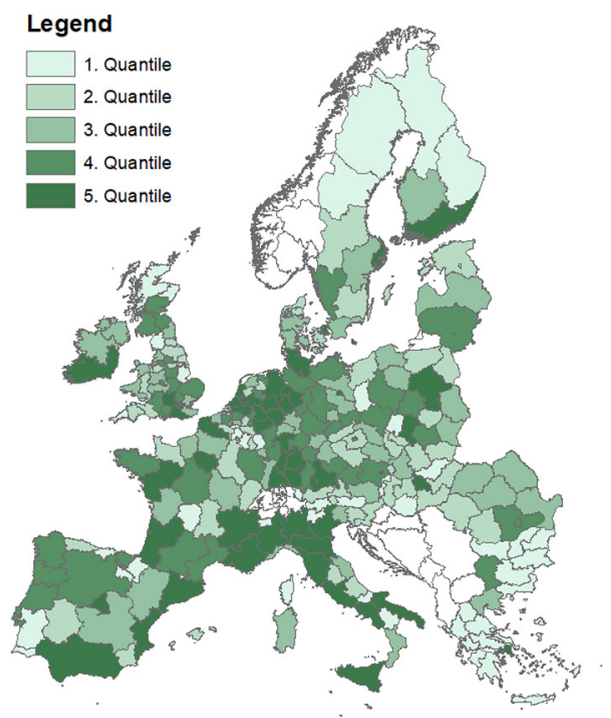

(b) Wage subsidies, high tax rates

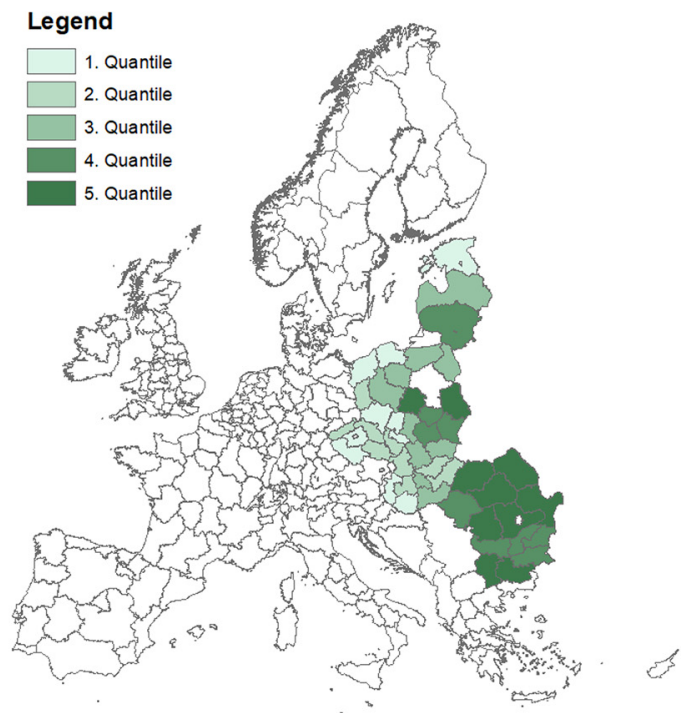

(d) Investment in transport infrastructure

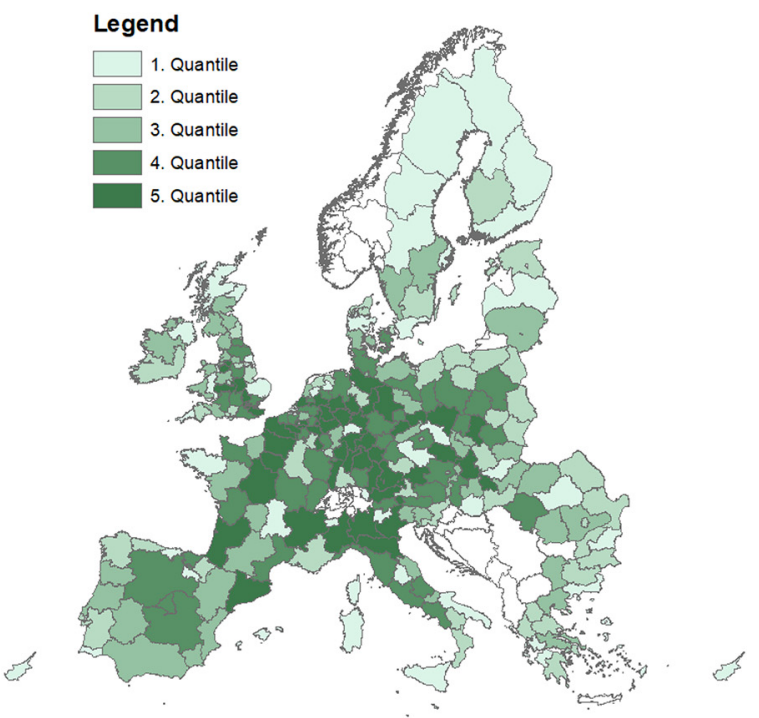

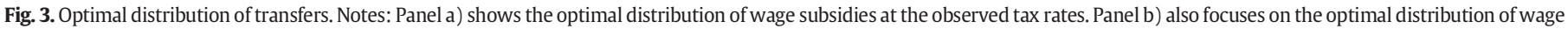

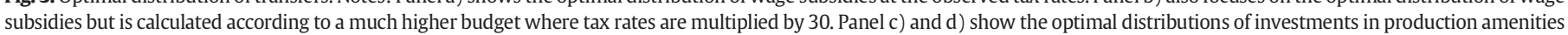

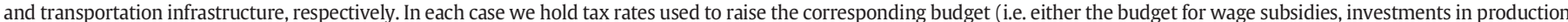

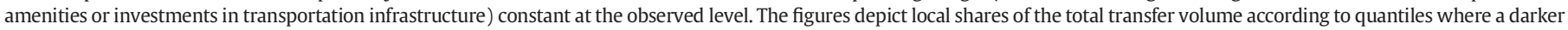
shading represents a higher transfer share.

expand the number of recipient regions according to the welfare optimal policy. For instance, in Fig. 3b we show the resulting distribution that would apply if we substantially increase tax rates by a factor of 30. In this case, a larger share of regions would receive transfers.

The optimal distribution of investments in transportation infrastructure is presented in Fig. 3d and indicates a very different pattern. The highest shares of the transfer budget are allocated to central regions in northern Italy, the Benelux countries, Germany, UK, and France. In order to maximize aggregate welfare, a transfer scheme focusing on transport cost reductions exerts the most significant spillover effects at central places. This implies a substantial reallocation of transfers compared to the current scheme: The correlation coefficient between the regional distribution according to the optimal scheme and the one of observed transfers under the official heading 'Transport infrastructure' is $-0.11 .^{33}$ Such a reallocation could achieve an efficiency gain of about 0.40 percentage points compared to the existing distribution (Table 2c). However, this welfare gain would come at higher regional income inequality.

With regard to investments in local production amenities, the optimal pattern suggests the highest transfer shares in Germany and the UK where $0.22 \%$ and $0.12 \%$ of the total budget for $T_{n}^{a}$ is supposed to be allocated. However, the optimal distribution generally advises a broad dispersion of transfers across European regions. The optimum is

\footnotetext{
33 Comparisons between the optimal and observed distributions of other transfer types yield similarly low correlations: -0.024 for total transfers; -0.0003 for wage subsidies ( 0.46 when restricting the sample to those with positive optimal level); 0.10 for investments in production amenities.
} 
characterized by a welfare gain of 0.48 percentage points compared to the observed distribution and yields a higher degree of regional income inequality than the observed one (Table $2 \mathrm{~b}$ ).

Finally, allocating all transfer types according to their optimal distributions while keeping the aggregate budget for each transfer type constant one could realize an efficiency gain of 1.06 percentage points compared to the observed one while keeping tax rates constant (Table 2d). Hence, a mere improvement of the distribution of transfers substantially raises the welfare gain of EU regional policy. Notably, this comes at the costs of somewhat higher regional inequality than in the observed distribution. In Appendix D.1, we analyze the potential efficiency gains if regional income inequality was to be held constant. $\mathrm{Ag}$ gregate welfare gains would still be material but are 0.35 percentage points lower than without this constraint.

The migration responses in these scenarios are governed by the optimal distributions of transfer types in Fig. 3. In the case of an optimal distribution of $T^{w}$, it is evident that Romania and Bulgaria would be the beneficiaries. There, the population would increase by about $8.30 \%$ relative to the observed equilibrium. As a response to the optimal distributions of $T^{d}$ and $T^{a}$, we would see a population increase mostly in regions in the center of the EU. We illustrate the changes in population and other local outcomes for the simultaneous optimal distribution of $T^{w}, T^{a}$, and $T^{d}$ in Fig. B.3 in the Appendix. This equilibrium would yield inter-regional migration of $0.87 \%$ of the population.

What about the optimal scale of the transfer program? Our scenario with an optimal distribution of transfers concerns a second-best allocation in the sense that we keep the level of taxes constant, which prevents the complete internalization of prevailing externalities. The optimal scale of the program would be determined by the combination of the estimated transfer elasticities, prevailing externalities and the efficiency costs of raising the budget - via taxes on labor income. Abstracting from the latter, it would be efficient to expand the program as is evident from an increase of welfare in the scenario with high taxes (Fig. $3 \mathrm{~b}$ ) compared to the optimal distribution given the observed taxes. ${ }^{34}$ However, significant increases in taxes required to finance an optimally scaled transfer are unlikely to be politically enforceable.

In the following, we analyze the marginal welfare effects of transfer types across regions, which outlines the intuition about the optimal allocations discussed above.

\section{Marginal welfare effects of transfers}

We decompose the marginal welfare effects of transfers into four components: The direct effect of transfers, the price index effect through adjustment in wages and the effects via changes in own trades shares and local population shares. Totally differentiating expected welfare $\bar{V}$ with respect to transfers illustrates the weights put on these components:

$$
\begin{gathered}
d \ln \bar{V}=-\frac{\alpha}{\sigma-1} \underbrace{d \ln \pi_{n n}}_{\text {Adjustment own trade share }}+\alpha \underbrace{\left(d \ln y_{n}+d \ln \tilde{a}_{n}-d \ln d_{n n}\right)}_{\text {Direct effects }}-\alpha \underbrace{d \ln w_{n}}_{\text {Price index effect }} \\
+(\underbrace{\alpha \mu}_{\text {Agglomeration force }}-\underbrace{(1-\alpha)}_{\text {Dispersion force }}-\underbrace{\frac{1}{\varepsilon}} \underbrace{d \ln \lambda_{n}}_{\text {Taste heterogeneity }} .
\end{gathered}
$$

The first welfare implication is common across a wide range of trade models and is due to changes in terms of trade, which result in adjustments in own trade share as described in Arkolakis et al. (2012). Transfers affect local prices and thereby alter the terms of trade. Second,

\footnotetext{
34 Restricting transfer effects to income gains and further abstracting from the externality via heterogeneous non-local ownership of land, the distortions via productivity spillovers and congestion could be internalized using a combination of proportional taxes and lump sum transfers as shown in Fajgelbaum and Gaubert (2019). In this case, the ranking of recipient regions according to their optimal net transfers under our fixed budget constraint corresponds to the one for the optimal budget.
}

direct effects of transfers are unambiguously positive as they raise local income, productivity or reduce local trade costs. This part of the marginal welfare effect is characterized by decreasing marginal returns. Regions contributing a high share of the local rent income to the global portfolio display a smaller direct effect of transfers because a share $\iota_{n}$ of the increase in land values will be passed on to residents of other regions. Third, as local income increases, local production expands and pays higher wages, which in turn translates into increases in the price index of this region. This, in turn, negatively affects welfare as local goods become relatively more expensive. Fourth, changes in population affect welfare through agglomeration forces, dispersion forces and heterogeneity of location tastes. As population concentrates in a location, productivity increases, which makes the location ceteris paribus more attractive. A population inflow into a location is accompanied by an increase in land prices which, due to inelastic supply, leads to less housing consumption per capita. If workers have relatively heterogeneous tastes for regions (low $\varepsilon$ ), it is more likely that a large fraction of the individuals entering the regions have a low amenity draw. In the extreme case with homogeneous tastes $(\varepsilon \rightarrow \infty)$ there are no costs in terms of amenity mismatch. In accordance with the literature on quantitative economic geography, we restrict the parameter space to ensure that the agglomeration force is dominated by the dispersion forces i.e. that the last channel is always negative for population immigration.

Regional distribution. In order to infer the spatial distribution of marginal welfare effects for each type of transfer, we conduct the following simulation experiments: we shock every region separately with a marginal transfer and obtain welfare changes relative to the situation without transfers. The government budget required for this experiment is again financed via the proportional tax rate introduced above and it is evidently negligible in this case. For the purpose of isolating the marginal utility gain by transfer type, we eliminate the potential responses of the respective other transfer types by alternately setting two out of the three transfer channels to zero. Note that according to our transfer functions, we refer to a unit increase of per capita transfers in the case of wage subsidies and investments in production amenities and to a unit increase in the absolute level in case of infrastructure investments. Fig. 4 illustrates the heterogeneous distribution of marginal welfare effects: In panel a), we consider wage subsidies and observe a strong positive effect on welfare in peripheral and relatively poor regions. Overall, the welfare change due to a wage subsidy is highest in Eastern and Southern European regions. In contrast, in panel b) it is evident that investments in transportation infrastructure are most effective in the core. Panel c) displays the effectiveness of investments in production amenities: Marginal welfare effects tend to be high in urban areas but generally show a relatively mixed pattern.

Role of location fundamentals. The heterogeneity of marginal welfare effects must be driven by fundamental characteristics of the regions. In order to gain insights into the role of location fundamentals, we homogenize regions in terms of all location fundamentals such that general equilibrium outcomes of marginal welfare effects of transfers are ex-ante identical across regions. Then, we alternately set one of the location fundamentals to its recovered or observed value while keeping all others constant and calculate the marginal welfare effects of transfers for each region separately. ${ }^{35}$ This returns a distribution of marginal welfare effects of transfers along the observed values of the location fundamental that is allowed to vary across regions. Following this procedure, we can make ceteribus paribus statements of how location fundamentals impact the marginal welfare effects of regional transfers.

\footnotetext{
35 This exercise can also be interpreted as a difference-in-difference estimation of regional transfers, where the second difference is the same for all regions. The marginal welfare effect is $E\left[\hat{U}_{n, T, A} \mid T=1, A=0\right]-E\left[\hat{U}_{n, T, A} \mid T=0, A=0\right]-\left(E\left[\hat{U}_{n, T, A} \mid T=1, A=\right.\right.$ $\left.1]-E\left[\hat{U}_{n T A} \mid T=0, A=1\right]\right)$, where $T=1$ indicates that region $n$ received a marginal transfer and $A=1$ denotes that all location fundamental are set to it's average value for all regions and $A=0$ denotes that one specific location fundamental is set to it's observed value.
} 
(a) Wage subsidy

Legend
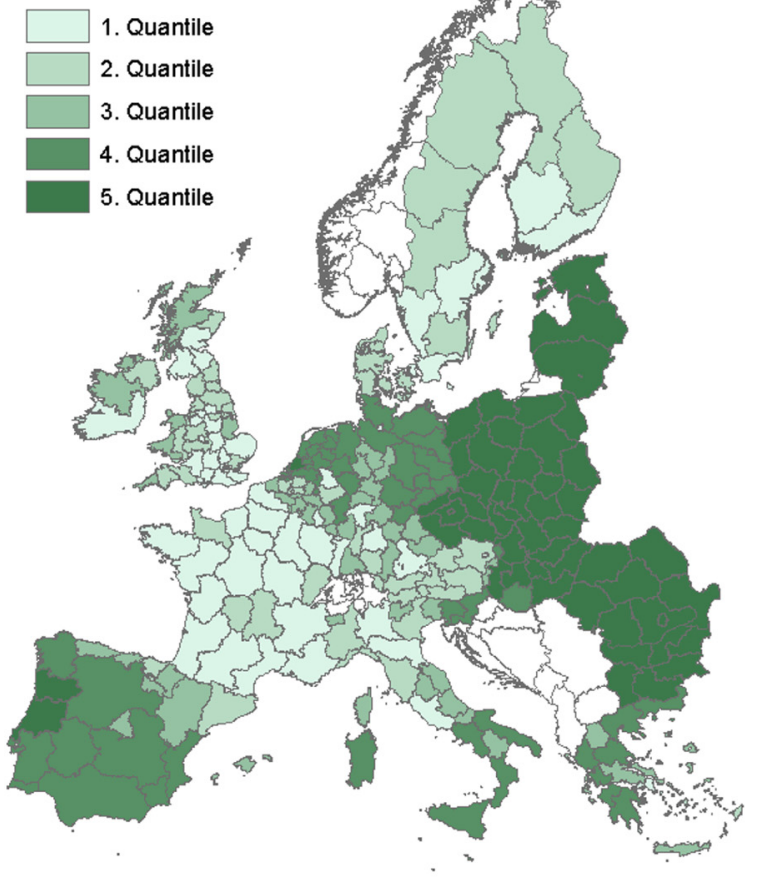

(b) Investment in transport infrastructure

Legend

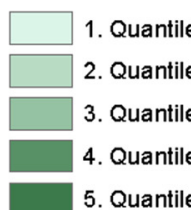

5. Quantile

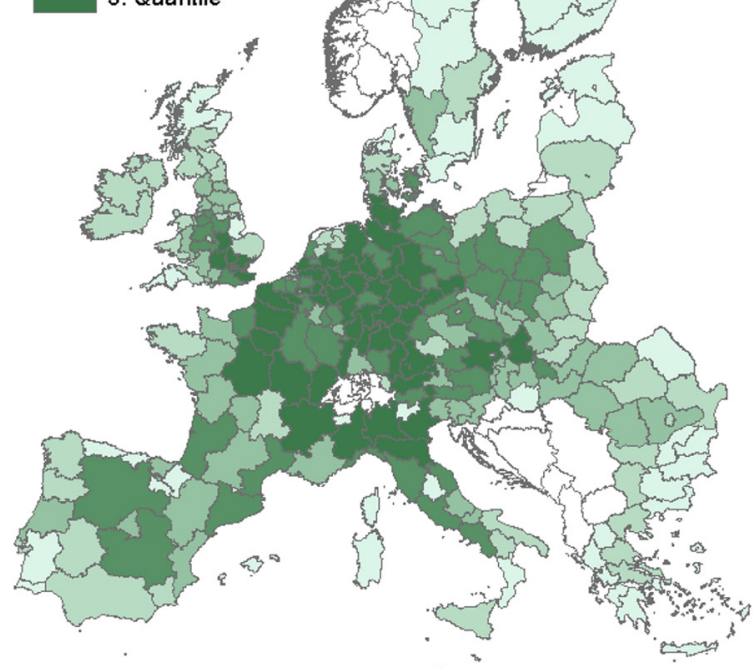

(c) Investment in production amenities

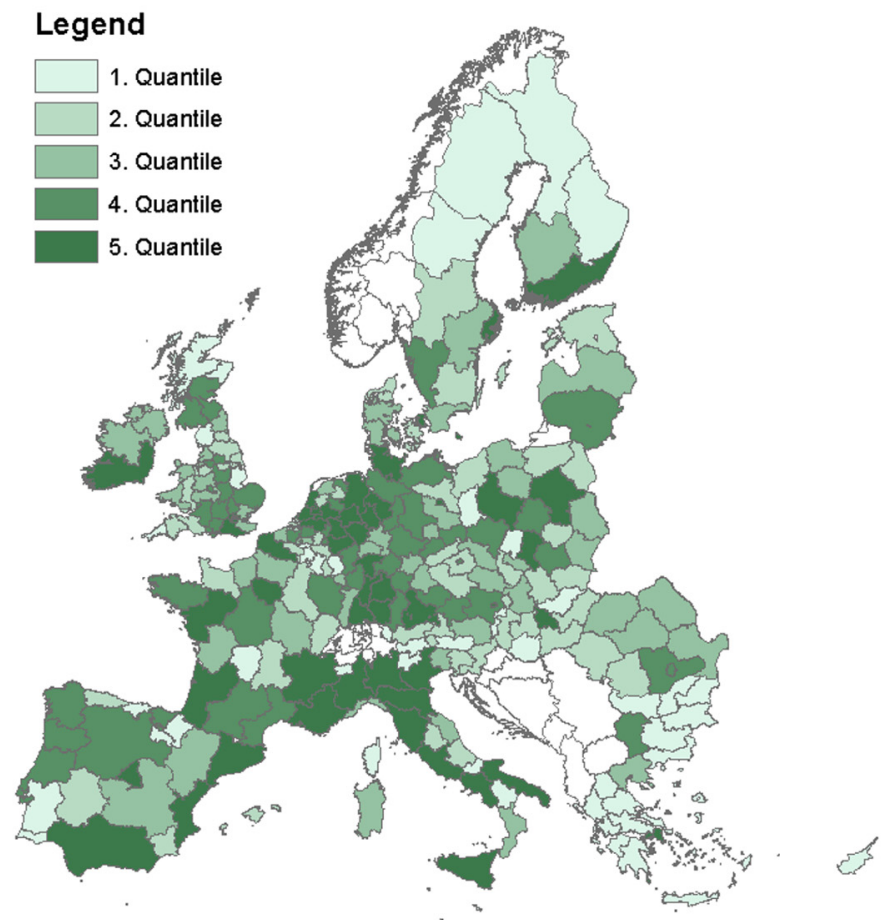

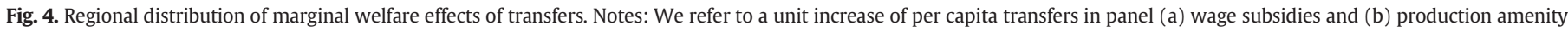

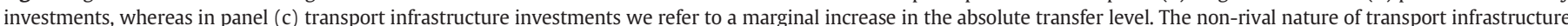

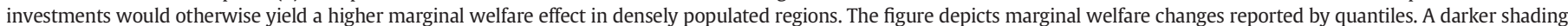
represents a stronger effect, whereas a green color illustrates a positive effect. 


\section{Wage subsidies}

(a) Fund. production amenity $\left(\bar{a}_{n}\right)$

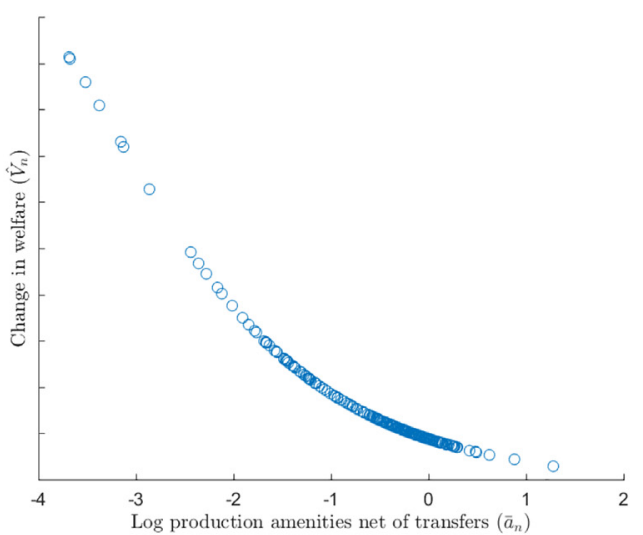

(b) Sum of trade costs $\left(\sum_{i} d_{n i}\right)$

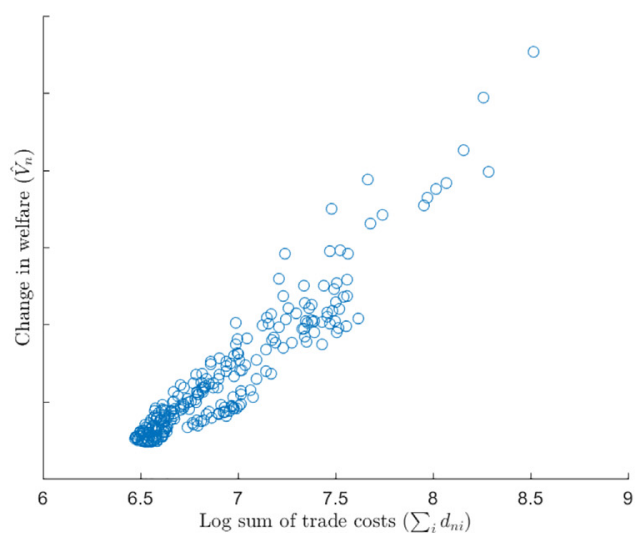

\section{Investments in production amenities}

(c) Fund. production amenity $\left(\bar{a}_{n}\right)$

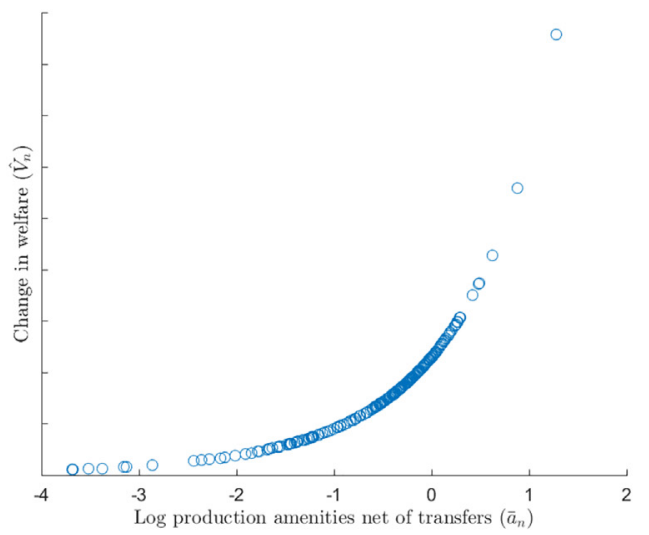

(d) Sum of trade costs $\left(\sum_{i} d_{n i}\right)$

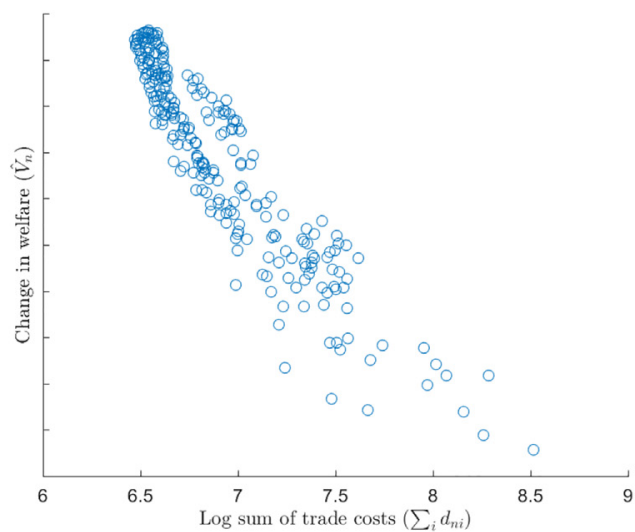

\section{Investments in transportation infrastructure}

(e) Fund. production amenity $\left(\bar{a}_{n}\right)$

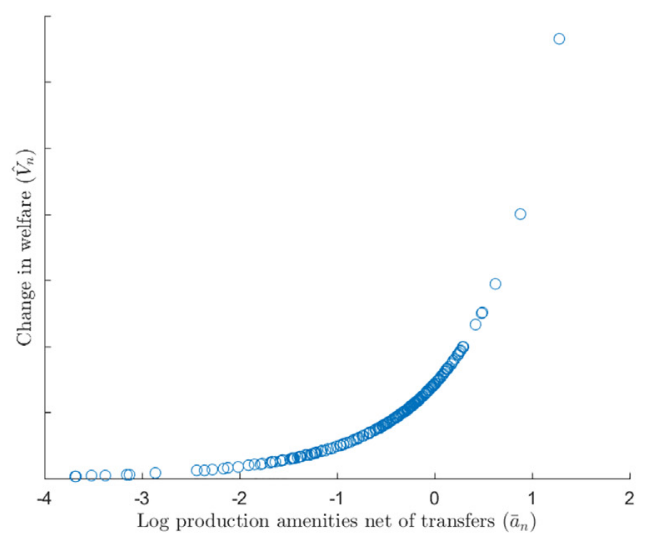

(f) Sum of trade costs $\left(\sum_{i} d_{n i}\right)$

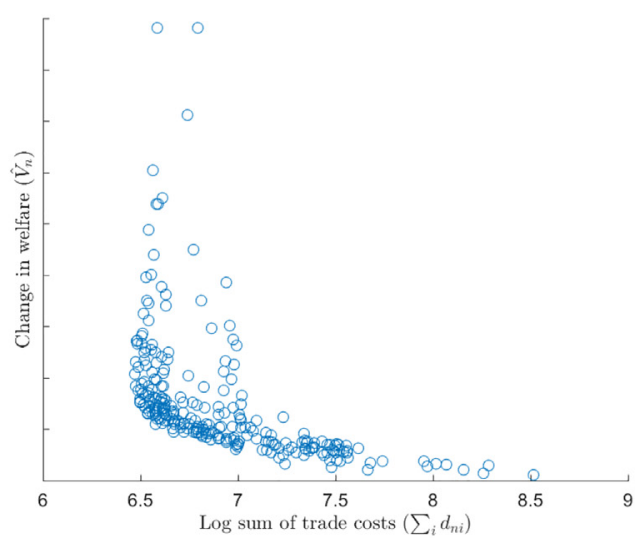

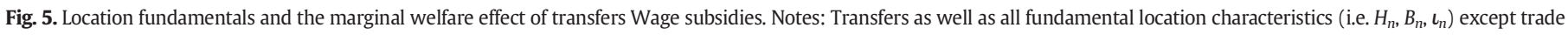

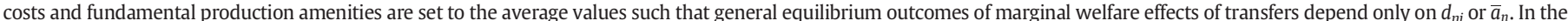

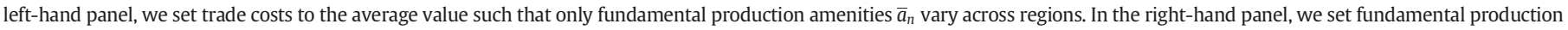

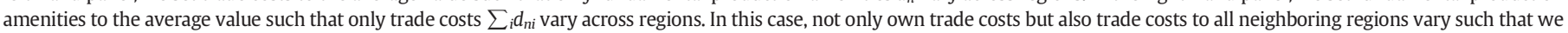

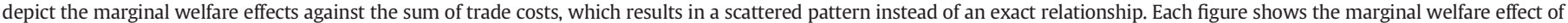
transfers. "Change in welfare" on the y-axis is normalized to facilitate comparison of welfare differences. 
In Fig. 5, we plot the respective marginal welfare effects against the distributions of fundamental production amenities and geographical accessibility (i.e. sum of trade costs). The correlations in panels a) and b) show that wage subsidies are most effective in regions with low productivity and low accessibility. The reason is as follows: Regions with low productivity or accessibility display relatively low income. In spatial equilibrium, they must be attractive in terms of less congestion on the housing market, which implies a relatively low population density. Given a lower income, a marginal transfer yields a higher utility gain. When choosing locations, individuals do not factor in the externalities via productivity spillovers and congestion on the housing market. Moreover, the parameter constellation is such that congestion effects dominate agglomeration spillovers. Thus, transfers towards regions characterized by low population density and correspondingly low income improve efficiency.

Panels c) and d), show that investments in production amenities reach the highest welfare gains in regions with high fundamental production amenities and high accessibility. The first result is due to our transfer function (12) raising production amenities proportionally. Similar reasoning applies for the role of accessibility: Ceteris paribus, central places feature a higher population due to a lower price index that attracts population until indirect utility is equalized. With productivity spillovers according to (4), a higher population raises the productivity gain due to a marginal transfer.

Considering investments in transportation infrastructure (panels e) and f)), we find the highest welfare gains in regions with high fundamental production amenities and high accessibility. The first result is due to agglomeration economies - high productivity leads to dense population and a sizable market, which raises the benefits of transport cost reductions. The latter result is due to positive spillovers via the transportation network: Central, highly accessible regions are relevant for trade between many region pairs because they are located in the close proximity of their respective least-cost routes. Accordingly, an improvement of the infrastructure in central regions will be passed on to the effective trade costs for a large share of other region pairs. Moreover, according to (11), the percentage reduction of travel time following a marginal investment is higher for adjacent region pairs with low travel time.

We illustrate the role of the remaining location fundamentals in Figs. B.4, B.5, and B.6 in the Appendix. Location amenities, residential land supply, and the share paid to the global portfolio enter positively into the marginal welfare effects of all three transfer types. The reasons are intuitive as a social planner would ceteris paribus aim to allocate individuals to places with high consumption amenities and plenty of land available such as to leverage the fundamental merits of locations and minimize congestion costs. ${ }^{36} \mathrm{~A}$ higher share of contributions to the global portfolio implies that the income gains from transfers are spread more broadly across regions. If regions are ceteris paribus identical due to decreasing marginal utility, a broad distribution generates a higher marginal welfare effect than a concentrated distribution.

Mix of transfer types. As shown above, the investments in local production amenities are optimally distributed towards central, well accessible places. At the same time, infrastructure investments are optimally allocated towards productive places, which implies a complementarity between these two types of transfers. In contrast, for wage subsidies, the most efficient distribution is towards low productivity and low accessibility places.

The model also allows us to change the aggregate shares of the budget allocated to the different types. If we allocate the whole budget into either one of the transfer types, the maximum attainable welfare is lower than for the observed aggregate mix due to decreasing returns to each transfer type. As long as there is a certain mix between the three transfer types on the aggregate level, welfare is relatively insensitive

\footnotetext{
36 Note that marginal utility increases in consumption amenities according to (1).
}

Table 3

General vs. partial equilibrium effects of the observed transfer distribution.

\begin{tabular}{llll}
\hline & GE Welfare $\left(\hat{V}_{n}\right)$ & PE Welfare & Difference \\
\hline Wage subsidies & 0.05 & 0.10 & -0.05 \\
Production amenities & 1.21 & 1.39 & -0.18 \\
Transport infrastructure & 0.82 & 0.04 & 0.78 \\
All transfers & 2.08 & 1.52 & 0.56 \\
\hline
\end{tabular}

Notes: The table compares welfare of the observed distribution of transfers relative to the no-transfer scenario. Column 1 shows the welfare change for the general equilibrium analysis (equivalent to column 2 of Table 2). Column 2 shows the corresponding partial equilibrium welfare changes (see direct effects in Eq. (24)). The partial equilibrium changes exclude adjustments via migration, trade, and local wages (price index). For the PE welfare changes we report the averages across regions. All values are reported in percentage points.

to changes in the specific aggregate shares. However, it reacts strongly to changes in the regional distribution of transfers, which is the focus of our analysis. One should bear in mind though that a comprehensive evaluation of changes in the aggregate shares should account for the durable nature of infrastructure and hence would call for a dynamic framework. We discuss this in more detail in Appendix D.2.

\section{General vs. partial equilibrium responses}

A simple cost-benefit analysis capturing only direct effects of transfers in recipient regions could lead to a significant misinterpretation of the welfare effects. According to (24), we define partial equilibrium effects of transfers as the direct changes in local income, production amenities and own trade costs, which can be identified by reduced form analyses. However, direct effects induce adjustments in migration, trade and wages as captured by the general equilibrium model.

Table 3 quantifies the differences between general and partial equilibrium responses to transfers. The results show that a policy maker considering only partial equilibrium effects overestimates the welfare effects in case of wage subsidies and production amenities. In case of investments in transportation infrastructure, the partial equilibrium in fact underestimates the aggregate welfare change. These opposite assessments arise due to investments in transportation infrastructure affecting the general equilibrium not only via own trade costs but also via reductions in travel time for other region pairs. ${ }^{37}$ This implies further welfare gains that are not accounted for in partial equilibrium. In our application, the latter category of transfers turns out to be relatively important. Thus, considering the welfare effects across all transfer types, we find that a partial equilibrium approach would underestimate the aggregate gains. This conclusion is supported by a comparison with the reduced form literature: Becker et al. (2010) estimate an impact of Objective 1 transfers on growth of real income per capita of about 1.6 percentage points, which is comparable to our partial equilibrium effect obtained for the sum of transfers in Table $3 .^{38}$

\section{Conclusions}

In this paper, we present a quantitative analysis of the general equilibrium effects of place-based policies. We integrate the three major types of regional transfers, i.e. wage subsidies, investments in local production amenities and investments in transportation infrastructure, into a rich economic geography framework. The model performs well in matching important patterns of the distribution of economic activity in Europe. Applying it to two decades of regional data, we estimate the parameters of the model and recover cross-sectional as

\footnotetext{
37 Note that the adjustments in own trade costs are relatively minor because they are only caused by traders having a taste for non-optimal routes, i.e. detours bypassing the own region.

${ }^{38}$ The reduced form analysis by Pellegrini et al. (2013) finds a similar effect on income growth of approximately $0.9 \%$.
} 
well as time variation in location fundamentals. For the causal identification of the elasticities of local production amenities and trade costs with regard to transfers, we exploit changes in the regional eligibility for EU transfers.

We then perform counterfactual experiments where we remove transfers or redistribute them uniformly across regions. Overall, we find that the EU place-based policy led to a positive welfare effect of $2.08 \%$ for the period 2007-13 compared to a scenario without transfers. This level effect has to be interpreted in the light of the assumption that there is no crowding-out of member state investments through EU transfers. Irrespective of the level effect, we show that EU regional policy does not realize the potential of distributing the investments in a welfare optimal way: A uniform distribution turns out to reach a higher welfare level for two out of three transfer types than the EU's current scheme.

Contrasting the welfare optimal distribution of transfers with the observed one provides us with a quantification of the potential welfare gains that could be realized. In total, switching from the observed to the optimal distribution could increase the efficiency gains of transfers by about $50 \%$ (from $2.08 \%$ to $3.14 \%$ compared to the no-transfer scenario). Regarding the type of transfers, there is no one-size-fits-all approach for optimal distribution: While wage subsidies should be limited to the few poorest regions, infrastructure investment should rather focus on central regions. This serves as a basis for our detailed derivation of the determinants of an optimal transfer scheme and the complementarities of different transfer types. We show that investments in local production amenities and transportation infrastructure can be leveraged by allocating them such as to maximize positive spillovers.

While there are certainly further dimension of heterogeneity in the effectiveness of transfers such as the quality of local institutions or differences in the production functions of public infrastructure, we believe that our systematic approach for an optimal distribution of a given transfer budget is informative for policy makers as it reveals the importance of adjustments via trade and migration.

\section{Appendix A. Estimation and calibration}

In this section, we describe how we estimate the parameters and how we invert the model to recover location fundamentals.

\section{A.1. Trade costs $\left(d_{n i}\right)$}

Trade costs are based on a framework developed in Allen and Arkolakis (2016). Trade is undertaken by a continuum of heterogeneous agents $v$ who endogenously choose a path $p$ with length $K$ to get from $n$ to $i$. We specify the cost of shipping a good from adjacent locations $r$ to $i$ as a function of road travel time $e^{39}$

$\tilde{d}_{r i}=e^{\beta \cdot \text { TravelTime }_{r i}}$,

where TravelTime $e_{r i}$ is measured in hours and $\beta$ is a factor converting travel time into transport costs. Aggregate trade costs $\breve{d}_{n i}(p)$ from $n$ to $i$ are the product of the transport costs along path $p$

$\breve{d}_{n i}(p)=\prod_{k=1}^{K} \tilde{d}_{p_{k-1}, p_{k}}$

Each trader faces a heterogenous path-specific taste $\varepsilon_{n i}(p, v)$ to ship a good from $n$ to $i$, which is assumed to be drawn i.i.d. from a Fréchet distribution with shape parameter $\theta>0$. Total costs of a trader $v$ travelling from $n$ to $i$ along path $p$ are $\breve{d}_{n i}(p) \varepsilon_{n i}(p, v)$. Let $d_{n i}(v)$ indicate the costs of trader $v$ choosing the trader-specific least-cost path between $n$ and $i$

$d_{n i}(v)=\min _{p \in P_{k}, K \geq 0} \breve{d}_{n i}(p) \varepsilon_{n i}(p, v)$

We allow traders to choose any possible path to ship a good from $n$ to $i$. The mistakes traders incur by choosing non-optimal routes are governed by the shape parameter $\theta$. A higher value of $\theta$ indicates greater agreement across traders, where in the limit case of no heterogeneity $\theta \rightarrow \infty$ all traders choose the least-cost route. The calibration of $\theta$ determines the likelihood of mistakes and randomness in the choice of routes. Thus, the framework we use is a generalization of the least-costs approach and allows a trader to ship a good on second-best routes. By using the properties of the Fréchet distribution, expected trade costs $d_{n i}$ become

$d_{n i} \equiv E_{v}\left[d_{n i}(v)\right]=c\left(\sum_{K=0}^{\infty} \sum_{p \in K} \breve{d}_{n i}(p)^{-\theta}\right)^{-\frac{1}{\theta}}$

where $c \equiv \Gamma\left(\frac{\theta-1}{\theta}\right)$ and consist of trade costs realized on all possible paths. Given the extreme value distribution, the probability a trader chooses path $p$ and goes from $n$ to $i$ is given by

$\Xi_{n i}^{d}(p)=\operatorname{Pr}\left(\breve{d}_{n i}(p) \leq \min \left\{\breve{d}_{n i}(p)\right\}, \forall p \in P_{K}, K \geq 0\right)=\frac{d_{n i}(p)^{-\theta}}{\sum_{K=0}^{\infty} \sum_{p^{\prime} \in P_{i j, K}}^{\infty} d_{n i}\left(p^{\prime}\right)^{-\theta}}$.

As shown in Allen and Arkolakis (2016) expected trade costs can be expressed as a Neumann series with weighted adjacency matrix $\tilde{\mathbf{D}}=\left[\tilde{d}_{n i}^{-\theta}\right]$ :

$d_{n i}^{-\theta}=c^{-\theta} \sum_{K=0}^{\infty} \tilde{\mathbf{D}}_{n i}^{K}$

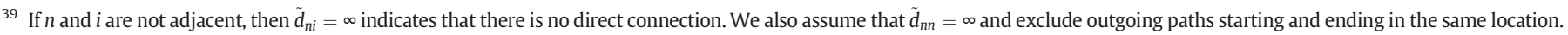
However, this does not restrict traders to ship goods from $n$ to $n$. 
where $\tilde{\mathbf{D}}_{n i}^{K}$ is $(n, i)$ 's element of adjacency matrix $\tilde{\mathbf{D}}$ to the power of $K^{40}$ The Neumann series converges to $\sum_{K=0}^{\infty} \tilde{\mathbf{D}}_{n i}^{K}=(\mathbf{I}-\tilde{\mathbf{D}})^{-1} \equiv \mathbf{F}$, where $\mathbf{I}$ is the identity matrix. Reformulating the above equation, we obtain Eq. (9) relating the adjacency matrix to expected trade cost

$d_{n i}=\Gamma\left(\frac{\theta-1}{\theta}\right)\left(f_{n i}\right)^{-\frac{1}{\theta}}$

where $f_{n i}$ refers to the (n,i) element of the route cost matrix $\mathbf{F}$. This expression takes into account that traders minimize heterogenous trader- and path-specific trade costs. By applying the matrix calculus described in Allen and Arkolakis (2016) we derive from Eq. (A.5) the probability of using link $k l$ when shipping a good from $i$ to $n$

$\Xi_{n i}^{k l}=\left(\frac{1}{c_{d_{n k} \tilde{d}_{k l} d_{l i}}}\right)^{\theta}$

The term $d_{n i}$ in the numerator reflects expected trade costs from $n$ to $i$, whereas the denominator represents expected trade costs from $n$ to $i$ along link $k l$. This equation provides a clear intuition: The more it costs to ship a good through link $k l$ relative to the unconstrained route, the less likely it is that traders use this link. The probability of making wide detours decreases with higher degrees of trade routes agreement (high $\theta$ ). As a result, the reduction of trade costs is more relevant, the closer the improved bilateral link on the optimal route. Hence, an investment reducing direct trade costs of link $\tilde{d}_{k l}$ will have consequences for expected bilateral trade costs of all other regions. These effects are more pronounced the closer the direct link to the unconstraint one. Thus, investments reducing travel time only marginally affect effective trade costs of distant links.

Estimation of trade costs. Using GIS software, we identify adjacent NUTS2 regions where we assume regions maintaining a ferry connection to be adjacent. Ferry connections ensure a comprehensive transport network, which connects the EU continent with the islands. The corresponding information is obtained from openstreetmap.com. Data about TravelTime ${ }_{r i}$ between adjacent regions $r$ and $i$ stems from the RRG GIS Database and contains detailed information about different speed limits, slope gradients, congestion etc.. The variable TravelTime $e_{r i}$ measures time (in hours) travelled on roads from the centroid of $r$ to the centroid of $i$ and is obtained at the NUTS2 level. To proceed and compute trade costs $d_{n i}$, we use Eq. (9) as well as information about direct trade costs $\tilde{d}_{n i}$ and parameters $\theta$ and $\beta$.

As Truck-specific trade data does not exist for Europe, we set the Fréchet parameter governing heterogeneity of traders $\theta=136.13$ according to estimates obtained by Allen and Arkolakis (2016). With this information and data about TravelTime $e_{r i}$ we can specify adjacency matrix $\tilde{\mathbf{D}}$. The parameter calibrations for $\theta$ and $\sigma$, together with gravity Eq. (5) and the definition of trade cost (9), can be used to estimate the factor converting travel time to trade $\operatorname{cost} \beta$ included in adjacency matrix $\tilde{\mathbf{D}}$. To obtain $\beta$, we perform a non-linear least squares estimation and minimize the sum of squared residuals between observed and implied trade by the model

$$
\min _{\beta} \sum_{n, i \in N}\left(\log \left(X_{n i}^{\text {Data }}\right)-\beta_{0}-\frac{\sigma-1}{\theta} \log \left([I-\tilde{\mathbf{D}}]_{n i}^{-1}\right)-\log \left(\delta_{n}\right)-\log \left(\eta_{i}\right)\right)^{2} .
$$

We demean trade and trade costs such that we can neglect the constant $\beta_{0}$ and importer and exporter fixed effects. Data on bilateral road freight $X_{n i}^{D A T A}$ among NUTS2 regions stem from the European Transport Policy Information System. We estimate a value of $\beta=0.068$. Fig. A.1 panel a) depicts a strong correlation of -0.709 between the freight data and the values of trade costs obtained from the estimation approach described above.

Robustness check. We compare the values for trade costs derived above with two alternative estimates. Specifically, we use a poisson pseudomaximum-likelihood (Santos Silva and Tenreyro, 2006) estimator and a purely distance-based approach using a constant elasticity $d_{n i}=$ dist $_{n i}^{0.43}$ as in Monte et al. (2018). Panels b) and c) in Fig. A.1 compare our benchmark estimates for trade costs $d_{n i}$ with the two alternative approaches. Overall, our measure of trade cost is qualitatively similar to the alternatives as is evident from this figure and the high correlations.

(a) Modeled trade costs and observed freight

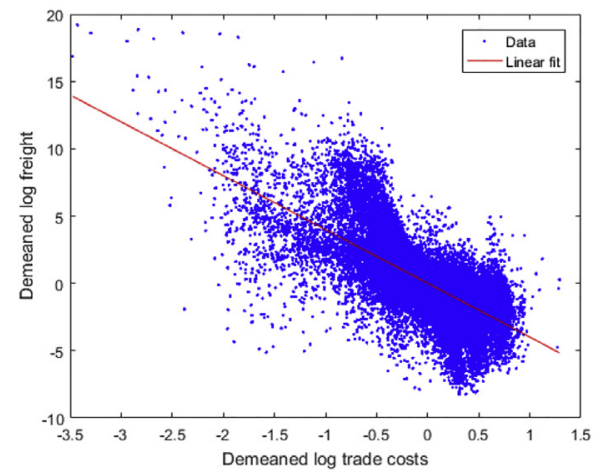

(b) Poisson-PML

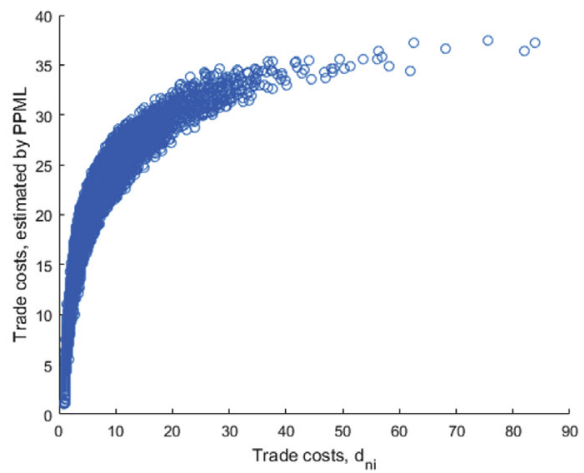

(c) Distance based

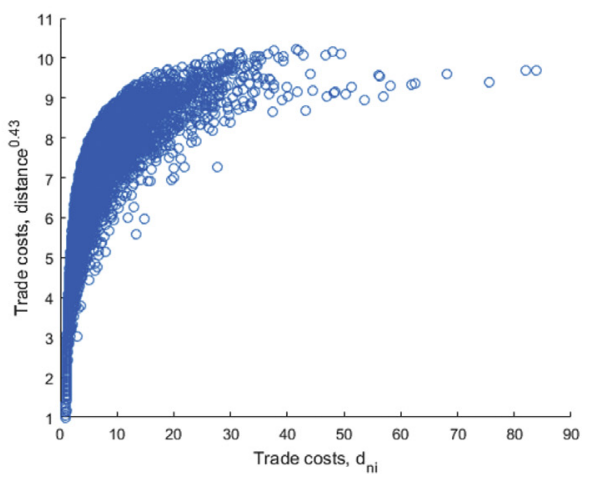

Fig. A.1. Comparison of trade cost. Note: We use our estimate of $\beta=0.068$ for the factor converting travel time to trade costs. This estimate minimizes the sum of squared residuals

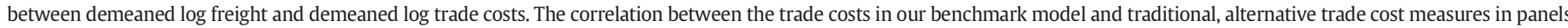
(b) and (c) is 0.8 and 0.7 , respectively.

${ }^{40}$ Note, $\tilde{\mathbf{D}}_{n i}=0$ indicates no connections between $n$ and $i, \tilde{\mathbf{D}}_{n i}=1$ indicates a costs-less connection and $\tilde{\mathbf{D}}_{n i} \in(0,1)$ indicates a costly connection. 
A.2. Estimation of transfer elasticities $\left(\kappa^{a}, \kappa^{d}\right)$

In order to obtain transfer elasticities $\kappa^{a}$ and $\kappa^{d}$ we pool three time periods $t \in\{1999,2006,2013\}$ and run regression equations corresponding to (11) and (12). In the regression equations we add time-fixed effects $\Omega_{t}^{d}, \Omega_{t}^{a}$, region-fixed effects absorb $\gamma_{r i}, \ln \left(\bar{a}_{n}\right)$, and $\zeta_{r i, t}^{d}, \zeta_{n, t}^{a}$ reflect the error terms:.

$$
\begin{aligned}
& \text { TravelTime }_{r i, t}=\gamma_{r i}-\kappa^{d} \cdot \ln \left(T_{r, t}^{d}+T_{i, t}^{d}+1\right)+\Omega_{t}^{d}+\zeta_{r i, t}^{d}, \\
& \ln \left(\tilde{a}_{n, t}\right)=\ln \left(\bar{a}_{n}\right)+\kappa^{a} \cdot \ln \left(T_{n, t}^{a} / L_{n, t}+1\right)+\Omega_{t}^{a}+\zeta_{n, t}^{a} .
\end{aligned}
$$

Table A. 1 reports the results of these regressions. For each of the two dependent variables $-\ln \left(\tilde{a}_{n, t}\right)$ and TravelTime $_{r i, t}-$ we run three types of specifications: columns (1) and (4) use the sum of transfers across all types to a region and a transportation $\operatorname{link}, \ln \left(T_{n, t} / L_{n, t}+1\right)$ and $\ln \left(T_{r, t}+T_{i, t}+\right.$ 1 ) as the explanatory variables of interest; columns (2) and (5) represent our benchmark specifications using only investments in production amenities and transportation infrastructure respectively (as shown in the equations above); columns (3) and (6) report the regression discontinuity specifications and show the effect of a binary indicator for whether a region received Objective 1 funds during the respective time period.

Transfers for the years 1999, 2006, and 2013 are measured as the average annual transfers between 1993 and 99, 2006-13, and 2007-13, respectively. Note that Objective 1 status was always assigned for the full budgeting period. By adding time-fixed effects, we absorb any differences across periods that are common across regions. Region-fixed effects capture time-invariant variation across regions.

While the fixed effects reduce potential endogeneity bias due to e.g. peripheral regions displaying a lower productivity and a higher transfer intensity, there may still be unobserved time-region-variant factors that influence transfer intensity as well as outcomes. Following Becker et al. (2010) we address these remaining endogeneity concerns by applying a regression discontinuity design. The regression discontinuity design exploits the fact that only regions with a per capita income of less than $75 \%$ of the EU average are eligible for the highest transfer intensity referred as Objective 1 funds. ${ }^{41}$ Intuitively, this identification strategy rests on the idea that the assignment of transfers is quasi-random for regions close to the threshold. Note that both RDD specifications include third-order polynomial functions of the forcing variable, which determined eligibility for Objective 1 transfers, i.e. per capita GDP relative to the EU average in the relevant years.

Comparing the fixed effects specifications for total transfers (column 1) and investments in production amenities (column 2) shows that the estimated elasticities, $\kappa^{a}$, are very similar ( 0.006 and 0.007$)$. This is due to the high correlation between $T_{n}$ and $T_{n}^{a}$. Likewise, the confidence bounds of the estimates for $\kappa^{d}$ ( 0.004 and 0.007 ) are overlapping for total transfers (column 4 ) and investments in transportation infrastructure (column 5).

The point estimates for Objective 1 status do not directly correspond to the parameters $\kappa^{a}$ and $\kappa^{d}$ as the RDD specifications identify the average treatment effect of Objective 1 transfers. Hence, in order to compute the implied values of $\kappa^{a}$ and $\kappa^{d}$, we divide the treatment effect by the log difference of average transfer intensities of Objective 1 and non-Objective 1 regions. This yields corresponding values of $\kappa^{a}=0.006$ and $\kappa^{d}=0.005$. Thus, the RDD estimates support our preferred estimates of $\kappa^{a}$ and $\kappa^{d}$ in columns (2) and (5), respectively. Note that the choice of specification has only a minor effect on the analysis of the optimal spatial distribution of transfers and is more crucial for the level effects of transfers.

Table A.1

\begin{tabular}{|c|c|c|c|c|c|c|}
\hline & \multicolumn{3}{|c|}{ Production amenities $\kappa^{a}$} & \multicolumn{3}{|c|}{ Transportation infrastructure $\kappa^{d}$} \\
\hline & \multicolumn{2}{|l|}{$\overline{\mathrm{FE}}$} & \multirow{2}{*}{$\frac{\mathrm{RDD}}{(3)}$} & \multicolumn{2}{|l|}{$\overline{\mathrm{FE}}$} & \multirow{2}{*}{$\begin{array}{l}\text { RDD } \\
(6)\end{array}$} \\
\hline & $\overline{(1)}$ & (2) & & $\overline{(4)}$ & (5) & \\
\hline Total Transfers & $\begin{array}{l}0.007^{* *} \\
(0.003)\end{array}$ & & & $\begin{array}{l}-0.007^{* *} \\
(0.003)\end{array}$ & & \\
\hline Prod. Transfers & & $\begin{array}{l}0.006^{* *} \\
(0.003)\end{array}$ & & & & \\
\hline Infra. Transfers & & & & & $\begin{array}{l}-0.004^{* * *} \\
(0.001)\end{array}$ & \\
\hline Objective 1 & & & $\begin{array}{l}0.015^{*} \\
(0.009)\end{array}$ & & & $\begin{array}{l}-0.028^{* *} \\
(0.014)\end{array}$ \\
\hline Observations & 712 & 712 & 712 & 2990 & 2990 & 2990 \\
\hline No. regions/No. links & 264 & 264 & 264 & 1080 & 1080 & 1080 \\
\hline
\end{tabular}

Direct effects of transfers.

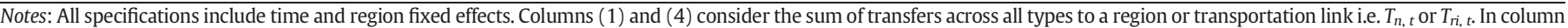

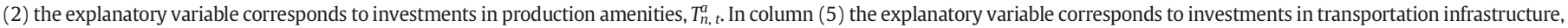

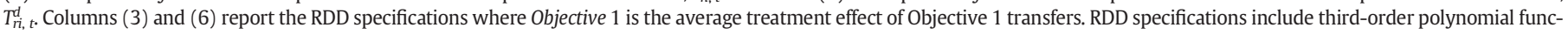

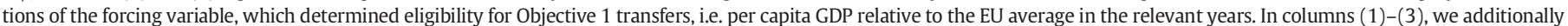

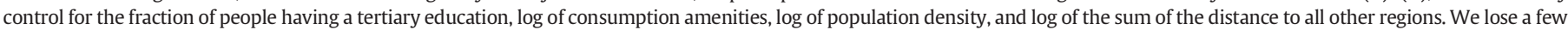

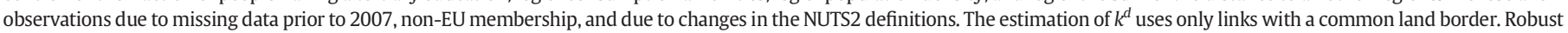
standard errors in brackets, ${ }^{*} \mathrm{p}<0.10,{ }^{* *} \mathrm{p}<0.05,{ }^{* * *} \mathrm{p}<0.01$

A.3. Estimation of heterogeneous location preferences and agglomeration elasticity $(\varepsilon, \mu)$

In panel a) of Table A.2, we show regression estimates of the heterogeneity of preferences and in panel b) we report the coefficients of the agglomeration elasticity as described in Section 4. For the estimations of both parameters, we apply instrumental variable approaches using different instruments.

In columns (1) and (2) of panel a), we use centrality measured by the sum of distance to all other regions to instrument real income. While column (1) includes the whole sample, column (2) uses a reduced sample for which have data to compute a Bartik-type instrument. The Bartik instrument is used in columns (3) and (4) and it is formally defined for our three time periods as.

\footnotetext{
41 Thresholds are well specified to years prior to the beginning of the respective budgeting period and are measured in PPP terms.
} 
$\operatorname{Bartik}_{n, t}=\sum_{\text {ind }}\left(\frac{L_{n, \text { ind }, 1985}}{\bar{L}_{n, 1985}}\right)\left(\frac{V A_{-n, i n d, t}-V A_{-n, i n d, 1985}}{V A_{-n, i n d, 1985}}\right)$,

where the first term measures the sectoral employment share of a predetermined time period and the second term corresponds to the average growth rate in gross value added in industry ind of year $t^{42}$ Subscript $-n$ indicates that region $n$ 's industry is excluded from the calculation of the average industry growth rates. The data to calculate the Bartik instrument stems from Cambridge Econometrics' European Regional Database and it is not available for the whole sample because we need sector shares well before the start of the first period (i.e. 1985). The latter does not exist for Eastern Europe. In column (4), we instrument real income using both a region's centrality and the Bartik instrument. The exogeneity assumption of our instruments is supported by the fact that estimates of all combination of instruments converge to values within a range of one standard deviation and that the instruments pass the Sargan test for overidentification.

For the estimation of the agglomeration elasticity in panel b), we use data about the quality of soils as an instrument for population shares. Specifically, in column (1) we employ dummy variables based on the "depth to rock" classification, whereas in column (2) we employ dummy variables based on the "Topsoil mineralogy" classification. The specification taking both instruments into account is reported in column (3). We find again strong support for the exogeneity assumption of our instruments, as all estimates of all combinations of instruments converge to values within a range of one standard deviation and the instruments pass the Sargan tests.

Table A.2

Heterogenous location preferences and agglomeration elasticity.

\begin{tabular}{|c|c|c|c|c|c|}
\hline & (1) & & (2) & (3) & $(4)$ \\
\hline Real income $\left(\ln \left(y_{n} P_{n}^{\alpha} r_{n}^{1-\alpha}\right)\right)$ & $\begin{array}{l}2.853^{\text {**** }} \\
(0.574)\end{array}$ & & $\begin{array}{l}3.326^{* * *} \\
(0.666)\end{array}$ & $\begin{array}{l}3.537^{\text {*** }} \\
(1.397)\end{array}$ & $\begin{array}{l}3.340^{* * * *} \\
(0.661)\end{array}$ \\
\hline Observations & 712 & & 584 & 584 & 584 \\
\hline No. regions & 264 & & 198 & 198 & 198 \\
\hline F first-stage & 219.973 & & 196.464 & 33.095 & 100.712 \\
\hline$R^{2}$ & 0.120 & & 0.119 & 0.096 & 0.117 \\
\hline Overidentification (p-val) & & & & & 0.871 \\
\hline \multicolumn{6}{|l|}{ Instruments: } \\
\hline Centrality & Yes & & Yes & No & Yes \\
\hline Bartik & No & & No & Yes & Yes \\
\hline \multicolumn{6}{|l|}{ Panel b) Agglomeration elasticity $\mu$} \\
\hline & & \multicolumn{2}{|l|}{$(1)$} & $(2)$ & (3) \\
\hline \multicolumn{2}{|l|}{ Log population density } & \multicolumn{2}{|l|}{$\begin{array}{l}0.152^{* * *} \\
(0.055)\end{array}$} & $\begin{array}{l}0.095^{* *} \\
(0.040)\end{array}$ & $\begin{array}{l}0.099^{\text {**** }} \\
(0.035)\end{array}$ \\
\hline Observations & & \multicolumn{2}{|l|}{699} & 699 & 699 \\
\hline No. regions & & \multicolumn{2}{|l|}{259} & 259 & 259 \\
\hline F first-stage & & \multicolumn{2}{|l|}{5.727} & 12.711 & 9.404 \\
\hline$R^{2}$ & & \multicolumn{2}{|l|}{0.888} & 0.885 & 0.886 \\
\hline Overidentification ( $\mathrm{p}$-val) & & \multicolumn{2}{|l|}{0.141} & 0.282 & 0.221 \\
\hline \multicolumn{6}{|l|}{ Instruments: } \\
\hline Land: Depth to rock (3 Dummies) & & \multicolumn{2}{|l|}{ Yes } & No & Yes \\
\hline Land: Topsoil mineralogy (4 Dummies) & & \multicolumn{2}{|l|}{ No } & Yes & Yes \\
\hline
\end{tabular}

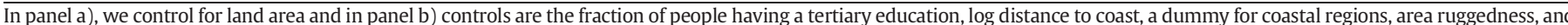

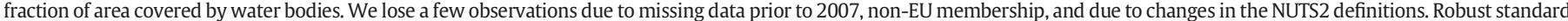
errors in brackets, ${ }^{*} \mathrm{p}<0.10,{ }^{* *} \mathrm{p}<0.05,{ }^{* * *} \mathrm{p}<0.01$.

\section{A.4. Trade balance}

Fig. A.2 illustrates the estimation of the share of payments to the global portfolio $(\iota)$ discussed in Section 4 as well as observed and predicted trade balances. Regions characterized by high trade surpluses as for instance North and South Holland (NL32 and NL33), contribute most of their land rents to the global portfolio. We observe small deviations between the observed and predicted trade balances, which is due to the bounds of $\iota_{n} \in$ $(0,1)$. An example where this parametric restriction is binding concerns regions with a substantial trade surplus. These regions should spend more than their returns from land to the global portfolio to exactly match the observed trade balance. Overall, we capture most of the heterogeneity of trade imbalances as is evident from the high correlation of 0.993 between modeled and predicted trade balances. Using the estimated $\iota_{n}$, we can compute the per-capita land rents paid into the global portfolio $\left(\frac{\iota_{n} H_{n} r_{n}}{L_{n}}\right)$ as well as the payments every individual obtains from the portfolio of land and commonly owned government sector $(\chi)$.

\footnotetext{
42 We use an industry classification covering the following sectors: Agriculture, industry, construction, wholesale-retail-transport \& distribution-communications-hotels-catering, financial \& business services, and non-market services.
} 

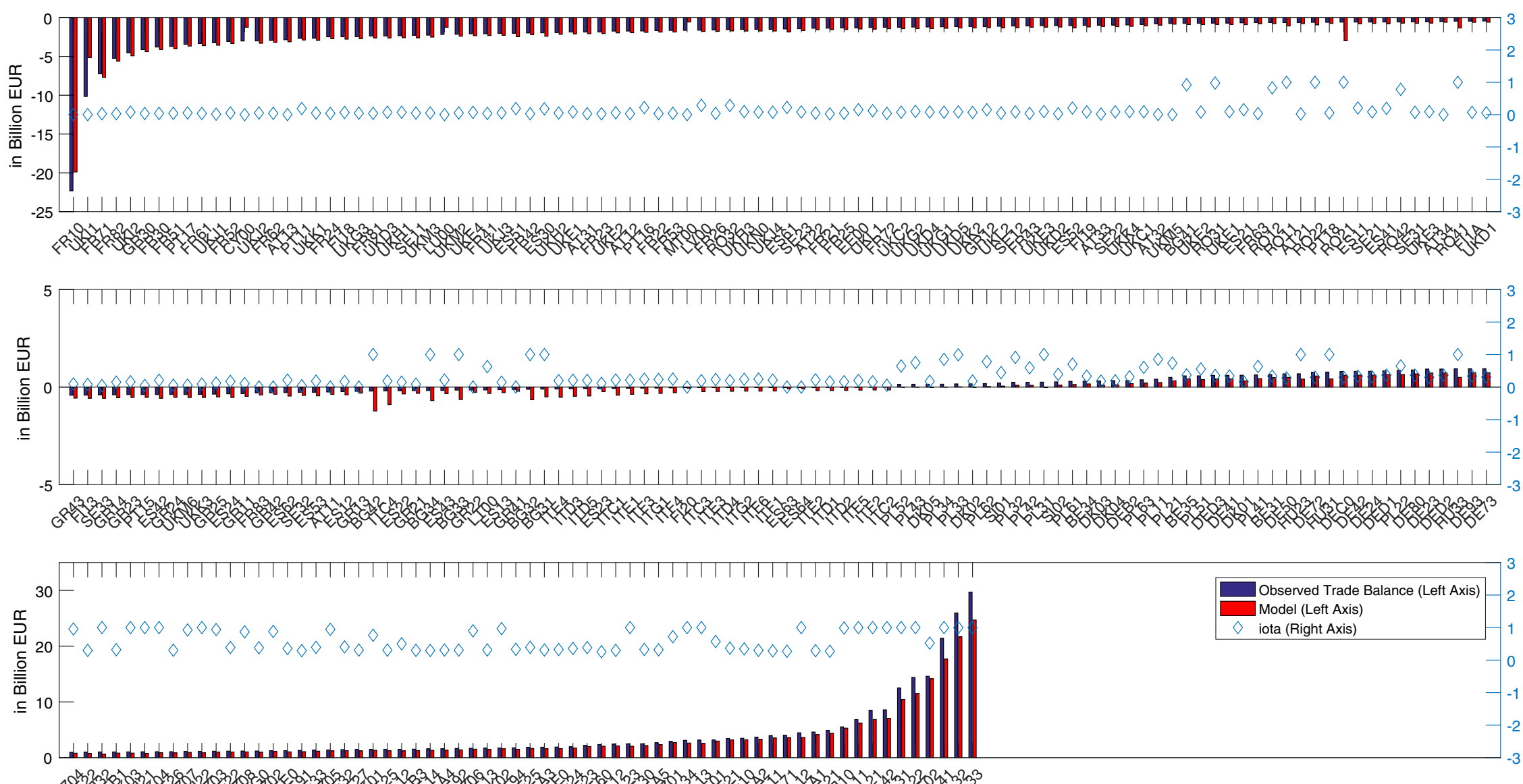

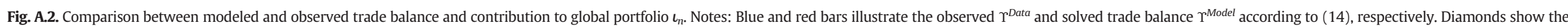
contribution to the global portfolio $\iota_{n}$ that minimize the least square deviations between the modeled and observed values. 
A.5. Production amenity $\left(\tilde{a}_{n}\right)$ and trade shares $\left(\pi_{n i}\right)$

We recover production amenities and trade shares as follows: Substituting equilibrium Eqs. (6) and (4) in (20) yields.

$\tilde{a}_{i}^{1-\sigma} L_{n}^{\mu(1-\sigma)+1}=\alpha w_{i}^{-\sigma} \sum_{n \in N} \frac{d_{n i}^{1-\sigma} L_{n} y_{n}}{\sum_{k \in N}\left(\frac{d_{n k} w_{k}}{a_{k}}\right)^{1-\sigma}}$.

By using Eq. (A.13) we can recover location $i$ ts production amenity $\tilde{a}_{n}$, given data for $\left\{L_{n}, y_{n}\right\}$ and substituting parameters $\{\sigma, \alpha, \mu\}$, estimates of trade costs $\left(d_{n i}\right)$ as well as the recovered information about wages $\left(w_{n}\right)$. Assuming balanced trade, Redding (2016) in his Proposition 6 proofs that the solution to this equation is unique (up to scale). We check the uniqueness of our solution by using random initial values for our fixed-pointiteration algorithm. As a result, we always converge to the same solution suggesting that the solution to this equation is unique, though it embodies unbalanced trade.

Once we know regions' production amenities, we can recover productivity by (4) and bilateral trade shares according to (6). Again, we substitute data for population shares $\left(\lambda_{n}\right)$, estimates of trade costs $\left(d_{n i}\right)$ as well as recovered information on wages and production amenities $\left\{w_{n}, \tilde{a}_{n}\right\}$.

A.6. Location amenities $\left(B_{n}\right)$

A similar approach allows us to recover location amenities. Substituting (16) in population shares (17) we obtain.

$\lambda_{n}^{-1} \Phi_{n} B_{n}=\sum_{k \in N} B_{k} \Phi_{k}$

where $\Phi_{n}{ }^{\frac{1}{\varepsilon}}=\left(\frac{a_{n} y_{n}}{d_{n n} w_{n}}\right)^{\alpha} \pi_{n n}^{\alpha /(1-\sigma)} \frac{H_{n}{ }^{1-\alpha}}{\lambda_{n}}$. Location amenities prevent people from consuming the highest attainable real income. Using Eq. (A.14) jointly with data for $\left\{\lambda_{n}, y_{n}, H_{n}\right\}$, already recovered information about $\left\{w_{n}, a_{n}, \pi_{n n}\right\}$, parameters $\{\sigma, \alpha, \varepsilon\}$, and estimates of own trade costs $\left(d_{n n}\right)$ we can recover $B_{n} \frac{1}{\varepsilon}$.

A.7. Summary statistics of exogenous and recovered variables

We present summary statistics of all our exogenous and recovered variables in Table A.3. Table A.4 shows that our recovered variables do not exhibit high correlations and capture sufficiently independent variation.

Table A.3

Summary statistics.

\begin{tabular}{|c|c|c|c|c|c|}
\hline Variable & Mean & Std. Dev. & Min. & Max. & $\mathrm{N}$ \\
\hline Own Trade Share $\left(\pi_{n n}\right)$ & 0.09 & 0.13 & 0 & 0.89 & 264 \\
\hline Population $\left(L_{n}\right)$ & 840.70 & 717.91 & 18.11 & 6055.46 & 264 \\
\hline Wages per-capita $\left(w_{n}\right)$ & 38.55 & 17.48 & 2.34 & 145.88 & 264 \\
\hline Income per-capita $\left(y_{n}\right)$ & 51.48 & 22.13 & 5.74 & 198.5 & 264 \\
\hline Trade costs $\left(d_{n i}\right)$ & 4.14 & 3.97 & 1 & 83.97 & 69,696 \\
\hline Bilateral trade costs $\left(d_{n i}\right)$ & 4.15 & 3.97 & 1.02 & 83.97 & 69,432 \\
\hline Own trade costs $\left(d_{n n}\right)$ & 1 & 0 & 1 & 1 & 264 \\
\hline Direct trade costs $\left(\tilde{d}_{r i}\right)$ & 1.22 & 0.32 & 1.02 & 3.7 & 1352 \\
\hline Travel time (TravelTime ${ }_{r i}$ ) & 2.62 & 2.84 & 0.27 & 19.08 & 1352 \\
\hline Transfers per-capita $\left(T_{n} L_{n}\right)$ & 136.84 & 190.34 & 0.34 & 891.56 & 264 \\
\hline in Obj. 1 regions & 366.55 & 184.54 & 55 & 891.56 & 80 \\
\hline non-Obj. 1 regions & 36.97 & 65.34 & 0.34 & 630.22 & 184 \\
\hline Objective 1 regions & 0.3 & 0.46 & 0 & 1 & 264 \\
\hline Transfers $\left(T_{n}\right)$ & 84.19 & 129.72 & 0.25 & 808.98 & 264 \\
\hline Wage subs. $\left(T_{n}^{w}\right)$ & 24.16 & 37.24 & 0.02 & 272.25 & 264 \\
\hline Prod. $\left(T_{n}^{a}\right)$ & 31.37 & 46.44 & 0.1 & 273.39 & 264 \\
\hline Infrastr. $\left(T_{n}^{d}\right)$ & 28.66 & 56.94 & 0 & 432.86 & 264 \\
\hline Productivity $\left(a_{n}\right)$ & 2.69 & 1.62 & 0.09 & 15.13 & 264 \\
\hline Location amenity $\left(B_{n}\right)$ & 10.8 & 47.17 & 0.03 & 588.26 & 264 \\
\hline Land supply $\left(H_{n}\right)$ & 828.46 & 599.13 & 7.53 & 3366.19 & 264 \\
\hline Share global portfolio $\left(\iota_{n}\right)$ & 0.33 & 0.34 & 0 & 1 & 264 \\
\hline Tax rates, in $\%\left(t_{n}\right)$ & 0.25 & 0 & 0.25 & 0.25 & 264 \\
\hline Price index $\left(P_{n}\right)$ & 10.36 & 2.53 & 8.02 & 24.18 & 264 \\
\hline Rental price of land $\left(r_{n}\right)$ & 16.51 & 21 & 0.45 & 277.69 & 264 \\
\hline Global portfolio return $(\chi)$ & 3283.76 & 0 & 3283.76 & 3283.76 & 264 \\
\hline
\end{tabular}

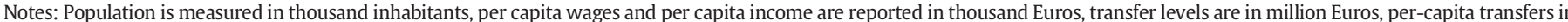
Euros, tax rates in percents, price index in thousand, rental price of land in million, and location amenity in $10^{16}$ units.

Table A.4

Correlation matrix of recovered variables.

\begin{tabular}{|c|c|c|c|}
\hline & $a_{n}$ & $B_{n}$ & $\pi_{n n}$ \\
\hline$a_{n}$ & 1 & -0.288 & 0.204 \\
\hline$B_{n}$ & & 1 & 0.060 \\
\hline$\pi_{n n}$ & & & 1 \\
\hline
\end{tabular}


(a) Wage subsidy $\left(T_{n}^{w} / T_{n}\right)$

\section{Legend}

1. Quantile

2. Quantile

3. Quantile

4. Quantile

5. Quantile

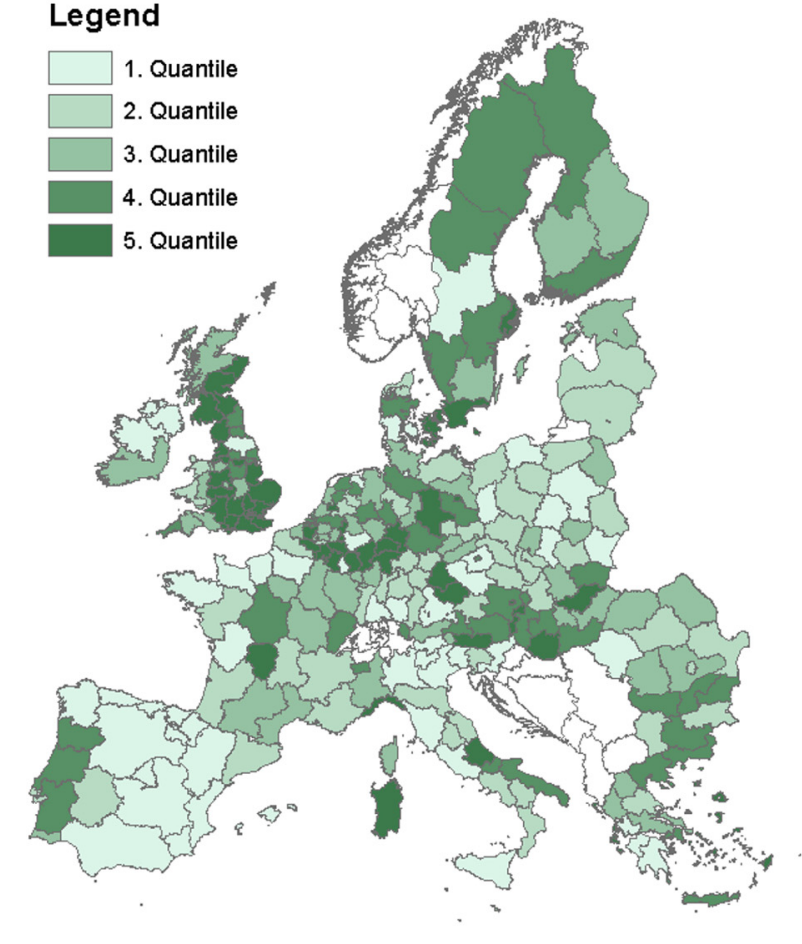

(b) Investment in transport infrastr. $\left(T_{n}^{d} / T_{n}\right)$

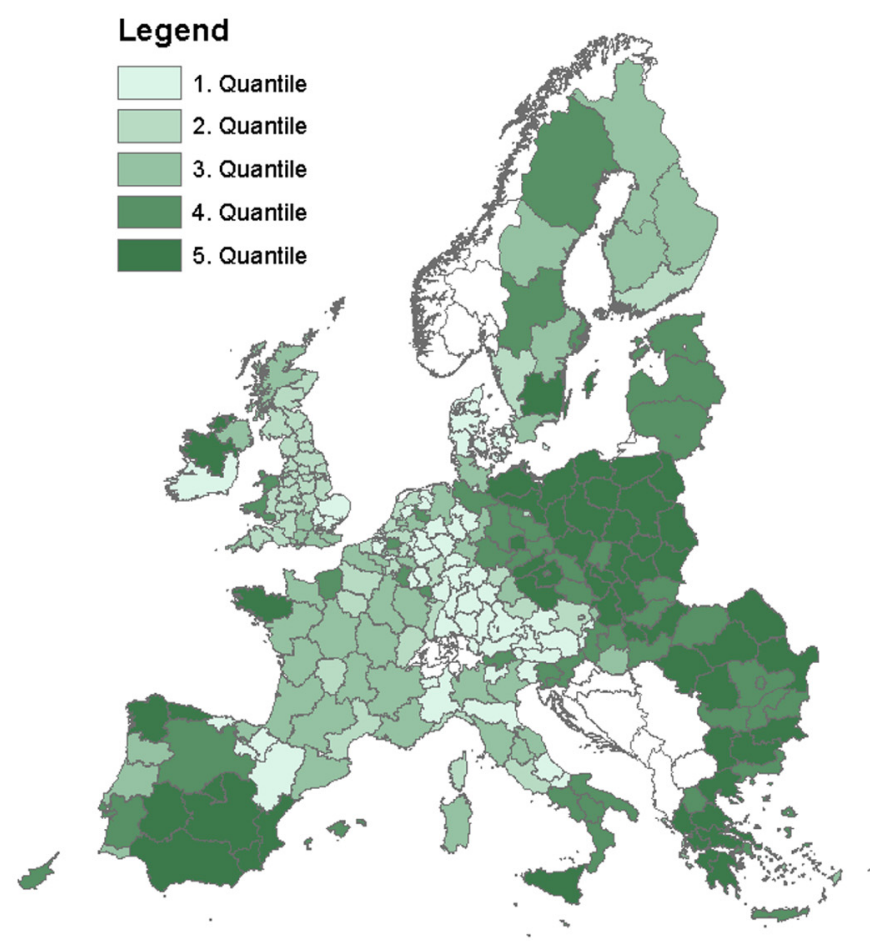

(c) Investment in prod. amenities $\left(T_{n}^{a} / T_{n}\right)$

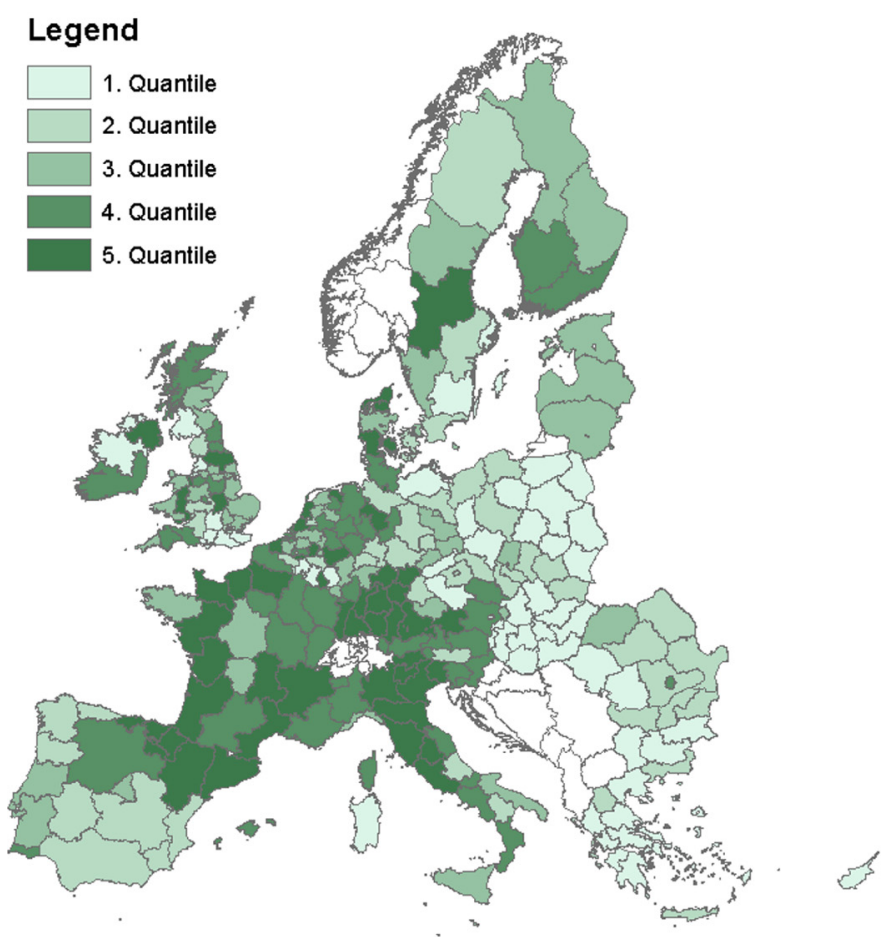

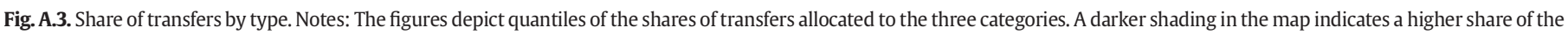
respective transfer category in total transfers paid to the respective region. 
Appendix B. Counterfactual analysis

In the following, we derive a system of equations allowing us to undertake a model based counterfactual analysis of EU regional policy. Following Dekle et al. (2007), we denote a counterfactual change as $\hat{x}=\frac{x^{\prime}}{x}$, where $x$ is the observed variable and $x^{\prime}$ is the unobserved counterfactual value of $x$. Given model's parameters $\left\{\alpha, \mu, \sigma, \varepsilon, \iota_{n}, \kappa^{a}, \kappa^{d}, \beta, \theta\right\}$ and variables $\left\{\lambda_{n}, w_{n}, \pi_{n i}, y_{n}, \tau_{n}, T_{n}, \gamma_{r i}^{d}, \bar{a}_{n}\right\}$, we use the following system of equations to solve for counterfactual changes in the model's endogenous variables $\left\{\hat{w}_{n}, \hat{y}_{n}, \hat{\lambda}_{n}, \hat{\pi}_{n i}, \hat{a}_{n}, \hat{d}_{n i}\right\}$, which determine changes in aggregate welfare.

Adjustments of regional wages follow directly from goods market clearing Eq. (20) and are.

$\hat{w}_{i} w_{i} \hat{\lambda}_{i} \lambda_{i}=\alpha \sum_{k \in N} \hat{\pi}_{k i} \pi_{k i} \hat{y}_{k} y_{k} \hat{\lambda}_{k} \lambda_{k}$

Changes in counterfactual productivity follow from (4) and become.

$\hat{a}_{n}=\widehat{\tilde{a}}_{n} \hat{L}_{n}^{\mu}$

Next, we divide the counterfactual by the equilibrium trade share using (6) and obtain.

$$
\hat{\pi}_{n i}=\frac{\left(\frac{\hat{d}_{n i} \hat{w}_{i}}{\hat{a}_{i}}\right)^{1-\sigma}}{\sum_{k \in N}\left(\frac{\hat{d}_{n k} \hat{w}_{k}}{\hat{a}_{k}}\right)^{1-\sigma} \pi_{n k}}
$$

Similarly, we can substitute information on real income (16) in population mobility (17). To express the change in counterfactual population, we divide the counterfactual with the equilibrium population share and obtain.

$\frac{\frac{\alpha \varepsilon}{1-\sigma}\left(\frac{\hat{a}_{n} \hat{y}_{n}}{\hat{d}_{n n} \hat{w}_{n}}\right)^{\alpha \varepsilon}\left(\frac{1}{\hat{\lambda}_{n}}\right)^{(1-\alpha) \varepsilon}}{\frac{\alpha \varepsilon}{1-\sigma}\left(\frac{\hat{a}_{k} \hat{y}_{k}}{\hat{d}_{k k} \hat{w}_{k}}\right)^{\alpha \varepsilon}\left(\frac{1}{\hat{\lambda}_{k}}\right)^{(1-\alpha) \varepsilon} \lambda_{k}}$.

Using Eq. (15), we can express per capita income in the counterfactual equilibrium as.

$\hat{y}_{n} y_{n}=\frac{1}{\alpha+\iota_{n}-\alpha \iota_{n}}\left(\hat{w}_{n} w_{n}\left(1-\tau_{n}\right)+\frac{\hat{T}_{n}^{w} T_{n}^{w}}{\hat{\lambda}_{n} \lambda_{n} \bar{L}}+\hat{\chi} \chi\right)$

where returns from global portfolio change due to adjustments in income and population are $\hat{\chi} \chi=(1-\alpha) \sum_{n} \iota_{n} \hat{y}_{n} y_{n} \hat{\lambda}_{n} \lambda_{n}+\sum_{n} \frac{1}{\bar{L}}\left(\hat{T}_{n}^{d} T_{n}^{d}+\hat{T}_{n}^{a} T_{n}^{a}\right)$. We run simulations for each investment type separately and alternately set two out of the three transfer channels to zero. Thus, local investments affect production amenities.

$\tilde{a}_{n}^{\prime}=\bar{a}_{n}\left(\frac{\hat{T}_{n}^{a} T_{n}^{a}}{\hat{\lambda}_{n} \lambda_{n} \bar{L}}+1\right)^{\kappa^{a}}$,

or.

TravelTime $e_{r i}^{\prime}=\gamma_{r i}^{d}-\kappa^{d} \cdot \ln \left(\hat{T}_{r}^{d} T_{r}^{d}+\hat{T}_{i}^{d} T_{i}^{d}+1\right)$,

where the trade cost routine (see Section A.1) converts travel time to trade costs. Tax revenue must be equal to place-based policy expenditure such that government budget is always balanced.

$\sum_{n \in N} \hat{w}_{n} w_{n} \hat{\lambda}_{n} \lambda_{n} \hat{\tau}_{n} \tau_{n}=\sum_{n \in N} \hat{\lambda}_{n} \lambda_{n} \hat{T}_{n} T_{n}$

We obtain the change in aggregate welfare from expected utility (19):.

$\widehat{\bar{V}}=\left(\frac{1}{\hat{\pi}_{n n}}\right)^{\frac{\alpha}{\sigma-1}}\left(\frac{\hat{y}_{n} \widehat{\tilde{a}}_{n}}{\hat{w}_{n} \hat{d}_{n n}}\right)^{\alpha}\left(\hat{\lambda}_{n}\right)^{\alpha \mu-(1-\alpha)-\frac{1}{\varepsilon}}$.

Eqs. (B.1)-(B.8) enable us to solve for counterfactual changes in wages $\hat{w}_{n}$, income $\hat{y}_{n}$, trade shares $\hat{\pi}_{n i}$, population shares $\hat{\lambda}_{n}$, production amenities $\hat{a}_{n}$ and own trade costs $\hat{d}_{n n}$, which are used to calculate counterfactual changes in welfare. 
(a) Population $\left(\hat{\lambda}_{n}\right)$

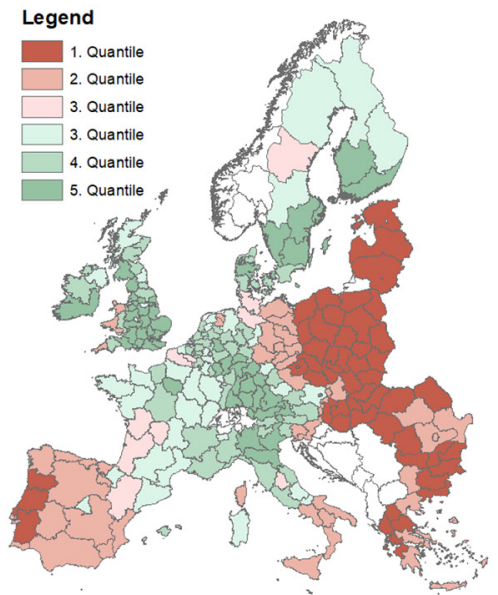

(b) Wages $\left(\hat{w}_{n}\right)$

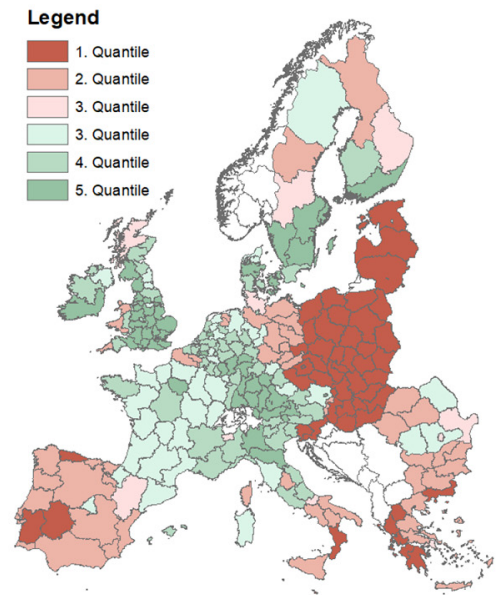

(c) Own trade share $\left(\hat{\pi}_{n n}\right)$ (d) Regional income $\left(\hat{y}_{n}\right)$

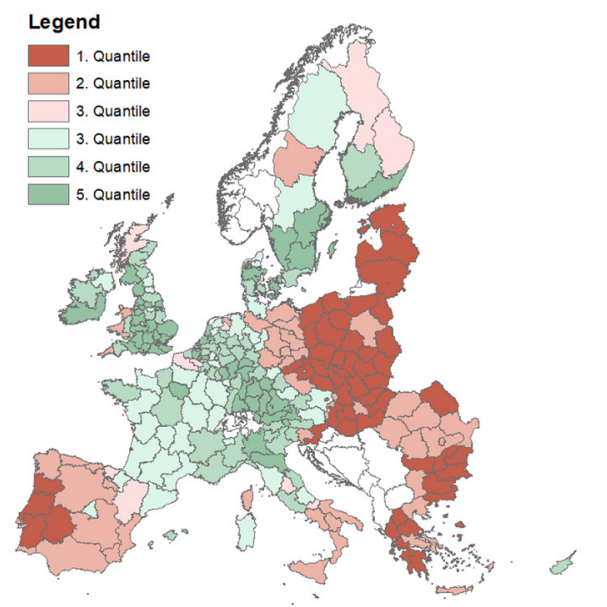

(e) Production amenities $\left(\hat{a}_{n}\right)$

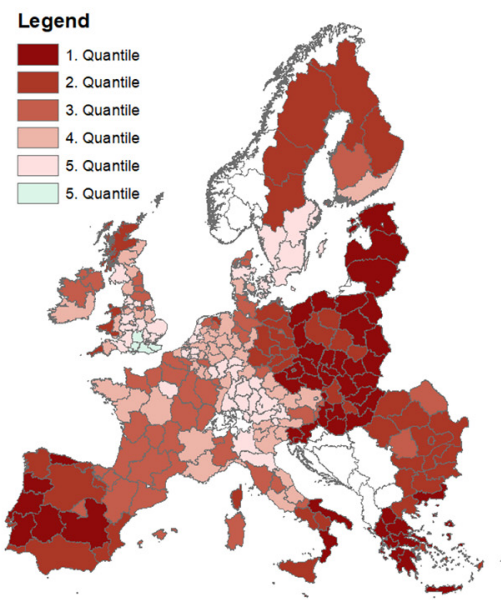

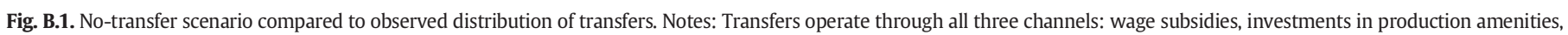

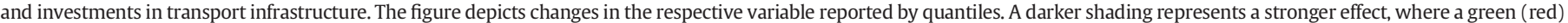

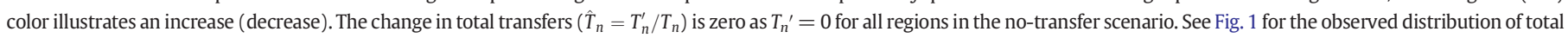
transfers. 

(a) Population $\left(\hat{\lambda}_{n}\right)$

(b) Wages $\left(\hat{w}_{n}\right)$

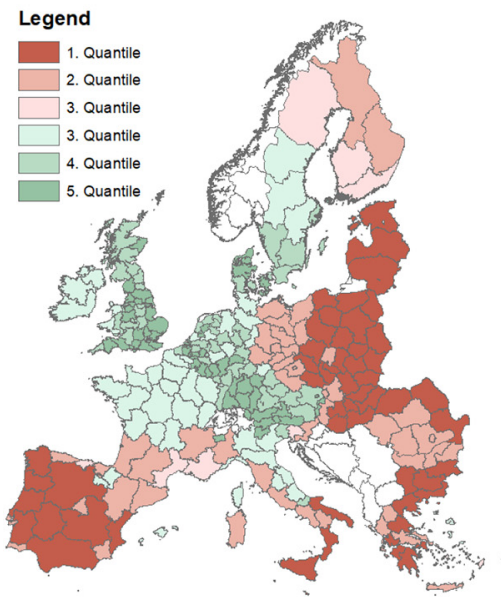

(d) Own trade share $\left(\hat{\pi}_{n n}\right)$
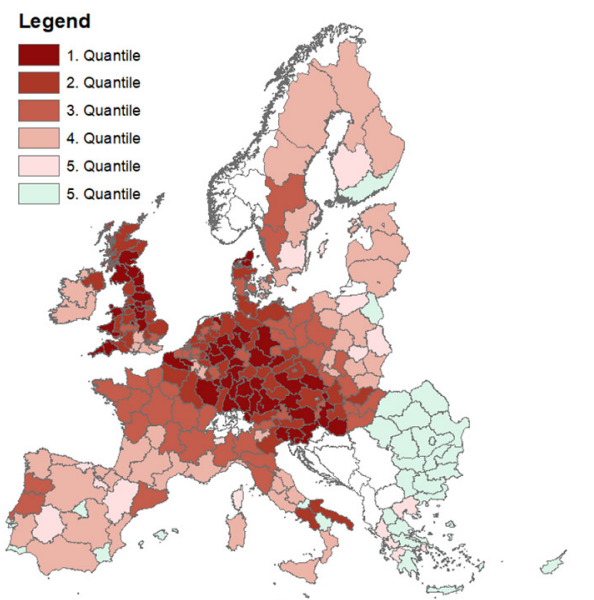

(c) Regional income $\left(\hat{y}_{n}\right)$



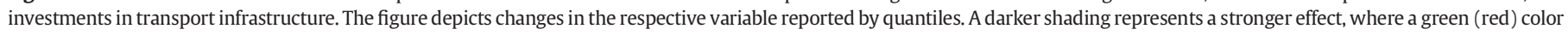
illustrates an increase (decrease). 
(a) Population $\left(\hat{\lambda}_{n}\right)$

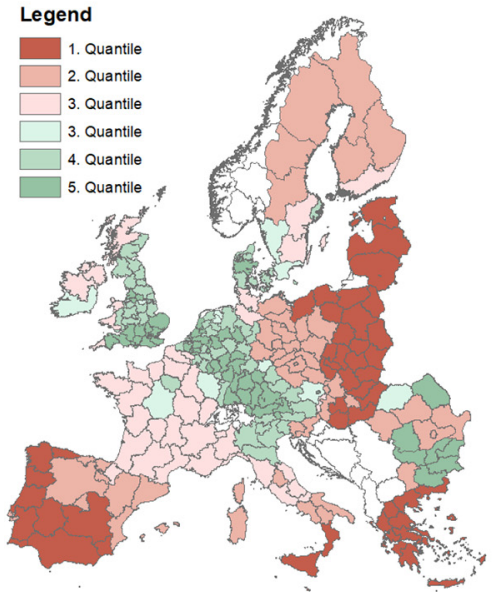

(d) Own trade share $\left(\hat{\pi}_{n n}\right)$

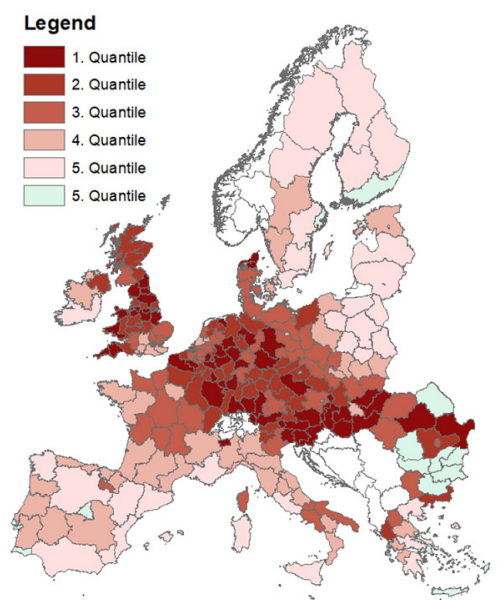

(b) Wages $\left(\hat{w}_{n}\right)$

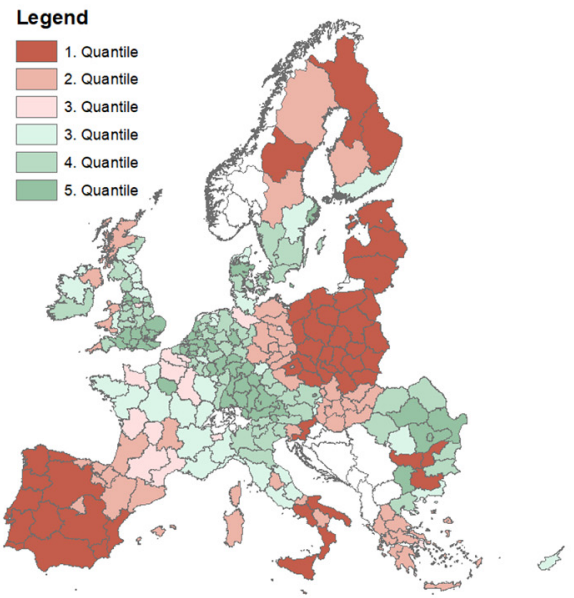

(e) Production amenities $\left(\hat{a}_{n}\right)$

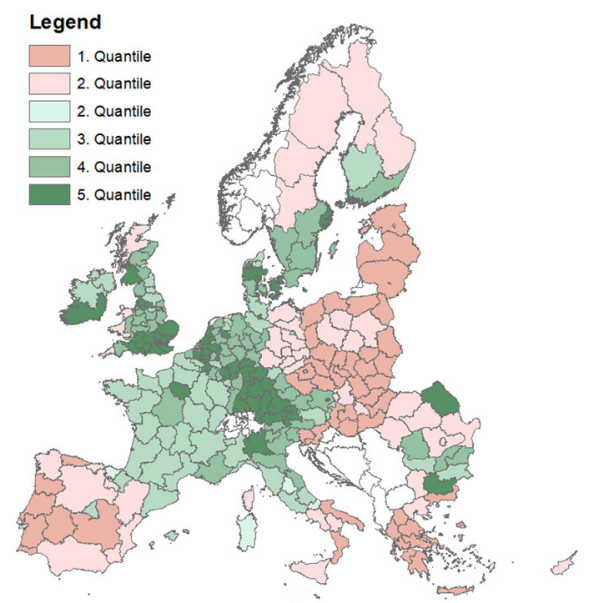

(c) Regional income $\left(\hat{y}_{n}\right)$

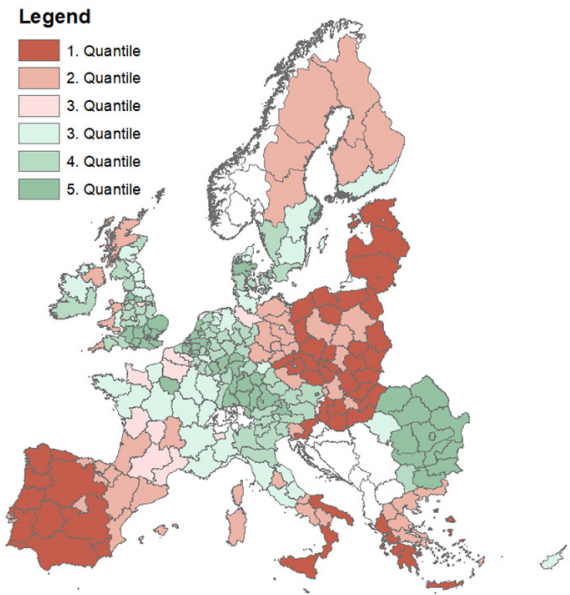

(f) Total transfers $\left(\hat{T}_{n}\right)$

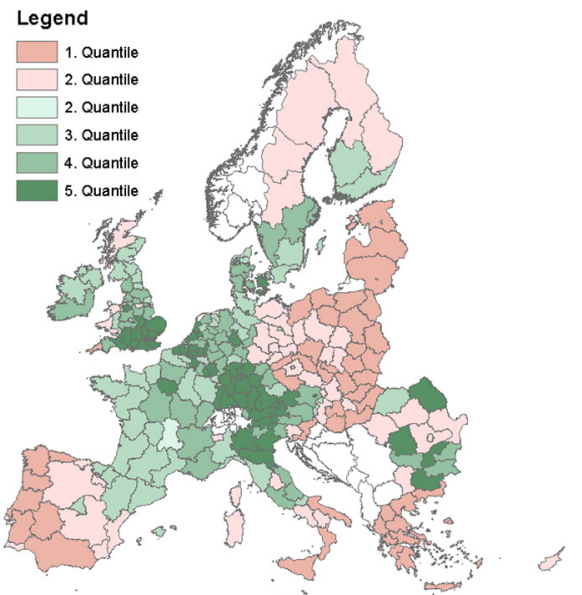

Fig. B.3. Optimal distribution compared to observed distribution of transfers. Notes: We consider the sum of transfers operating through wage subsidies, investments in production amenities, and investments in transport infrastructure. The figures above compare the observed equilibrium to a counterfactual situation where all three types of transfers are distributed optimally. The figure depicts changes in the respective variable reported by quantiles. A darker shading represents a stronger effect, where a green (red) color illustrates an increase (decrease). 
ARTICLE IN PRESS

28

Y. Blouri, M.V. Ehrlich / Journal of International Economics 125 (2020) 103319

(a) Location attractiveness $\left(B_{n}\right)$

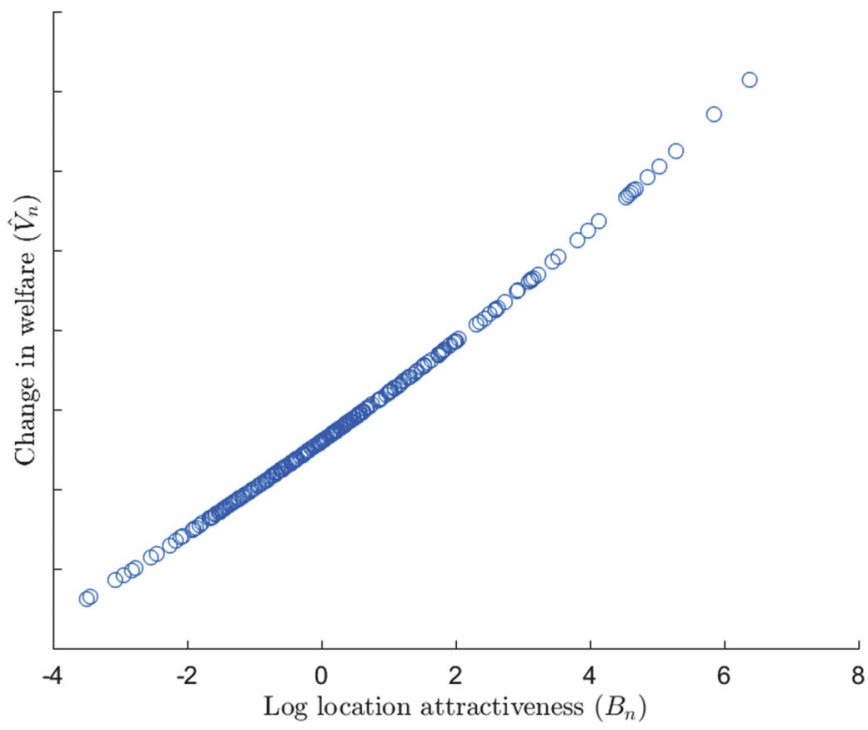

(b) Reside. land supply $\left(H_{n}\right)$

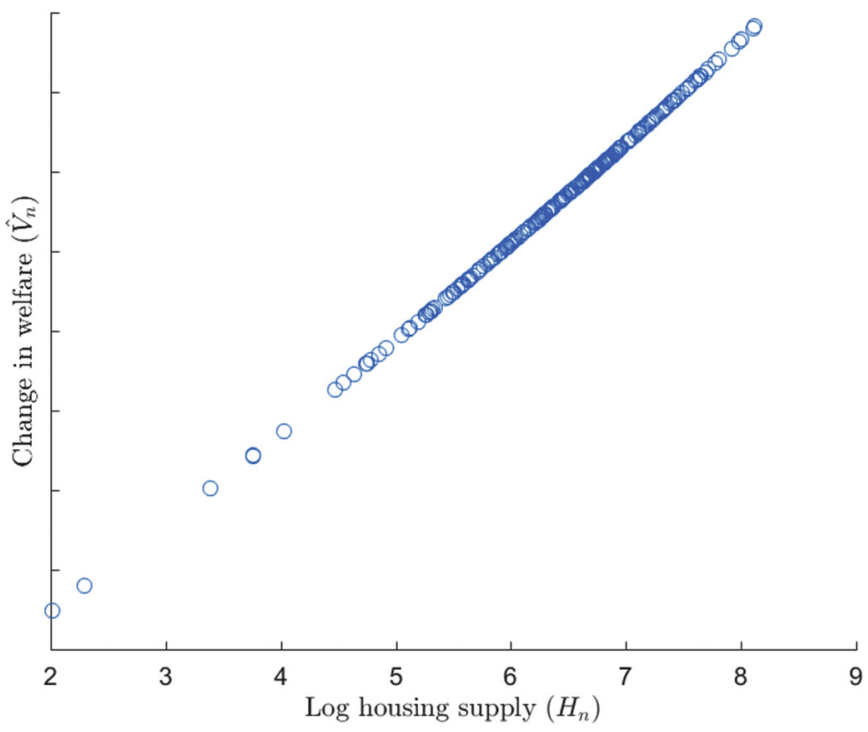

(c) Share to global portfolio $\left(\iota_{n}\right)$

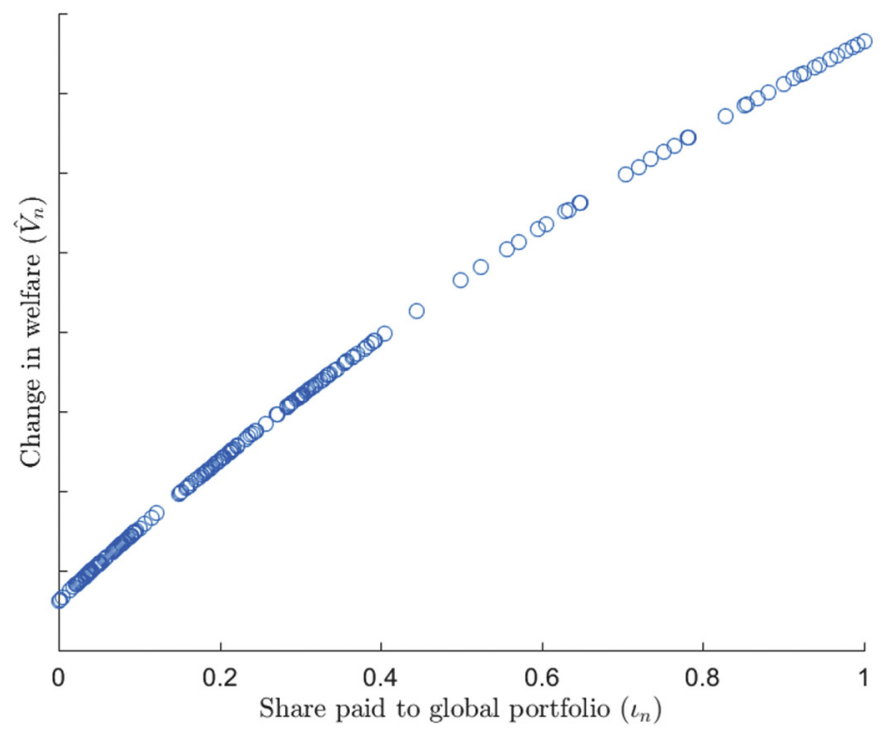

Fig. B.4. Marginal welfare effects of wage subsidies. Notes: Transfers, as well as all fundamental location characteristics (ie. $\left.\bar{a}_{n}, d_{n i}\right)$, except location attractiveness, residential land supply and share to global portfolio are set to the average values such that general equilibrium outcomes of marginal welfare effects of wage subsidies depend only on $B_{n}$, $H_{n}$ or $\iota_{n}$. Each figure shows the marginal welfare effect of wage subsidies. "Change in welfare" on the y-axis is normalized to facilitate comparison of welfare differences.

Please cite this article as: Y. Blouri and M.V. Ehrlich, On the optimal design of place-based policies: A structural evaluation of EU regional transfers,

J. Int. Econ., https://doi.org/10.1016/j.jinteco.2020.103319 
ARTICLE IN PRESS

Y. Blouri, M.V. Ehrlich / Journal of International Economics 125 (2020) 103319

29

(a) Location attractiveness $\left(B_{n}\right)$

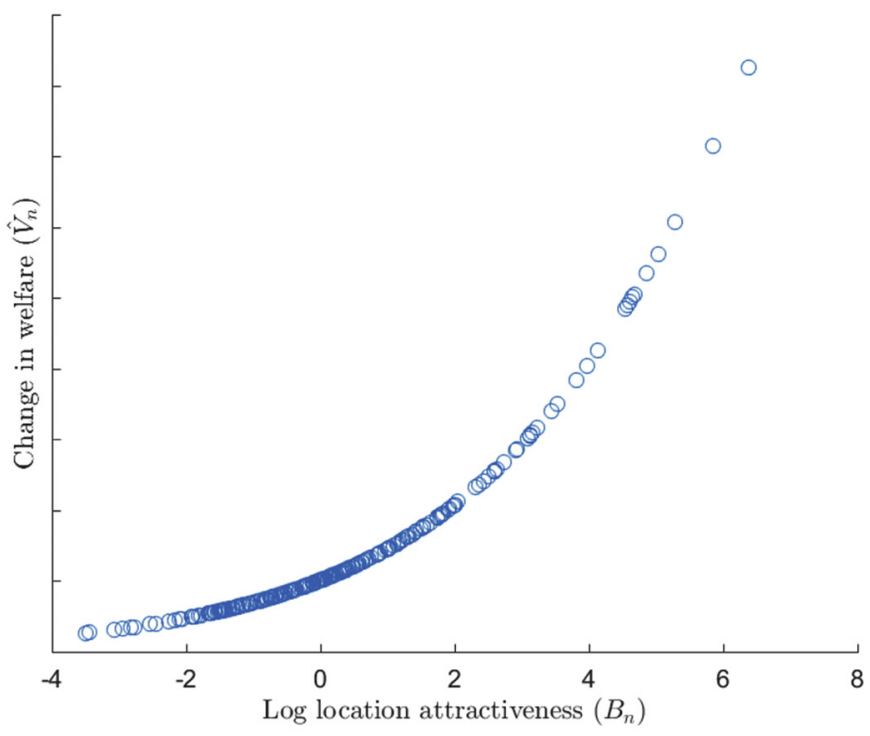

(b) Reside. land supply $\left(H_{n}\right)$

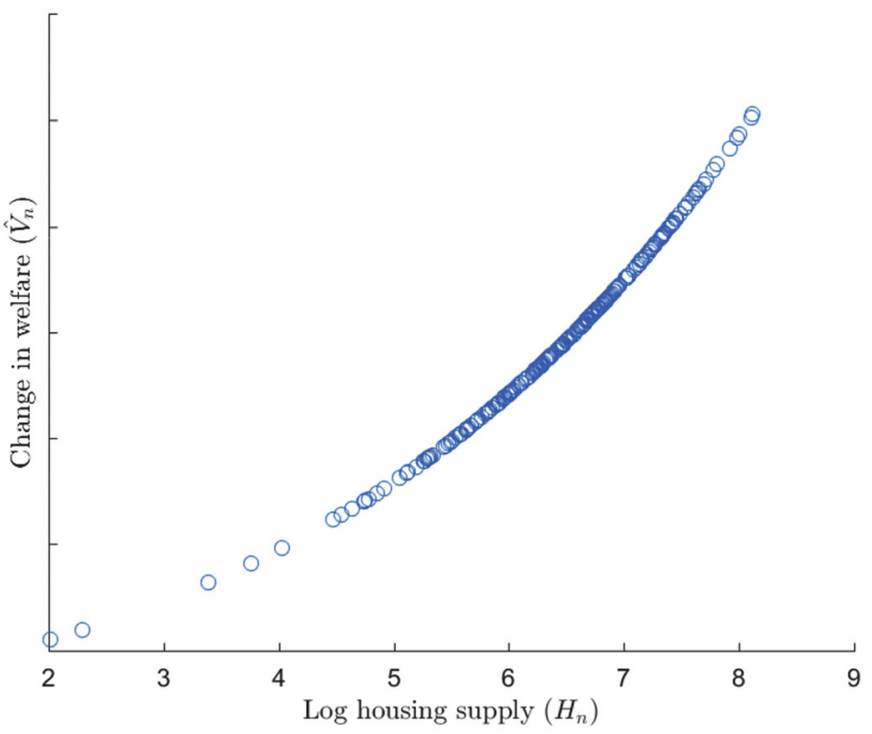

(c) Share to global portfolio $\left(\iota_{n}\right)$

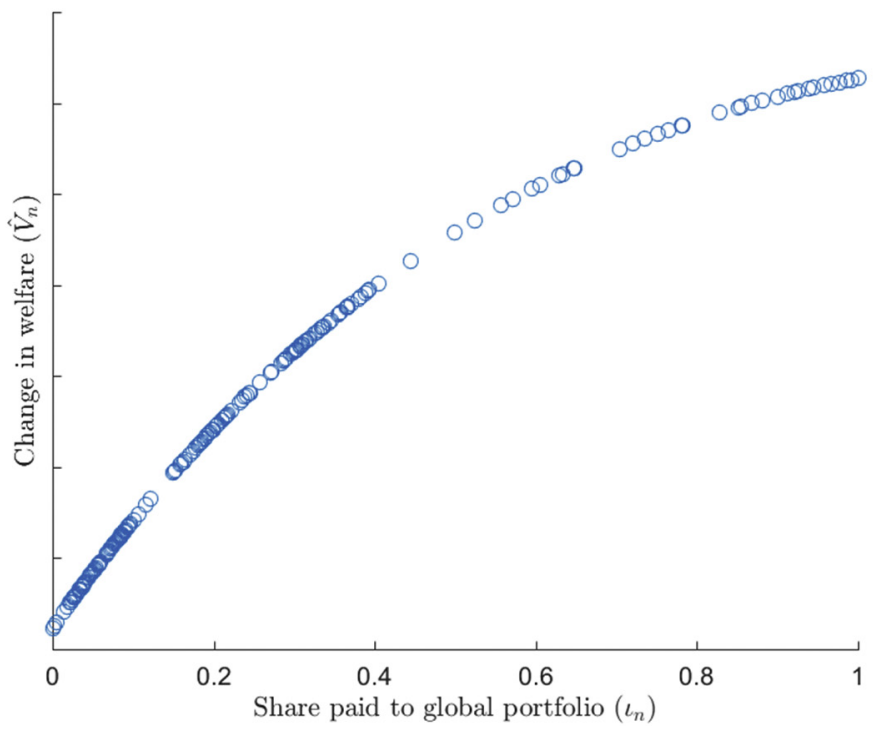

Fig. B.5. Marginal welfare effects of investments in production amenities. Notes: Transfers, as well as all fundamental location characteristics (ie. $\left.\bar{a}_{n}, d_{n i}\right)$, except location attractiveness, residential land supply and share to global portfolio are set to the average values such that general equilibrium outcomes of marginal welfare effects of investments in production amenities depend only on $B_{n}, H_{n}$ or $\iota_{n}$. Each figure shows the marginal welfare effect of investments in production amenities. "Change in welfare" on the $\mathrm{y}$-axis is normalized to facilitate comparison of welfare differences.

Please cite this article as: Y. Blouri and M.V. Ehrlich, On the optimal design of place-based policies: A structural evaluation of EU regional transfers,

J. Int. Econ., https://doi.org/10.1016/j.jinteco.2020.103319 
(a) Location attractiveness $\left(B_{n}\right)$

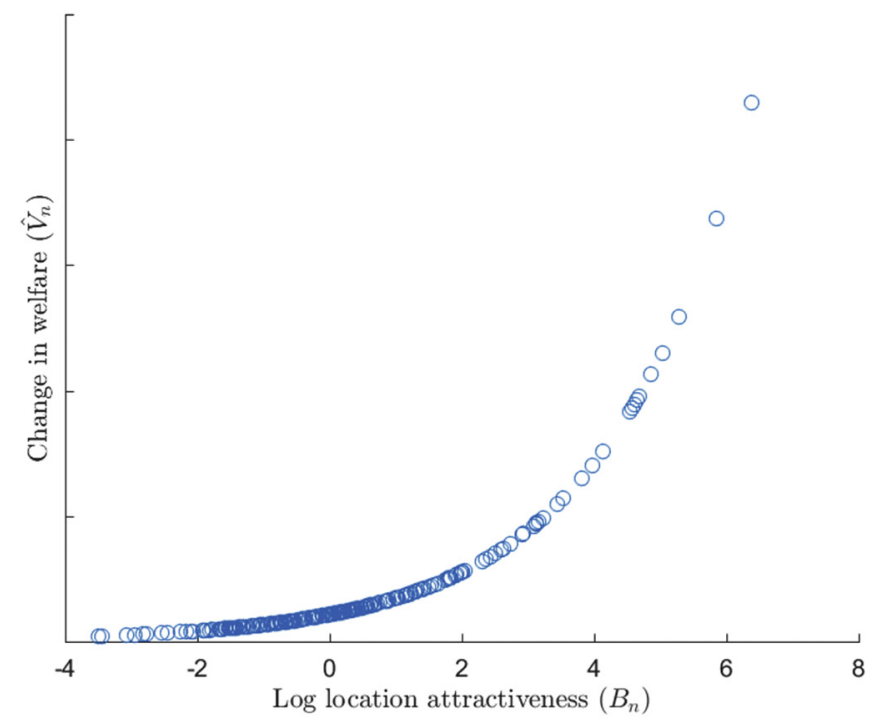

(b) Resid. land supply $\left(H_{n}\right)$

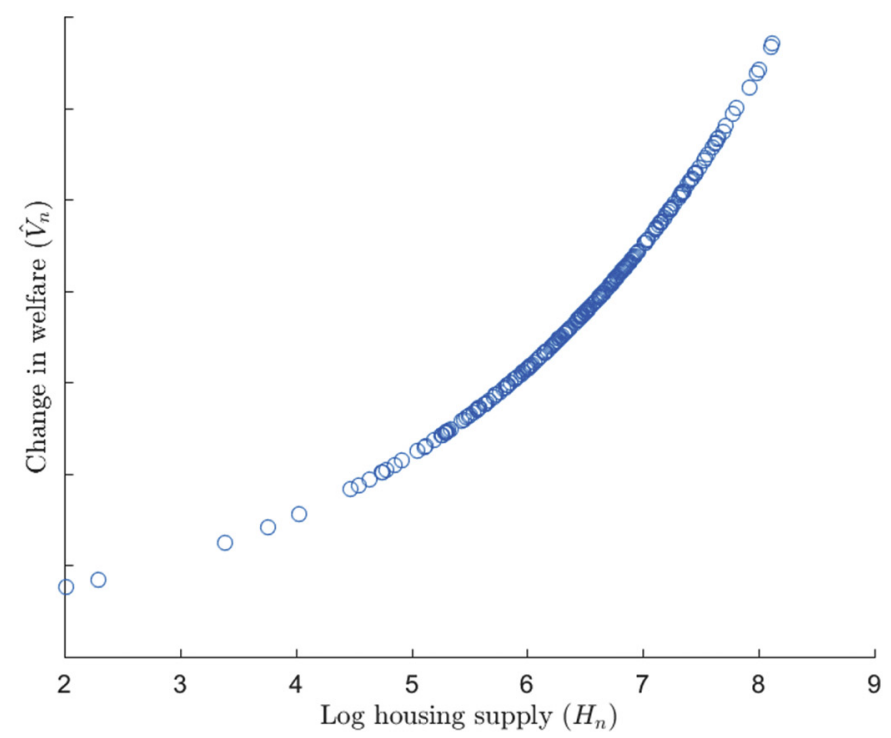

(c) Share to global portfolio $\left(\iota_{n}\right)$

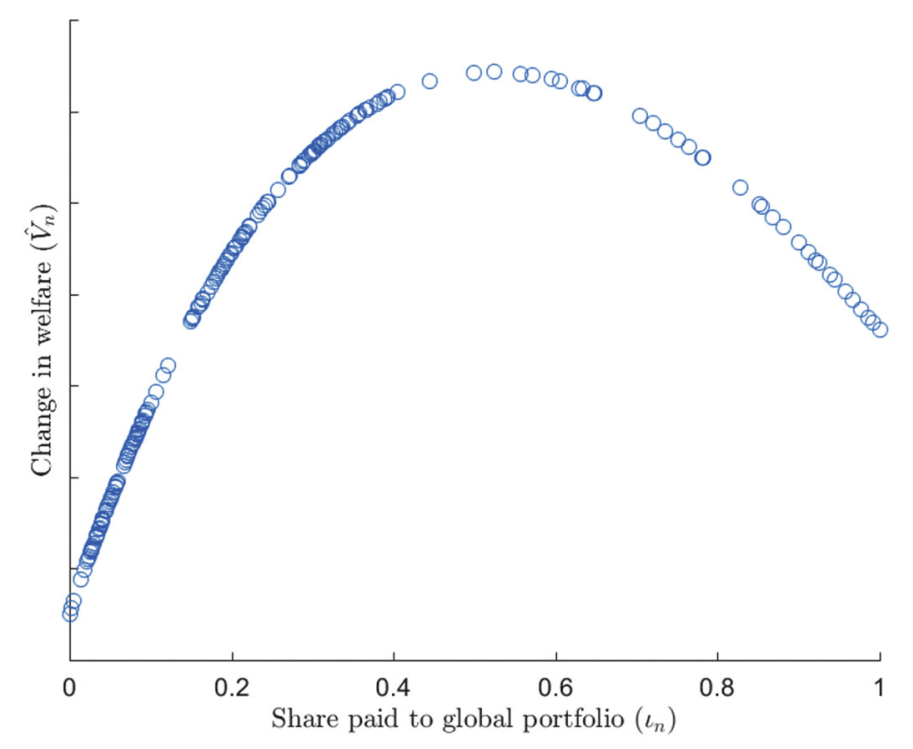

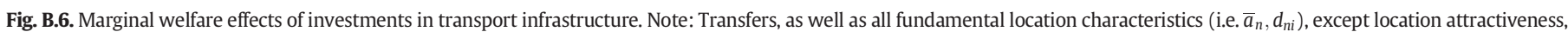
residential land supply and share to global portfolio are set to the average values such that general equilibrium outcomes of marginal welfare effects of investments in transportation

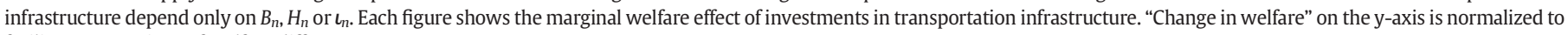
facilitate comparison of welfare differences.

Appendix C. Optimal transfers

The numerical optimization routine with a government setting the welfare optimizing transfer policy follows the Mathematical Programs With Equilibrium Constraints (MPEC) approach described in Su and Judd (2012) for economic models and particularly applied to trade models in Ossa (2014). We maximize indirect utility of one arbitrary region and take the model's equilibrium conditions as constraints. Given this nonlinear constrained optimization procedure, the solution characterizes a spatial equilibrium defined in Section 3.6.

We either allow the government to provide per-capita wage subsidies or to undertake investments in production amenities or investments in transport infrastructure. Accordingly, we set two of our three transfer channels to zero to compute the optimal transfer shares. For all our optimizations, we hold tax rates constant such that a shift in the transfer budget may only be generated by different distributions of transfers. 
C.1. Solving approach

The step-by-step solution procedure for the problem stated above is as follows

1. We form a random initial guess for transfer shares $\left(T_{n}^{w}, T_{n}^{a}\right.$ or $\left.T_{n}^{d}\right)$ from a normal distribution with mean zero and variance $10^{9}$. We take absolute values to ensure a positive initial guess and normalize it such that the sum is equal to 1 .

2. Based on random transfer shares we compute equilibrium values for wages $\left(w_{n}\right)$, population shares $\left(\lambda_{n}\right)$, own trade shares $\left(\pi_{n n}\right)$, indirect utility of region $1\left(V_{1}\right)$ and total transfers paid $(\bar{T})$ satisfying equilibrium constraints (B.1)-(B.8). We take this as an initial guess for the endogenous variables.

3. We maximize welfare subject to the equilibrium constraints by numerically running the problem in Artely's Knitro solver.

For any random initial guess, our problem converges to the same solution. In this optimal allocation, utility is equalized, government budget is balanced and all equilibrium conditions (as described in Section 3.6) are fulfilled up to a small epsilon $\varepsilon<1^{-10}$.

Appendix D. Extensions

D.1. Optimal distribution of transfers conditional on constant inequality

Given the aim of the European Union to enhance efficiency while strengthening regional cohesion, the objective function assumed in the benchmark model may not necessarily conform with the political ambitions. Our setting is flexible enough to incorporate an additional constraint, which holds regional income inequality constant. In particular, we use the coefficient of variation as a dispersion measure because it is scale-invariant and differentiable such that we can provide the gradients for the MPEC approach solving the optimization problem. The results are summarized in Table D.1.

Table D.1

Welfare effects of transfers while holding income inequality stable.

\begin{tabular}{|c|c|c|c|c|}
\hline & \multicolumn{2}{|l|}{ (a) Wage subsidies } & \multicolumn{2}{|c|}{ (b) Production amenities } \\
\hline & Observed & Optimal & Observed & Optimal \\
\hline & $\overline{(1)}$ & $\overline{(2)}$ & $\overline{(1)}$ & $\overline{(2)}$ \\
\hline Welfare $\left(\hat{V}_{n}\right)$ & $0.05 \%$ & $0.19 \%$ & $1.21 \%$ & $1.63 \%$ \\
\hline$\widehat{C V}\left(y_{n}\right)$ & $\begin{array}{l}-0.34 \% \\
\text { (c) Transportation infrastructure }\end{array}$ & $-0.34 \%$ & $\begin{array}{l}-0.82 \% \\
\text { (d) All transfers }\end{array}$ & $-0.82 \%$ \\
\hline & $\begin{array}{l}\text { Observed } \\
(1)\end{array}$ & $\begin{array}{l}\text { Optimal } \\
(2)\end{array}$ & $\begin{array}{l}\text { Observed } \\
\text { (1) }\end{array}$ & $\begin{array}{l}\text { Optimal } \\
(2)\end{array}$ \\
\hline Welfare $\left(\hat{V}_{n}\right)$ & $0.82 \%$ & $0.95 \%$ & $2.08 \%$ & $2.79 \%$ \\
\hline$\widehat{C V}\left(y_{n}\right)$ & $-0.07 \%$ & $-0.07 \%$ & $-1.22 \%$ & $-1.22 \%$ \\
\hline
\end{tabular}

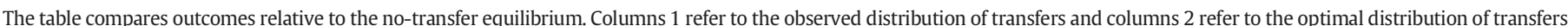

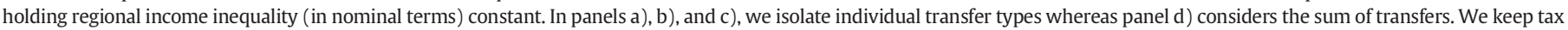

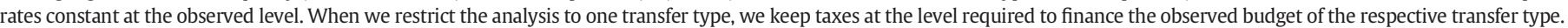

Recall that the optimal distribution of wage subsidies does not only increase welfare but also reduces income inequality compared to the ob-

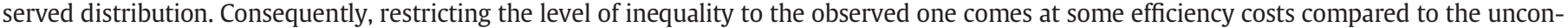

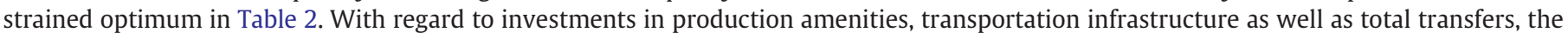

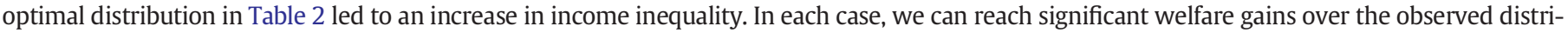

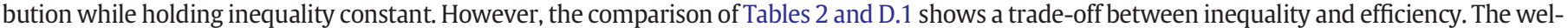

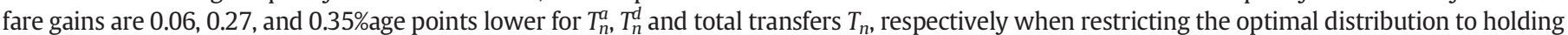
income inequality at the observed level.

D.2. Variations in the aggregate shares of transfer types

The welfare gains of the optimal distribution over the observed distribution in Table 2 are fully due to adjustments in the spatial distribution as we keep the aggregate shares of each transfer type constant. The model also allows us to change the aggregate mix of transfer types. In the following, we iterate over a set of combinations of aggregate shares of transfers and compute for each set the optimal spatial distribution of each transfer type and the corresponding welfare level, see Table D.2. For ease of reference, the first line repeats the observed allocation across transfer types with an optimal spatial distribution of each as shown in Table 2 (d), column 3. In lines 2-4 of Table D.2, we set the share of either transfer type to unity. Line 5 shows the welfare realized in a situation where each transfer type receives one third of the aggregate budget and the spatial distribution of each type is optimized again. Lines 6-8 allocate half of the budget to one transfer type and split the remainder equally among the other transfer types.

Table D.2

Different aggregate shares of transfer types.

\begin{tabular}{|c|c|c|c|}
\hline \multicolumn{3}{|c|}{ Shares of aggregate budget by transfer type (in percent) } & \multirow{2}{*}{$\frac{\text { Welfare change }}{\hat{V}_{n}}$} \\
\hline$\overline{T^{w}}$ & $T^{a}$ & $T^{d}$ & \\
\hline 29(observed) & 37 (observed) & 34 (observed) & 3.144 \\
\hline 100 & 0 & 0 & 0.543 \\
\hline 0 & 100 & 0 & 2.079 \\
\hline 0 & 0 & 100 & 1.340 \\
\hline
\end{tabular}


Table D.2 (continued)

\begin{tabular}{|c|c|c|c|}
\hline \multicolumn{3}{|c|}{ Shares of aggregate budget by transfer type (in percent) } & \multirow{2}{*}{$\frac{\text { Welfare change }}{\hat{V}_{n}}$} \\
\hline$T^{w}$ & $T^{a}$ & $T^{d}$ & \\
\hline 33 & 33 & 33 & 3.144 \\
\hline 50 & 25 & 25 & 3.139 \\
\hline 25 & 25 & 50 & 3.144 \\
\hline
\end{tabular}

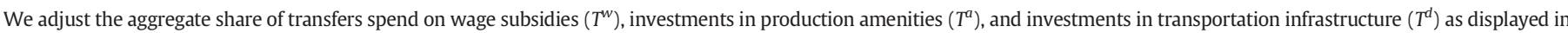

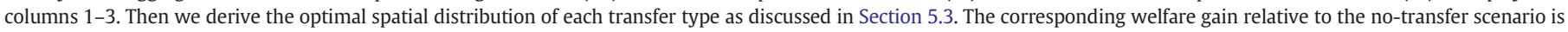
displayed in column 4 .

Overall, these counterfactual experiments show two main results: First, a full concentration of expenditures on one type is not optimal. Second, as long as there is a certain mix between the three transfer types, welfare is relatively insensitive regarding changes in the aggregate shares. It reacts much more strongly to changes in the regional distribution of transfers, which is the focus of our analysis in Section 5.3. Note however that given the setting with the input factor for infrastructure and production amenities not drawing away resources from other economic activities, the evaluation of different mixes of aggregate shares is likely to be somewhat biased towards investments in infrastructure and production amenities.

On the other hand, infrastructure is a durable investment and generates benefits over several years. Our analysis quantifies the static welfare gains realized from improvements in production amenities and transportation infrastructure attained at the end of the respective budgeting period 2007-13. For investments in infrastructure and production amenities, our estimated elasticities $\kappa^{a}, \kappa^{d}$ capture the cumulative effect of the sum of investments over these seven years. In contrast, for wage subsidies - assuming immediate adjustment - it requires only a one-year transfer to realize the welfare effect. As infrastructure is durable, a part of the benefit is likely to remain after the end of the budgeting period, whereas the benefit of wage subsidies vanishes relatively quickly once transfers are stopped.

In the following back-of-the-envelope calculation, we adjust the static welfare effect of infrastructure investments by differences in initial costs, durability and maintenance costs in order to compare them with the welfare effect estimated for wage subsidies. For this analysis, we assume a discount rate of 5 percent and an average remaining lifetime of the infrastructure investments after the end of the budgeting period of 26 years. The latter is based on the literature suggesting a depreciation of roads of about 30 years. ${ }^{43}$ Using these values, we obtain a discount factor of $D F=\sum_{t=1}^{26}$ $\frac{1}{(1.05)^{t}}=14.38$. The present value of the benefits from infrastructure investments is the static gain multiplied with $D F$. On the cost side, we need to account for the fact that infrastructure payments were made over seven years and that maintenance costs will apply during the 26 years of remaining lifetime. According to the EU Parliament (2014), the EU invested about 41\% of initial road investments into maintenance and operating during the period of 2006-11. Taking the cost shares of infrastructure investments and wage subsidies (of 0.34 and 0.29 ), this implies in our calculation that the costs of infrastructure investments compared to wage subsidies are higher by Cost Factor $=\frac{7 \times 0.34(1+0.41 D F)}{0.29}$. Note that the maintenance costs are a share of initial investments and, as they apply in the future, have to be discounted by $D F$ as well. Given these considerations, we can now compute the adjusted welfare effect of infrastructure investments (for the observed equilibrium in Table 2c, column 2 ), which would be 0.82

DF Cost Factor equilibrium (in Table 2a, column 2) shows that the welfare gain due to infrastructure investments is about four times higher.

With regard to investments in production amenities, which consist of a bundle of measures that affect productivity, we cannot perform such a back-of-the-envelope calculation as we have neither data on the maintenance costs nor on average lifetime.

\section{D.3. Region-specific factor prices for the production of infrastructure}

In the following, we outline how our setting would change if we assumed that transportation infrastructure and production amenities are produced using local factors, i.e. land and final goods, in each region. We lay out the model extension for investments in transportation infrastructure noting that the case of production amenities follows analogously. Land and final goods are used to produce infrastructure according to a CobbDouglas technology such that transfers $T_{n}^{d}$ yield infrastructure investments.

$D_{n}=\frac{T_{n}^{d}}{P_{n}^{\alpha} r_{n}^{1-\alpha}}$

Infrastructure investments translate into reductions of travel time according to Eq. (11) which becomes.

TravelTime $_{r i}=\gamma_{r i}-\kappa^{d} \cdot \ln \left(D_{r}+D_{i}+1\right)$.

In this model extension, a given level of transfers yields a more pronounced travel time reduction in low price regions than in high price regions, which would shift the optimal distribution towards low price regions. In the following, we characterize how these changes affect the housing and goods markets. Since transportation infrastructure is now produced using local land and final goods, regional income is given by (13) where payments from the global portfolio change to $\chi=(1 / \bar{L}) \sum_{n \in N}\left(\iota_{n} H_{n} r_{n}\right)$. Total expenditure on goods and housing markets is now composed of workers'

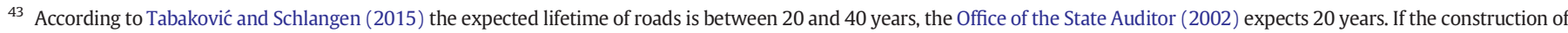
roads was uniformly distributed over the seven-year period, a 30 year lifetime would yield 26 years of remaining lifetime for roads constructed during the budgeting period.
} 
disposable income and tax revenues used for the production of infrastructure. Accordingly, goods market clearing becomes

$w_{n} \lambda_{n}=\alpha \sum_{k \in N} \pi_{k n} \lambda_{k}\left(y_{k}+T_{k}^{a} / L_{k}+T_{k}^{d} / L_{k}\right)$

Analogously, total housing expenditure becomes.

$r_{n} H_{n}=(1-\alpha)\left(y_{n} L_{n}+T_{n}^{a}+T_{n}^{d}\right)$.

In this model extension, government investments into local infrastructure affect prices indirectly by a change in local demand for land and final goods, which feeds back into regional income. As we do not have empirical information about the specific cost structure of infrastructure production, we assume that the expenditure share equals the workers' consumption share $\alpha=0.75$. We compute the marginal welfare effects of transfers in the model extension as shown in Fig. 4 for the benchmark model. The correlation coefficient (rank correlation coefficient in brackets) of the marginal welfare effects of investments in production amenities in the model extension and the benchmark mode is 0.962 (0.948). For investments in transportation infrastructure the correlation is 0.966 (0.976). Marginal welfare effects of wage subsidies remain almost identical to the benchmark version.

\section{References}

Albouy, D., 2012. Evaluating the efficiency and equity of federal fiscal equalization. J. Public Econ. 96 (9-10), 824-839.

Alder, S., 2016. Chinese roads in India: The effect of transport infrastructure on economic development. mimeo.

Allen, T., Arkolakis, C., 2014. Trade and the topography of the spatial economy. Q. J. Econ. 129 (3), 1085-1140.

Allen, T., Arkolakis, C., 2016. The welfare effects of transportation infrastructure improvements. mimeo.

Arkolakis, C., Costinot, A., Rodríguez-Clare, A., 2012. New trade models, same old gains? Am. Econ. Rev. 102 (1), 94-130.

Armington, P.S., 1969. A theory of demand for products distinguished by place of production. IMF Staff. Pap. 16 (1), 159-178.

Bartik, T.J., 1991. Who Benefits from State and Local Economic Development Policies? W.E. Upjohn Institute for Employment Research, Kalamazoo, MI

Baum-Snow, N., Henderson, V., Turner, M.A., Brandt, L., 2018. Does investment in national highways help or hurt hinterland city growth? J. Urban Econ. (Forthcoming).

Becker, S.O., Egger, P.H., Ehrlich, M.v., 2010. Going NUTS: the effect of EU structural funds on regional performance. J. Public Econ. 94 (9), 578-590.

Boldrin, M., Canova, F., 2001. Inequality and convergence in Europe's regions: reconsidering European regional policies. Econ. Policy 16 (32), 205-253.

Brülhart, M., Mathys, N.A., 2008. Sectoral agglomeration economies in a panel of European regions. Reg. Sci. Urban Econ. 38 (4), 348-362.

Bryan, G., Morten, M., 2019. The aggregate productivity effects of internal migration: evidence from Indonesia. J. Polit. Econ. 127 (5), 2229-2268.

Caliendo, L., Parro, F., Rossi-Hansberg. E., Sarte, P.-D., 2018. The impact of regional and sectoral productivity changes on the U.S. economy. Rev. Econ. Stud. 85 (4), 2042-2096.

Charron, N., 2016. Explaining the allocation of regional structural funds: the conditional effect of governance and self-rule. Eur. Union Politics 17 (4), 638-659.

Combes, P.-P., Duranton, G., Gobillon, L., Roux, S., 2010. Estimating agglomeration economies with history, geology, and worker effects. In: Glaeser, E.L. (Ed.), Agglomeration Economics. vol. 4. National Bureau of Economic Research, Inc, pp. 15-66.

Dekle, R., Eaton, J., Kortum, S., 2007. Unbalanced trade. Am. Econ. Rev. 97 (2), 351-355.

Desmet, K., Nagy, D.K., Rossi-Hansberg, E., 2018. The geography of development. J. Polit. Econ. 126 (3), 903-983.

Diamond, R., 2016. The determinants and welfare implications of US workers', diverging location choices by skill: 1980-2000. Am. Econ. Rev. 106 (3), 479-524.

Eeckhout, J., Guner, N., 2017. Optimal spatial taxation: Are big cities too small? mimeo.

Egger, P., Eggert, W., Larch, M., 2014. Structural operations and net migration across European Union member countries. Rev. Int. Econ. 22 (2), 352-378.

Ehrlich, M.v., Seidel, T., 2018. The persistent effects of place-based policy: evidence from the west-German Zonenrandgebiet. Am. Econ. J. Econ. Pol. 10 (4), 344-374.

Einiö, E., Overman, H.G., 2016. The (displacement) effects of spatially targeted enterprise initiatives: evidence from UK LEGI. SERC Discussion Papers 191.

EU Parliament, 2014. EU road surfaces: Economic and safety impact of the lack of regular road maintenance. Technical Report, EU Parliament, Directorate-General for Internal Policies. Policy Department for Structural and Cohesion Policies.

European Commission, 1996. Structural and Cohesion Funds 1994-99: Regulations and Commentary.

European Commission, 2008. Working for the Regions. EU regional policy, pp. 2007-2013.
European Commission, 2014. 2014 Annual Report on Labour Mobility.

European Commission, 2017. Cohesion Policy at Work.

Eurostat, 2016. Expenditure of Households by Consumption Purpose, A Quarter of Household Expenditure Allocated to Housing, Growing Weight Over Last Ten Years.

Fajgelbaum, P.D., Gaubert, C., 2019. Optimal spatial policies, geography and sorting. Q. J. Econ. (Forthcoming).

Fajgelbaum, P.D., Schaal, E., 2019. Optimal transport networks in spatial equilibrium. Econometrica (Forthcoming).

Fajgelbaum, P.D., Morales, E., Suarez Serrato, J.C., Zidar, O., 2019. State taxes and spatial misallocation. Rev. Econ. Stud. 86 (1), 333-376.

Gaubert, C., 2017. Firm sorting and agglomeration. Am. Econ. Rev. 108 (11), 3117-3153.

Glaeser, E.L., Gottlieb, J.D., 2008. The economics of place-making policies. Brook. Pap. Econ. Act. 39 (1), 155-253.

Henkel, M., Seidel, T., Suedekum, J., 2018. Fiscal equalization in the spatial economy. CESifo Working Paper 7012.

Kline, P., Moretti, E., 2014. Local economic development, agglomeration economies, and the big push: 100 years of evidence from the Tennessee Valley authority. Q. J. Econ. 129 (1), 275-331.

Kolko, J., Neumark, D., 2010. Do enterprise zones create jobs? Evidence from California's enterprise zone program. J. Urban Econ. 68 (1), 1-19.

Midelfart-Knarvik, K.H., Overman, H.G., 2002. Delocation and European integration: is structural spending justified? Econ. Policy 17 (35), 321-359.

Mohl, P., Hagen, T., 2010. Do EU structural funds promote regional growth? New evidence from various panel data approaches. Reg. Sci. Urban Econ. 40 (5), 353-365.

Monte, F., Redding, S.J., Rossi-Hansberg, E., 2018. Commuting, migration and local employment elasticities. Am. Econ. Rev. 108 (12), 3855-3890.

Neumark, D., Simpson, H., 2015. Place-based policies. In: Duranton, G., Henderson, J.V., Strange, W.C. (Eds.), Handbook of Regional and Urban Economics. vol. 5. Elsevier, pp. 1197-1287.

Office of the State Auditor, 2002. Capitalization and Depreciation of Infrastructure. Technical report. Mississippi Association of Governmental Purchasing and Property Agents.

Ossa, R., 2014. Trade wars and trade talks with data. Am. Econ. Rev. 104 (12), 4104-4146.

Ossa, R., 2017. A quantitative analysis of subsidy competition in the U.S. NBER Working Paper 20975.

Pellegrini, G., Terribile, F., Tarola, O., Muccigrosso, T., Busillo, F., 2013. Measuring the effects of European regional policy on economic growth: a regression discontinuity approach. Pap. Reg. Sci. 92 (1), 217-233.

Redding, S.J., 2012. Goods trade, factor mobility and welfare. CEP Discussion Paper 1140. Redding, S.J., 2016. Goods trade, factor mobility and welfare. J. Int. Econ. 101 (1), 148-167.

Redding, S.J., Rossi-Hansberg, E., 2017. Quantitative spatial economics. Annu. Rev. Econ. 9 (1), 21-58.

Santos Silva, J., Tenreyro, S., 2006. The log of gravity. Rev. Econ. Stat. 88 (4), 641-658.

Simonovska, I., Waugh, M., 2014. The elasticity of trade: estimates and evidence. J. Int. Econ. 92 (1), 34-50.

Su, C.-L., Judd, K.L., 2012. Constrained optimization approaches to estimation of structural models. Econometrica 80 (5), 2213-2230

Tabaković, A., Schlangen, E., 2015. Self-healing technology for asphalt pavements. In: Hager, M.D., Schubert, U.S., van der Zwaag, S. (Eds.), Advances in Polymer Science. vol. 273. Springer, pp. 1-22. 